\title{
Stability of carbon dioxide and methane hydrates in water in presence of small driving forces using MD simulations
}

\author{
Venkata S. Vedam \\ West Virginia University
}

Follow this and additional works at: https://researchrepository.wvu.edu/etd

\section{Recommended Citation}

Vedam, Venkata S., "Stability of carbon dioxide and methane hydrates in water in presence of small driving forces using MD simulations" (2009). Graduate Theses, Dissertations, and Problem Reports. 2083. https://researchrepository.wvu.edu/etd/2083

This Thesis is protected by copyright and/or related rights. It has been brought to you by the The Research Repository @ WVU with permission from the rights-holder(s). You are free to use this Thesis in any way that is permitted by the copyright and related rights legislation that applies to your use. For other uses you must obtain permission from the rights-holder(s) directly, unless additional rights are indicated by a Creative Commons license in the record and/ or on the work itself. This Thesis has been accepted for inclusion in WVU Graduate Theses, Dissertations, and Problem Reports collection by an authorized administrator of The Research Repository @ WVU. For more information, please contact researchrepository@mail.wvu.edu. 
Stability of Carbon dioxide and Methane Hydrates in Water in Presence of Small Driving Forces using MD simulations

\author{
Venkata S. Vedam \\ Thesis submitted to the \\ College of Engineering and Mineral Resources \\ at West Virginia University \\ in Partial Fulfillment of the requirements \\ for the degree of \\ Master of Science \\ in \\ Chemical Engineering
}

Dr. Brian J. Anderson, Ph.D., Chair

Dr. Charter D. Stinespring, Ph.D., Dr. James P. Lewis, Ph.D.

Department of Chemical Engineering

Morgantown, West Virginia

2009

Keywords: Gas hydrates, Stability, MD simulations, Driving forces, Dissolution, Dissociation, Methane, Carbon Dioxide. 


\title{
Abstract \\ Stability of Carbon dioxide and Methane Hydrates in Water in Presence of Small Driving Forces using MD simulations
}

\begin{abstract}
Venkata S. Vedam
Gas hydrates are a potential source of energy as a large fraction of natural gas worldwide is stored in the form of gas hydrates. Methane hydrates are widely distributed in sediments along the continental margins and contain more energy than all other fossil fuel reserves in the world. However, methane is also a potential greenhouse gas which could play a major role in global climate change. Accurately characterizing the stability of methane and $\mathrm{CO}_{2}$ hydrates in water can help us understand their effects on earth's environment and also the feasibility of long term $\mathrm{CO}_{2}$ sequestration in the sediments under the ocean floor. Hydrate stability can be better predicted by understanding the phenomena related to the hydrate dissolution in water. Under the hydrate stability conditions, the concentration difference of hydrate forming gases between the hydrate and water phases should be an important factor affecting the hydrate stability as oceanic hydrates are exposed to undersaturated seawater.

In this work, the dissolution of methane and $\mathrm{CO}_{2}$ hydrates have been studied and compared to one another in the presence of water using molecular dynamic simulations. The average lattice constant for structure I and II methane hydrate was calculated for two different potentials of methane OPLS and GROMACS and compared to the experimental value to validate these potentials. Methane hydrate dissociation in presence of water was also studied at these 2 potentials of methane and also at the Anderson et al. model. The effect of temperature and pressure on hydrate dissociation was studied. The TIP4P model for water and Harris and Yung model for $\mathrm{CO}_{2}$ were used in all of the simulations of $\mathrm{CO}_{2}$ hydrate in this study. Molecular dynamic simulations were done on methane and $\mathrm{CO}_{2}$ hydrates at $275 \mathrm{~K}$ and 50 bar to study the effect of changing the small cage occupancy in the hydrate and the percentage level of gas saturation in the water phase on hydrate dissolution in water. A higher amount of dissolution occurred in the case of $\mathrm{CO}_{2}$ hydrates compared to methane hydrates in all the simulations. Methane hydrate was found to be more stable at cage occupancies close to $100 \%$ while $\mathrm{CO}_{2}$ hydrate was found to be stable at small cage occupancies close to $0 \%$ with large cage completely occupied. The amount of dissolution was found to increase with a decrease in the level of gas saturation in the water phase and the dissolution seemed to be driven by a difference between gas concentration and its solubility in water phase for both methane and $\mathrm{CO}_{2}$ hydrates. In all the simulations on methane hydrate, water molecules in the liquid phase close to hydrate-water interface were found to be regrouping to become tetrahedrally bonded which is predicted to be indication towards a hydrate growth. An increase in $\mathrm{CO}_{2}$ solubility in water was observed in all the simulations on $\mathrm{CO}_{2}$ hydrate the reason for which is not yet understood. A structural change of water molecules in the liquid phase in the presence of hydrate is proposed to be a reason.
\end{abstract}




\section{Acknowledgements}

First and foremost, I would like to express my sincere gratitude to my advisor Dr. Brian Anderson for his guidance and support for this work. I can never forget the encouragement and motivation he gave me for my work. I would like to thank my committee members Dr. Charter Stinespring and Dr. James Lewis for their valuable suggestions to this work. I am very thankful to Dr. Niall English, NETL for giving the phase recognition code and Dr. Evgeny Myshakin, NETL, Pittsburgh who has been helpful in using the code in this work.

I thank my parents, brother and sister who have always been there for me and encouraged me throughout my studies. I should specially thank my brother Anand Vedam for his support and motivation.

I am very grateful to all my fellow lab members for their help and support. I also thank my roommates and friends in Morgantown who made this period memorable.

Finally, I would like to thank NETL/DOE and the Department of Chemical Engineering, WVU for funding this research project and my studies in masters. 


\section{Table of Contents}

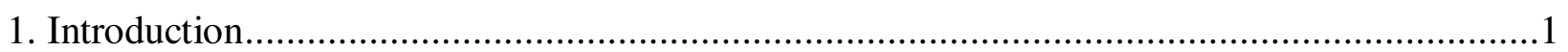

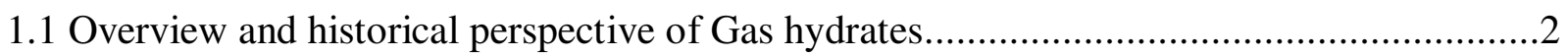

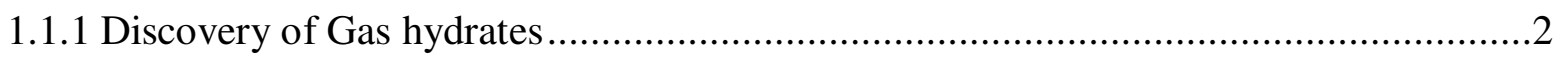

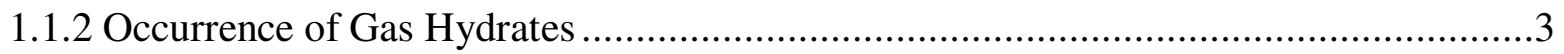

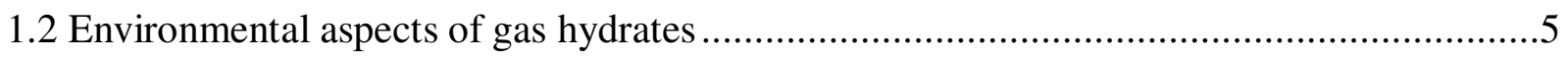

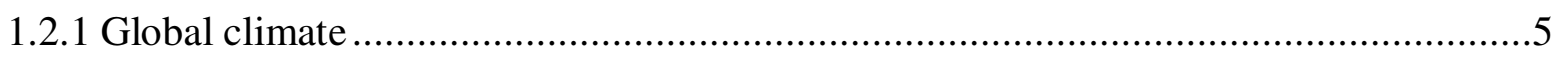

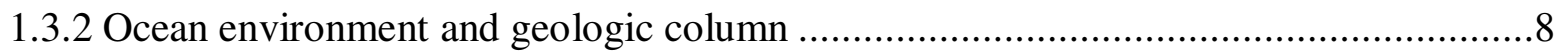

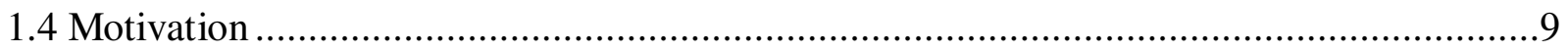

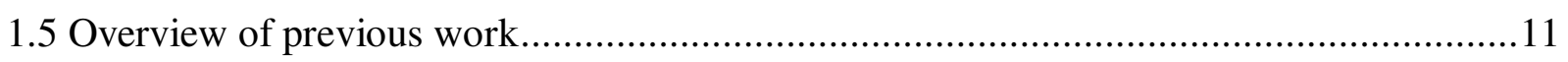

1.5.1 Insitu experiments on bubble injection in oceans .....................................................

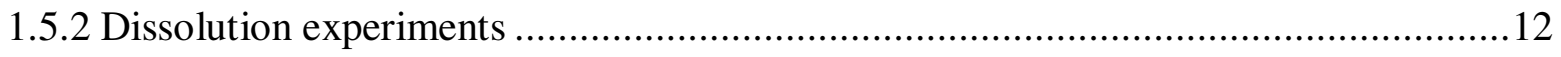

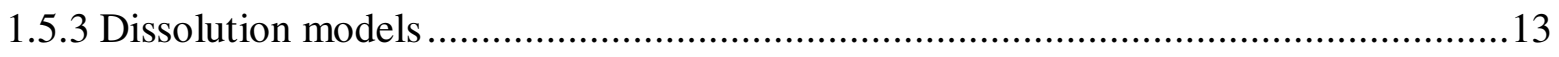

1.5.4 Dissolution and dissociation studies using MD simulations ..................................15

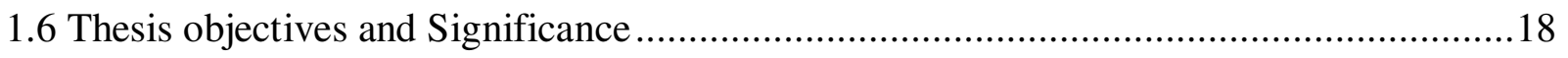

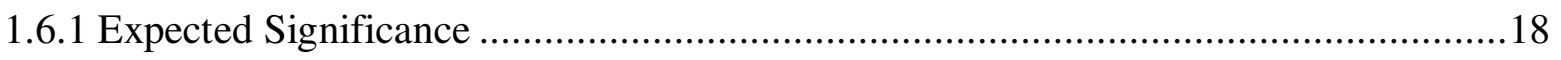

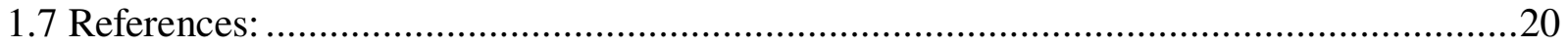

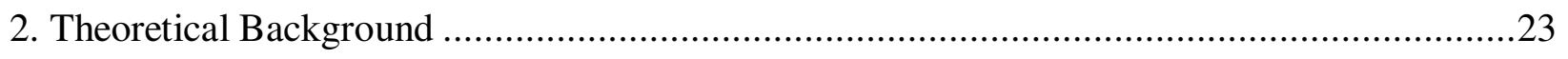

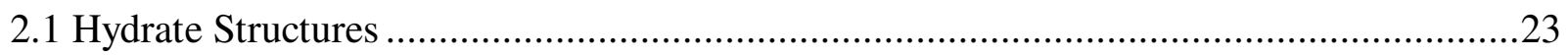

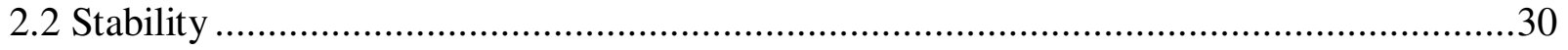

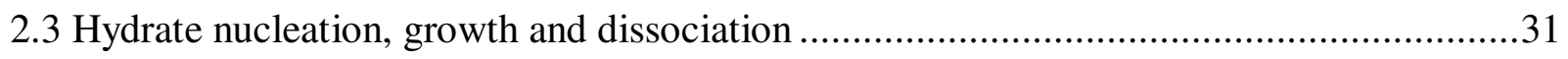

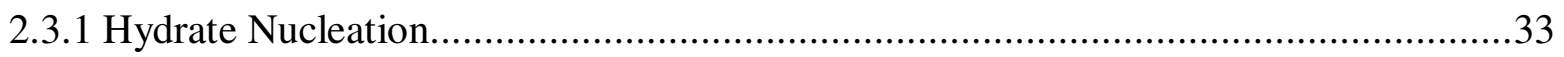

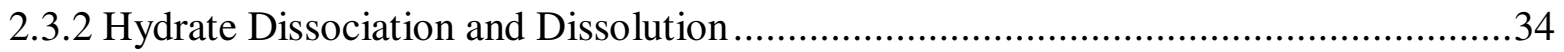

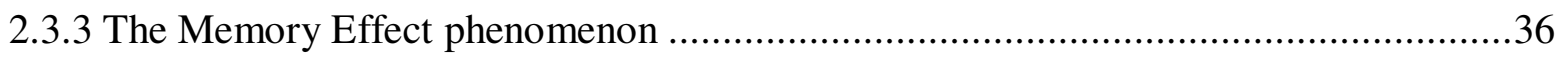

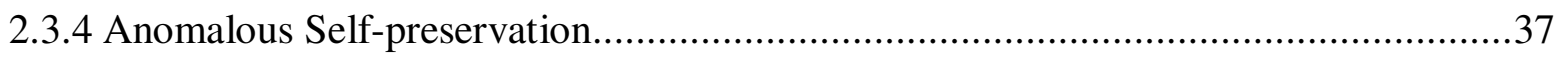

2.4 Molecular dynamic simulations ...................................................................................

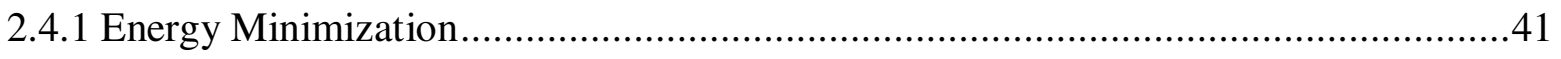

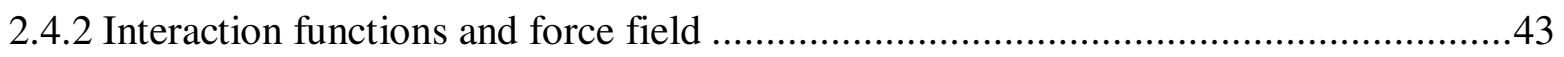




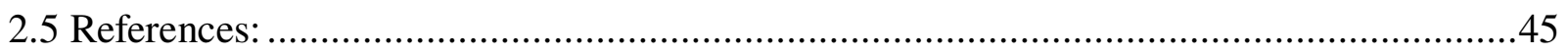

3. Molecular dynamic simulations on methane and $\mathrm{CO}_{2}$ hydrates ....................................47

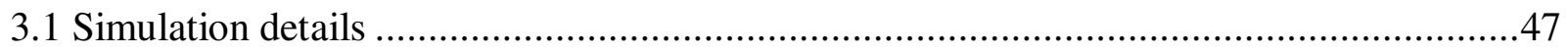

3.1.1 Initial conditions and force fields used in this study .......................................47

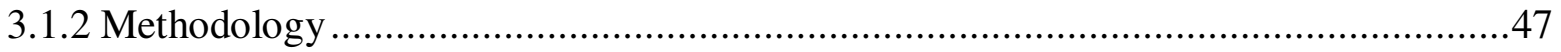

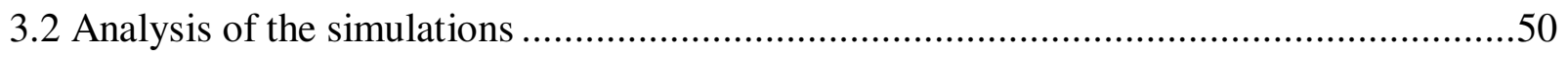

3.2.1 Identification of hydrate and liquid phases.................................................51

3.3 Comparison of lattice constants of methane hydrate for different potentials of methane ...52

3.3.1 Effect of temperature on the lattice constant of the simulation box.........................53

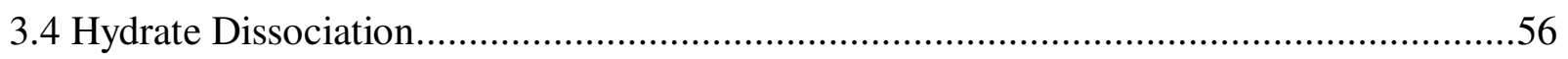

3.5 Simulation Configurations for Hydrate Dissolution................................................60

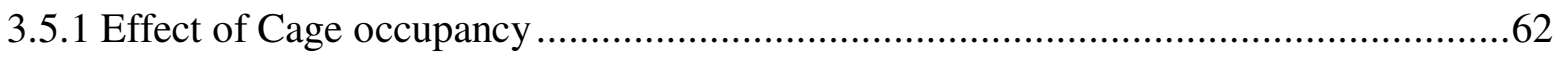

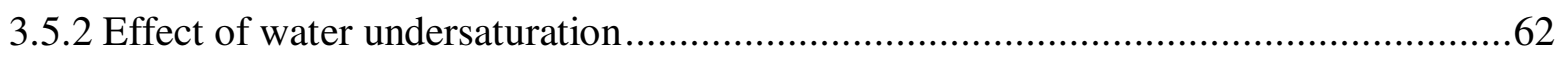

3.6 Intermolecular potential used for Carbon dioxide ................................................65

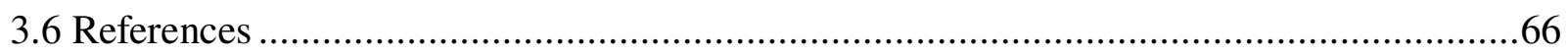

4. Dissolution of methane and $\mathrm{CO}_{2}$ hydrates in water and the effect of small driving forces

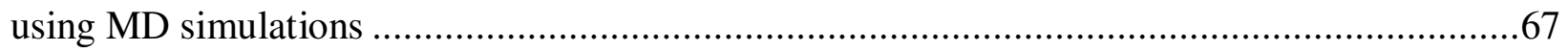

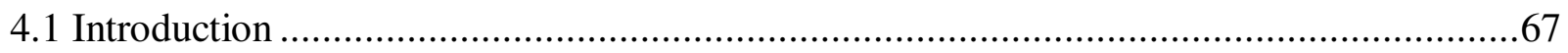

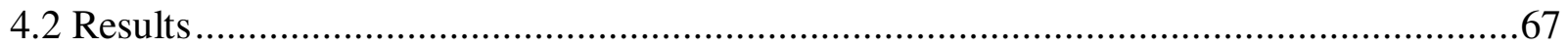

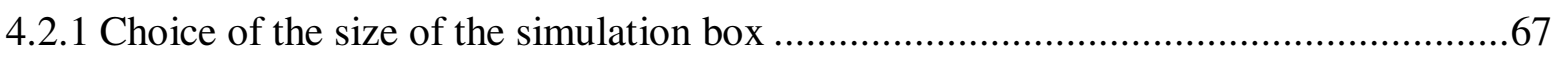

4.2.2 Dissolution of methane and $\mathrm{CO}_{2}$ hydrates.....................................................68

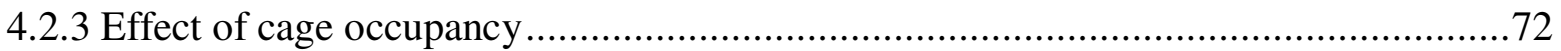

4.2.4 Effect of water phase undersaturation ...................................................... 76

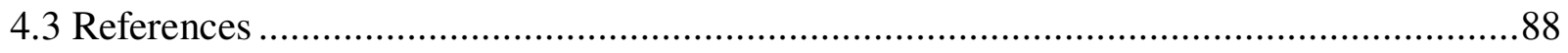

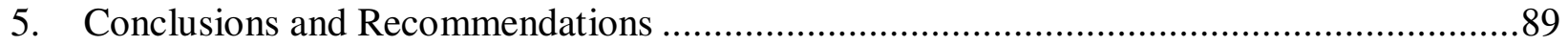

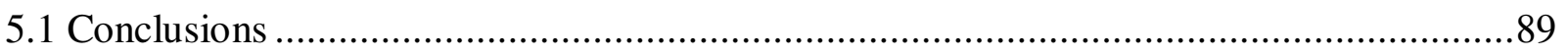

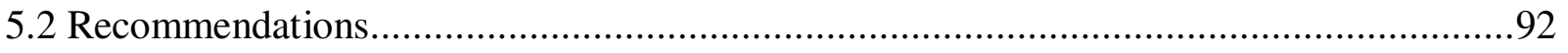

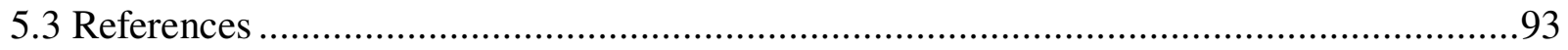




\section{List of Figures}

Figure 1.1 World hydrate reserves showing inferred reserves (black circles) and recovered reserves (white circles) ${ }^{6}$. Figure source: Lorenson, T. D.; Kvenvolden, K. A. "Global Occurrences of Gas Hydrate." Geophysical Monograph.2001, 124, 3...................................4 Figure 1.2 Temperature-pressure profile of $\mathrm{CO}_{2}$ and methane for the insitu experiments by Rehder et al. showing the phase boundaries of gas-liquid transition and gas hydrate boundary ${ }^{40}$. Source: Rehder et al. , Geochimica et Cosmologica Acta, 2004, 68, 285................................13

Figure 2. 1 Cavities of different hydrate structures: (a) Pentagonal dodecahedron $\left(5^{12}\right)$

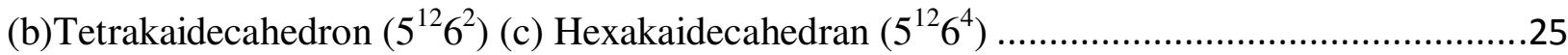

Figure 2. 2 Cavities of different hydrate structures (a) Irregular dodecahedron $\left(4^{3} 5^{6} 6^{3}\right)$ (b)

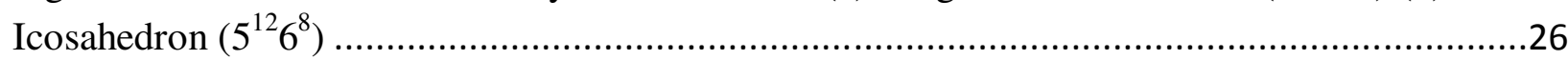

Figure 2. 3 Struture I hydrate in 2 adjacent unit cells in $\mathrm{x}$-direction ..................................27

Figure 2. 4 Struture II hydrate in one unit cell of cubic structure...........................................28

Figure 2. 5 Struture $H$ hydrate in 2 adjacent unit cells of hexagonal structure in x-direction. (The $\mathrm{y}$-axis is perpendicular to the plane of the paper) ..........................................................29

Figure 2. 6 Phase diagram for methane hydrate showing hydrate stability zone in the ocean settings.

Figure 2. 7 Periodic boundary conditions ${ }^{20}$. This figure is taken from Allen, Comp. S. Matter,

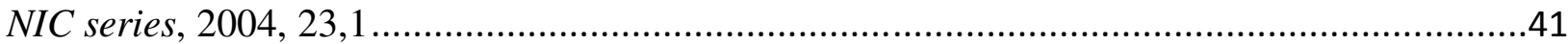

Figure 3.1 2-dimentional view of an 8 unit cell $(2 \times 2 \times 2)$ simulation box of methane hydrate .....53 Figure 3.2 2-dimentional view of a simulation cell with 32 unit cell $(4 \times 4 \times 2)$ box of S-I methane hydrate appended to water phase in z-direction. .57

Figure 3.32 -dimentional view of a simulation cell with 64 unit cell $(4 \times 4 \times 4)$ box of S-I $\mathrm{CO}_{2}$ hydrate appended to water phase in z-direction. 61

Figure 3.4 Effect of temperature on lattice constant of the structure-I methane hydrate for 2potentials .55

Figure 3.5 Effect of temperature on lattice constant of the structure-II methane hydrate for 2 potentials .56

Figure 3.6 Density plot of $\mathrm{CH}_{4}$ molecules and snapshot of S-I $\mathrm{CH}_{4}$ hydrate-water system which shows the dissociation of the hydrate at $265 \mathrm{~K}$ up to $13 \mathrm{~ns}$ .59

Figure 3.7 Density plot of $\mathrm{CH}_{4}$ molecules and a snapshot of $\mathrm{S}-\mathrm{I} \mathrm{CH}_{4}$ hydrate-water system which shows the dissociation of the hydrate at $270 \mathrm{~K}$ up to $5 \mathrm{~ns}$. .60

Figure 4.1 The amount of dissolution of methane and $\mathrm{CO}_{2}$ from hydrate in to water as a function of time with water phase completely unsaturated at the start of the simulation 69 
Figure 4. 2 Density plot of $\mathrm{CO}_{2}$ molecules in the box (divided in to 100 slabs) after $36 \mathrm{~ns}$ across the simulation box and a corresponding snapshot of $\mathrm{CO}_{2}$ hydrate simulation box showing the dissolution of the hydrate after $36 \mathrm{~ns}$. 70

Figure 4.3 Density plot of gas molecules across the simulation box truncated at the interface on either sides to view the change in number density within the hydrate phase of the box before and after simulation till $36 \mathrm{~ns}$ for (a) methane (b) $\mathrm{CO}_{2}$ 71 Figure 4.4 Number of methane molecules that moved in to the liquid phase from the hydrate phase as a function of time at different cage occupancies at $0 \%$ gas saturation in the water phase

Figure 4.5 Number of $\mathrm{CO}_{2}$ molecules that moved in to the water phase from the hydrate phase as a function of time during the simulation at different cage occupancies at $57.6 \%$ gas saturation in water phase .73

Figure 4.6 Comparing the effect of small cage occupancy on the dissolution of methane and $\mathrm{CO}_{2}$ hydrates in water. .75

Figure 4.7 Density plot of $\mathrm{CO}_{2}$ molecules across the box in the simulation used to calculate the solubility of $\mathrm{CO}_{2}$ in water. .77 Figure 4.8 Snapshots of simulation box in the simulation done to calculate solubility in water for (a) methane (b) $\mathrm{CO}_{2}$ after $20 \mathrm{~ns}$ .77

Figure 4.9 Total energy of the system as a function of time along with a moving average in the simulation for calculating solubility of $\mathrm{CO}_{2}$ in water 78 Figure 4.10 Total energy of the system as a function of time along with a moving average in the simulation for calculating solubility of $\mathrm{CO}_{2}$ in water .78 Figure 4.11 Average number of gas molecules in the water phase as a function of time for both methane and $\mathrm{CO}_{2}$

Figure 4.12 (a) Number of methane molecules in the hydrate phase at different times during the simulation corresponding to the initial number of methane molecules marked by a black solid line (b) Number of $\mathrm{CO}_{2}$ molecules moving in to the liquid phase as a function of time during the simulation at different levels of gas undersaturation in water phase at $100 \%$ cage occupancy ....81 Figure 4.13 Simulation at $100 \%$ gas saturation in water phase and $0 \%$ cage occupancy (a) Number of methane molecules in the hydrate phase as a function of time corresponding to the initial number of methane marked by a solid black line (b) Number of hydrate-like waters in the simulation box as a function of time during the simulation

Figure 4.14 Comparing the number of hydrate-like waters in each of 10 slices before and after simulation at $100 \%$ water phase saturation and $0 \%$ cage occupancy in methane hydrate. (The simulation box is divided in the z-direction in to 10 slices) A corresponding snapshot of methane hydrate simulation box. 


\section{List of Tables}

Table 1.1 World's hydrate potential compared to conventional gas resources ${ }^{11}$. Table source:

Kvenvolden, U. S. Geological survey Professional paper, 1993, 1570, 555 ............................4

Table 2. 1 Description of three different hydrate structures..................................................24

Table 3.1 Relative positions of all cavities in a unit cell of S-I hydrate showing the cavity

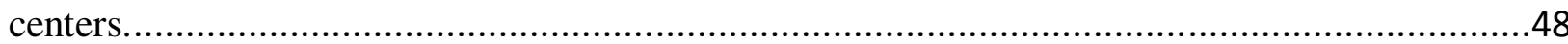

Table 3.2 The cartesian coordinates of the atoms in a methane and $\mathrm{CO}_{2}$ molecule with respect to

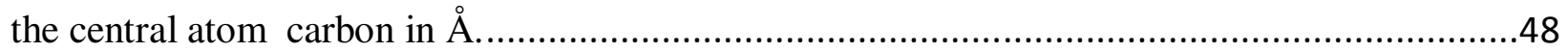

Table 3.3 Relative positions of atoms of a water molecule in a unit cell of S-I hydrate ............49

Table 3.4 Number of molecules in each phase in each of the simulations on $\mathrm{CO}_{2}$ hydrate........63

Table 3.5 Number of molecules in each phase in each of the simulations on methane hydrate ..64 Table 4. 1 Effect of cage occupancy on the average amount of dissolution of methane and $\mathrm{CO}_{2}$

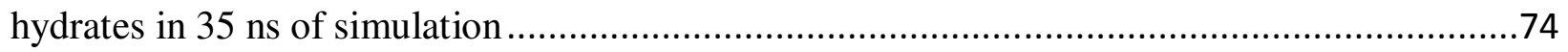

Table 4. 2 Effect of gas undersaturation in the water phase on methane and $\mathrm{CO}_{2}$ hydrate

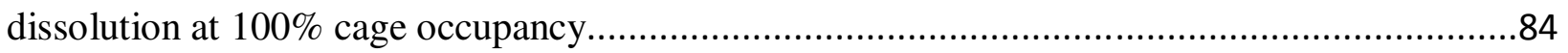

Table 4. 3 Effect of gas undersaturation in the water phase on methane and $\mathrm{CO}_{2}$ hydrate

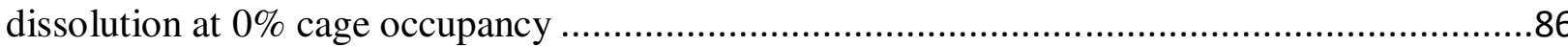




\section{Introduction}

Gas hydrates are crystalline compounds which occur under conditions of low temperature and moderate pressures, when water forms a cage-like structure around a guest molecule. These guest molecules are encaged in polyhedral cells formed by hydrogen-bonded water molecules. These guest molecules are usually non-polar molecules which typically have sizes between 0.35 $\mathrm{nm}$ and $0.95 \mathrm{~nm}$.

Natural gas, which primarily contains hydrocarbons like methane, is a better fuel compared to other fossil fuels like coal and oil as it burns cleanly and produces lesser carbon dioxide per unit energy released. Hydrocarbon-based fuels will remain widely used in the short term in order to meet the world's growing energy demand. A large fraction of the natural gas worldwide is stored in the form of clathrate or gas hydrates. A huge amount of gas hydrates are stored in the sediments under the ocean floor mostly in the form of methane hydrates. These seafloor gas hydrates are receiving a special attention for two major reasons that they store huge amounts of energy higher than other conventional energy resources and that they are capable of releasing enormous amounts of methane, which is a potential greenhouse gas, in to the atmosphere. It is important to ensure that these methane hydrates under the seafloor are stable and study the factors affecting their stability.

Stability of gas hydrates in water majorly depends on the temperature, pressure and the chemical potential in both hydrate and water phases. A change in these parameters can affect the equilibrium of gas hydrates and cause the hydrate to dissolve in to the water. A molecular 
dynamic study of hydrate dissolution and the effect of changing these parameters have been done in this work.

\subsection{Overview and historical perspective of Gas hydrates}

\subsubsection{Discovery of Gas hydrates}

The first gas hydrate to be discovered was of chlorine gas which was obtained in the laboratory of Sir Humphrey Davy ${ }^{1}$ in 1810 . He observed a yellow precipitate while passing chlorine gas through water at temperature near $0^{\circ} \mathrm{C}$ and identified the solid to be chlorine hydrate. However, there was evidence of hydrate retrieval more than 30 years prior to Davy by Joseph Priestley, who observed the formation of $\mathrm{SO}_{2}$ hydrate ${ }^{2}$. In 1892 , Wroblewsky ${ }^{3}$ observed ice-like crystals in carbondioxide-water systems, and found them to be stable at $0^{\circ} \mathrm{C}$ and pressures above $12.2 \mathrm{~atm}$. which was later confirmed by several other observers. Early research on clathrate hydrates was focused on finding the guest species which form hydrates and the temperature and pressure conditions at which they form hydrates. It was soon realized that these gas hydrates differ significantly from what are commonly known as "hydrates" ${ }^{2}$. Unlike other hydrates, clathrate hydrates are not considered chemical compounds as the water molecules which surround the guest molecule are not bonded to the lattice. In 1934, Hammerschmidt ${ }^{4}$ indicated that the plugging of natural gas pipeline was caused by the formation of natural gas hydrates but not by the formation of ice. It was observed that hydrates often form in producing wells, or in gas and oil pipelines. So, further studies on gas hydrates were focused more on the technologic aspects of gas hydrates like hydrate properties, hydrate formation and decomposition, with the objective of preventing their formation. After the first discovery of naturally-occurring gas hydrates, the hydrate research was motivated by production, transport and its environmental effects. 


\subsubsection{Occurrence of Gas Hydrates}

Hydrates are found in places where high pressures accompany water near the freezing point of water. Hydrates are commonly found to occur in oceans wherever suitable gases, usually hydrocarbons, are released from sediments. They are found at ocean depths of $500 \mathrm{~m}$ or more. Hydrates also exist in permafrost regions at depths greater than $200 \mathrm{~m}$ as well as in the sedimentary formations, where hydrocarbons, water and low temperatures are found.

The recovery of hydrate saturated cores from the exploratory drilling in Russia in 1967 gave an earliest evidence for the existence of natural gas hydrates. The first estimate of the worldwide resource of natural gas hydrates was made by Trofimuk $^{7}$ in 1973 with an estimated $57 \times 10^{12}$ $\mathrm{m}^{3}$ of gas in continental hydrates, and $5-25 \times 10^{15} \mathrm{~m}^{3}$ of gas in subsea hydrates on the ocean floor. Soloview ${ }^{8}$ gave an estimate of $0.2 \times 10^{15} \mathrm{~m}^{3}$ of methane by also taking in to account the limiting factors like availability of methane, limited porosity, percentages of organic matter in estimating the hydrates reserve.

Figure 1.1 shows a world map with the positions of hydrate reserves marked. It can be seen from the estimates provided by Kvenvolden et $\mathrm{al}^{11}$. in 1993 in Table 1.1 that the world's hydrate potential exceeds the amount of worldwide conventional gas resources available. It was estimated that the total amount of natural gas trapped in the hydrates is approximately two times the total conventional gas resources in the world ${ }^{9}$. These hydrate resources of natural gas have a potential of being an energy source for 10,000 years $^{10}$. 


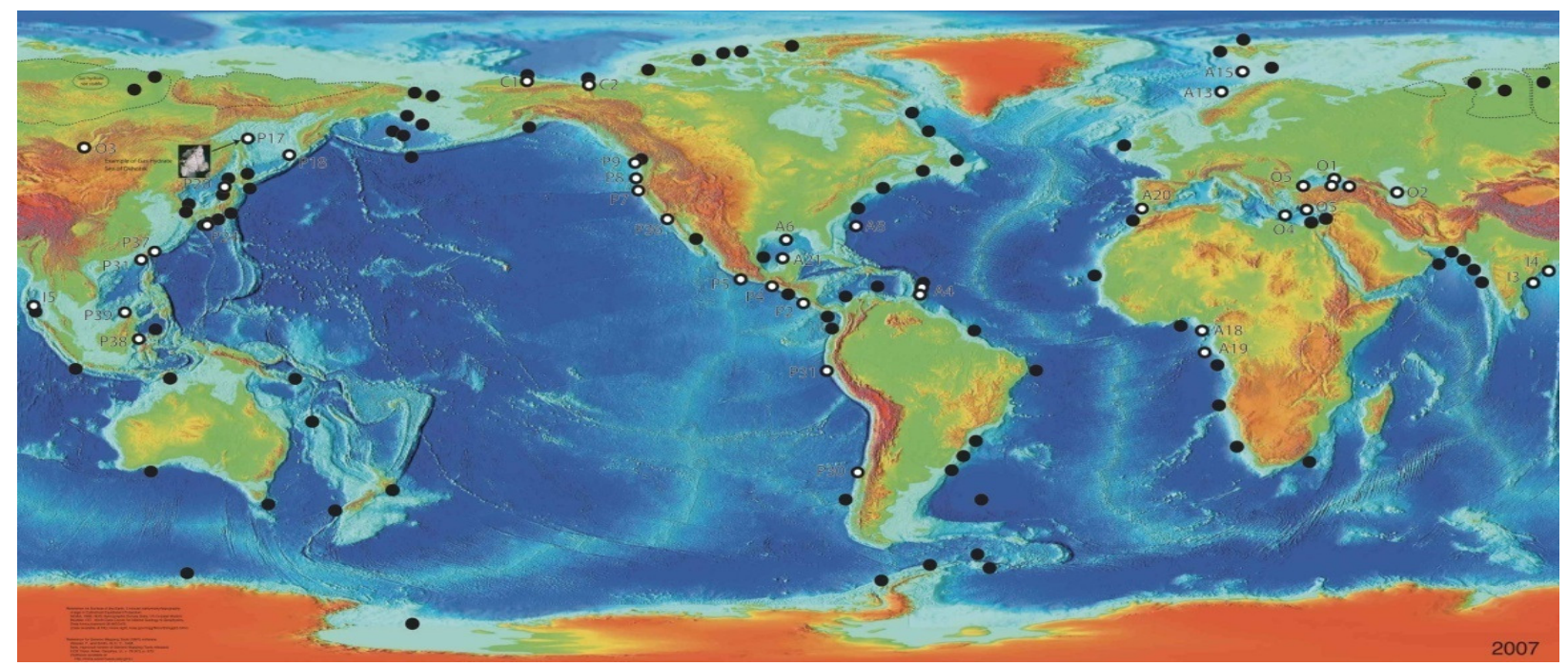

Figure 1.1 World hydrate reserves showing inferred reserves (black circles) and recovered reserves (white circles) ${ }^{6}$. Figure source: Lorenson, T. D.; Kvenvolden, K. A. "Global Occurrences of Gas Hydrate." Geophysical Monograph.2001, 124, 3.

Table 1.1 World's hydrate potential compared to conventional gas resources ${ }^{11}$. Table source: Kvenvolden, $U$. S. Geological survey Professional paper, 1993, 1570, 555

\begin{tabular}{|l|l|}
\hline Energy Resource & Hydrate potential, Tcf \\
\hline World Oceanic hydrate potential & 30,000 to $49,100,000 \times 10^{12}$ \\
World Continental hydrate potential & 5,000 to $12,000,000 \times 10^{12}$ \\
United States Hydrate potential & $1331 \times 10^{12}$ \\
Alaska Hydrate potential & $590 \times 10^{12}$ \\
India Hydrate potential & $4,307 \times 10^{12}$ \\
Japan Hydrate potential & $1,765 \times 10^{12}$ \\
World's conventional gas resources & $13,000 \times 10^{12}$ \\
\hline
\end{tabular}




\subsection{Environmental aspects of gas hydrates}

The study of impacts of gas hydrates on the earth's climate has been a challenge, especially related to methane evolution and $\mathrm{CO}_{2}$ sequestration. The amount of methane present in gas hydrate onshore and offshore was said to be around 3000 times the amount in the present atmosphere $^{16}$. Destabilization of oceanic hydrates can release large amounts of methane in to the ocean and atmosphere. So, the stability of seafloor gas hydrates and a continuous change in the global climate could be interdependent.

\subsubsection{Global climate}

Global warming, a steady increase in the global temperature of the earth's atmosphere, has been a problem over the last century because it has been occurring at a rapid rate. The increase in the greenhouse gases in the atmosphere has been considered as one of the major causes of global warming ${ }^{15}$. Since 1850 , the amounts of three main greenhouse gases $\mathrm{CO}_{2}$, methane and nitrous oxide in the atmosphere have been increasing at extraordinary rapid rates which are evident from the Figure 1.7. According to the 2007 Intergovernmental panel on climate change report ${ }^{13}$, the concentration of carbon dioxide has increased by $35 \%$ to a current level of around $380 \mathrm{ppm}$ in 2005. The amount of increase in the levels of methane has been $142 \%$ from 1750 to 1990 while the current level is around $1.774 \mathrm{ppm}$ in $2005^{14}$. It is predicted that most of these increased greenhouse gas emissions are due to the human activities such as the extensive use of fossil fuels. However, effects of gas hydrates on the global climate have been an area of research from a long time. 


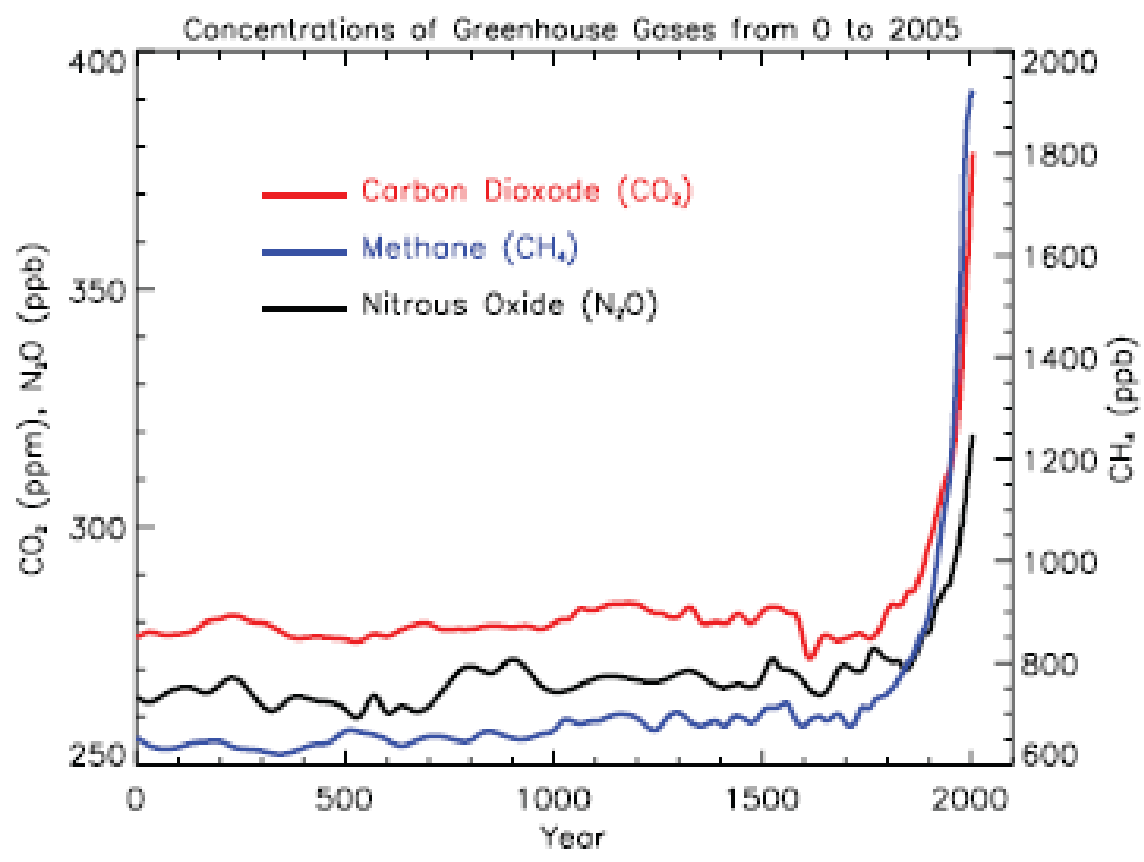

Figure 1.2 Atmospheric levels of greenhouse gases over the years ${ }^{14}$. Source: IPCC report 2007, The Physical Science Basis, Contribution of Working Group I to the Fourth Assessment Report of the IPCC, Cambridge University Press, United Kingdom, 996 pp.

The $\mathrm{CO}_{2}$ concentration levels in the atmosphere are much higher compared to methane, but its greenhouse effects are lesser compared to methane. Methane is 8 times stronger greenhouse gas than carbon dioxide on a molecule-for-molecule basis ${ }^{15}$. Methane is a transient species in the atmosphere because it can oxidize itself to $\mathrm{CO}_{2}$. So, it may have a lifetime of about a decade in the atmosphere, unlike $\mathrm{CO}_{2}$, which when accumulated in the atmosphere persists to affect climate for hundreds of years.

The effects of global warming are being seen in the form of an increase in global and ocean temperatures and a rise in sea level. It is known that changes in pressure and temperature will 
affect the stability of gas hydrate deposits in the ocean. So, there has been a concern for the possibility that the destabilization of gas hydrates can affect the global climate through the release of methane in to the atmosphere. The question of how dangerous this methane release can be, with respect to the earth's environment, has been debated for a long time. The effect of methane release from oceanic gas hydrates on the global climate depends on the rate at which it is being released. This is still unknown, though there are evidences for very slow gas releases from the oceanic sediments ${ }^{18}$. Conversely, the explosive release of methane from hydrates has been a suggested cause for the Paleocene-Eocene thermal Maximum, one of the notable events which was a consequence of a sudden global warming event 55 million years ago which saw global temperatures rise by around $6^{\circ} \mathrm{C}$ over 20,000 years and a rise in sea-level ${ }^{19}$. The evidence of marked Carbon isotope excursion at the same time period as that of PETM was a primary basis for such a belief. However, this has been strongly disproven. At this period the $\mathrm{CO}_{2}$ concentration levels rose to $2000-3000 \mathrm{ppm}$ while it is $380 \mathrm{ppm}$ currently ${ }^{20}$. There have been investigations in to knowing the probable reason for such a sudden event. Storey et $\mathrm{al}^{22}$ believe that the dissociation of methane hydrates initiated by ocean rifting due to increased volcanism could be a cause for such a sudden warming. Some scientists believe that similar methane bursts triggered by submarine landslides, sea level drops may have caused this rapid warming event and many other events of this kind at the end of glacial age.

On the other side, Todd Sowers ${ }^{23}$, a palaeoceanographer found evidences from three distinct warming episodes, disproving this theory of methane gas emissions from the hydrates being responsible for many global warming events in the past. Some climate scientists believe that the methane outbursts are an effect rather than a cause for these warming episodes. David Archer ${ }^{17}$ 
also indicated that the effect of methane release could be "chronic rather than catastrophic" with respect to the earth's climate. However, these ideas are speculative and the role of methane released by the oceanic hydrates in changing the global climate is still being studied. But, it can be assessed that, whether it is a cause or effect, the destabilization of oceanic hydrates could be a possible threat to the earth's climate, keeping in view the increasing rate of global and ocean temperatures due to the anthropogenic global warming.

\subsubsection{Ocean environment and geologic column}

Destabilization of seafloor gas hydrates also affect the ocean environment and geologic column along with the atmosphere. Methane, when released from the seafloor sediments as a consequence of destabilization of gas hydrates would be present in the water column in the ocean before escaping in to the atmosphere. A part of the methane released in to the water column would dissolve and get microbially oxidized to $\mathrm{CO}_{2}{ }^{27}$. The ocean has the capacity to absorb vast amounts of carbon dioxide, but it would make the ocean water more acidic. This could make life difficult for marine organisms that build shells and skeletons out of calcium carbonate. The

ecological effects of a near $3^{\circ} \mathrm{C}$ increase are estimated to result in large scale degradation of coral reeves, which are a vital habitat for many ocean species ${ }^{21}$.

Gas hydrates can also be a geologic hazard. It is believed that the gas hydrate decomposition in the geologic column causes weakening of the sediments leading to instability of this column. It is predicted that it can be further dangerous resulting in uncontrollable gas releases, if these unstable seafloor sediments are disturbed for seafloor developmental activities ${ }^{21}$. 


\subsection{Motivation}

Knowing the stability of methane and $\mathrm{CO}_{2}$ hydrates in presence of water will help in predicting their effects on the earth's environment and the feasibility of long term storage of $\mathrm{CO}_{2}$ as hydrates under the ocean floor. Gas hydrates are stable at low temperatures and high pressures and are a potential source of energy. The occurrence of pure natural $\mathrm{CO}_{2}$ hydrates is very rare. They have so far been reported only from a single hydrogen sulphide-rich environment in the Okinawa Trough $^{24}$. Methane hydrates are widely distributed in sediments along continental margins and are believed to contain more energy than all other fossil fuel resources. But, they may also play a role in global climate change as noted in the previous section. The global gas hydrate deposits store a quantity of methane, so large that if even a small fraction was released to the atmosphere, it could have a greater impact on the earth's climate than all of the anthropogenic $\mathrm{CO}_{2}$ currently in the atmosphere ${ }^{17}$. The destabilization of methane hydrates under the seafloor is believed to trigger slump slides which can result in a release of large amounts of methane into the water column and atmosphere eventually ${ }^{47}$. So, a study of the stability of methane hydrates in water needs a special attention.

Capture and long term storage of $\mathrm{CO}_{2}$ released from the fossil fuels has emerged as a possible means to reduce the anthropogenic release of this gas. Disposal of liquid $\mathrm{CO}_{2}$ at extreme depths in the ocean, owing to its higher density compared to water, was proposed to be a means for long term $\mathrm{CO}_{2}$ storage $^{26}$. But, the possibility that ocean currents will transport them back to the ocean surface would make it an inefficient method for long term storage of $\mathrm{CO}_{2}$. Injecting $\mathrm{CO}_{2}$ at a depth of few hundreds of meters of sediments underneath the ocean floor is believed to serve as a better means of $\mathrm{CO}_{2}$ sequestration ${ }^{25}$. This is because hydrates, when formed in the oceanic 
sediments, would occupy pore space as an immobile phase, unlike water and gas, thereby reducing the permeability of the sediments. This would help in restricting the transport of the gases disposed underneath to the ocean floor. The ability of $\mathrm{CO}_{2}$ to form hydrate can play a role in sequestering $\mathrm{CO}_{2}$ for a longer term. There is a large portion in the oceans and the sediments underneath the ocean floor which has temperature and pressure conditions which could support $\mathrm{CO}_{2}$ hydrate formation. The stability of $\mathrm{CO}_{2}$ hydrates will affect the term of $\mathrm{CO}_{2}$ sequestration and the ocean environment.

It is important to understand the phenomena governing the evolution of gas hydrates in water to predict their stability. When temperature and pressure changes of the ocean occurring as a result of the changing climate could be a factor affecting the stability of hydrates, difference in chemical potentials of the gas forming hydrate in the hydrate and water phases also influence the stability of gas hydrates. When the instability of hydrates is caused by the existing temperature and pressure conditions, then the phenomenon of decomposition of hydrates can be referred as dissociation. In this case, the hydrate is said to be outside the hydrate stability zone. But, when hydrate is inherently stable at the existing temperature and pressure conditions, then the concentration differences of the gas forming hydrate between the hydrate and the liquid phase if any, initiates the decomposition of hydrate. This phenomenon can be referred as dissolution and it is a slower process compared to dissociation. Usually, the concentration of methane or carbon dioxide in the ocean is significantly smaller than its solubility in seawater. Thus, when a hydrate of methane or carbon dioxide is exposed to ocean water, both hydrate and the water phases are not in equilibrium with respect to the concentrations of the corresponding gas. This can result in dissolution of these gas hydrates in to the water. This work has been an attempt to understand 
this hydrate dissolution process and the factors affecting it such as the gas concentration in the hydrate or water phase.

\subsection{Overview of previous work}

A lot of research was put in to the study of dissolution of methane hydrates in terms of both experiments and molecular modeling to predict their stability in water.

\subsubsection{Insitu experiments on bubble injection in oceans}

Brewer et al. ${ }^{26}$ conducted a set of experiments on $\mathrm{CO}_{2}$ disposal at depths ranging from 349 to 3627 meters where the temperatures range from $8^{\circ} \mathrm{C}$ to $1.6^{\circ} \mathrm{C}$. It was observed that at 349 meters, a liquid droplet of $\mathrm{CO}_{2}$ became coated with a thin hydrate film. The droplet broke down into smaller globules that rose rapidly because of the density differences between liquid $\mathrm{CO}_{2}$ and seawater. At 3627 meters, liquid $\mathrm{CO}_{2}$ was found to convert in to hydrate more readily. But, the hydrate phase being denser than the liquid $\mathrm{CO}_{2}$ at those conditions, the hydrate layer that formed at the $\mathrm{CO}_{2}$-seawater interface was found to sink through the liquid $\mathrm{CO}_{2}$ in the container, renewing the liquid $\mathrm{CO}_{2}$-seawater interface. This interface was observed to rise rapidly because of a rapid hydrate formation. They concluded from their experiments that the liquid $\mathrm{CO}_{2}$ in the oceans, in the depth range of 2700 to $4500 \mathrm{~m}$, would quickly react with water, form hydrate, and swell to many times its original size. Similar experiments were conducted recently by Rehder et al. $^{27}$ studying the bubble dissolution of methane and Argon within and outside hydrate stability zone. They observed that the methane bubbles released within the hydrate stability field have an enhanced lifetime and lesser dissolution rates because of the hydrate layer formation. The bubble propagation model proposed by them gave better predictions of the observed methane bubble behavior by considering the effects of decreasing solubility of methane with depth in the hydrate 
stability zone. This shows that the hydrate formation has an effect on the dissolution of methane or $\mathrm{CO}_{2}$ bubbles in to the seawater.

\subsubsection{Dissolution experiments}

There have been a fewer experimental studies on dissolution of methane and carbon dioxide hydrates compared to those on the solubility ${ }^{28-30}$ of these gases in water in presence of a hydrate. Within the hydrate stability fields, the solubilities of both methane and $\mathrm{CO}_{2}$ are supposed to increase with temperature and decrease with pressure, while the trends outside the hydrate stability field are expected to be opposite ${ }^{28-30}$. The decrease in solubility with increasing ocean depth for both the gases below $1000 \mathrm{~m}$ is mainly caused by decreasing temperature, while the effect of pressure is very small ${ }^{31,32}$.

The only in-situ experimental studies known to be done on dissolution of hydrates in the oceans were done by Rehder et al. ${ }^{31}$ They measured the dissolution rates of pure synthetic samples of methane and carbon dioxide hydrates directly on the seafloor at conditions of pressure and temperature of 104.8 bar and $3.6^{\circ} \mathrm{C}$. The temperature and pressure conditions of the experiment are indicated by a black circle in the Figure 1.8, which are well within the hydrate stability zone. Figure 1.8 shows the pressure-temperature phase boundaries for the seawater-methane and seawater- $\mathrm{CO}_{2}$ systems. The methane hydrate was found to dissolve much slower compared to $\mathrm{CO}_{2}$ hydrate. They proposed a diffusive boundary layer model for the dissolution process, the kinetics of which is mass transfer controlled. The mass transfer occurs by the diffusion of the molecules of the guest species from the hydrate boundary to the bulk of the ocean. The proposed diffusive boundary layer model for the dissolution phenomena of hydrates requires that the ratio of dissolution rates of hydrates measured be equal to the ratio of the solubilities of respective 
guest species in water. The ratio of dissolution rates of $\mathrm{CO}_{2}$ hydrate to methane hydrate was measured to be 11 , which was comparable to the solubility ratio of $\mathrm{CO}_{2}$ to methane in water. The solubility ratio of $\mathrm{CO}_{2}$ to methane was calculated at the same conditions of temperature and pressure to be 10.4 .

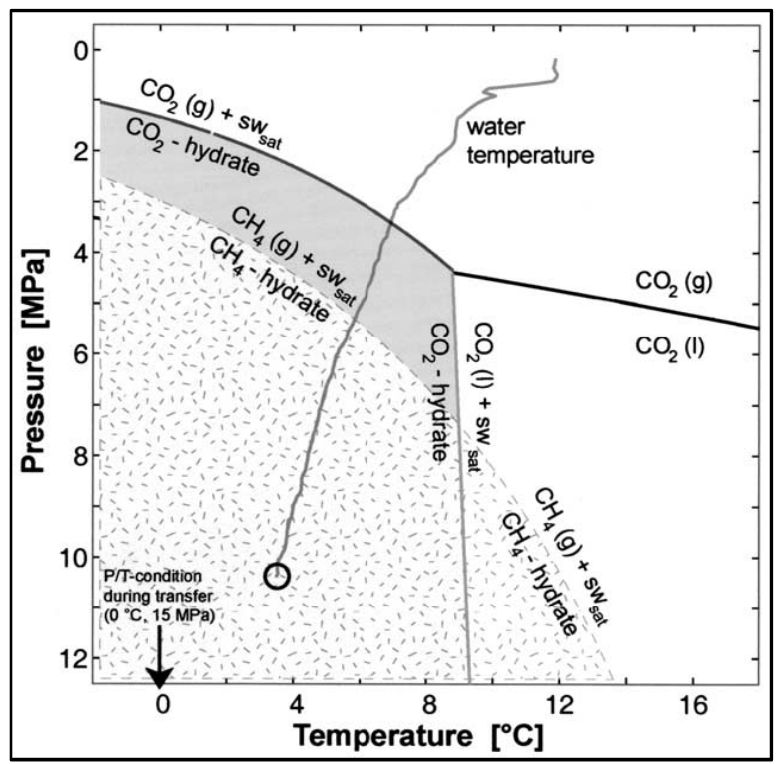

Figure 1.2 Temperature-pressure profile of $\mathrm{CO}_{2}$ and methane for the insitu experiments by Rehder et al. showing the phase boundaries of gas-liquid transition and gas hydrate boundary ${ }^{40}$. Source: Rehder et al. , Geochimica et Cosmologica Acta, 2004, 68, 285

\subsubsection{Dissolution models}

A simple heterogeneous model was proposed by Gabbito et al. ${ }^{33}$ to explain the dissolution of hydrate-coated $\mathrm{CO}_{2}$ in water, in which there is a simultaneous hydrate formation at the $\mathrm{CO}_{2}$ hydrate interface and hydrate dissolution at the hydrate-water interface. They indicated that the rate controlling step for the dissolution process is either a mass transfer within the hydrate phase or a dissolution reaction in the hydrate-water interface. This model was applied to the data obtained from experimental work by Brewer et al. ${ }^{26}$ on a small amount of liquid $\mathrm{CO}_{2}$ released at $800 \mathrm{~m}$ open ocean depth. The calculations showed that the dissolution rate depends on the mass 
transfer coefficient of $\mathrm{CO}_{2}$ within the hydrate. It was also found that the mass transfer within the hydrate phase depends on the flow condition outside the hydrate layer, which was not considered in the model. The model predicts a complete disappearance of the $\mathrm{CO}_{2}$ hydrate layer, in contrary to that observed in the experiments of Brewer et al..

Similar results were found by Shindo et al. ${ }^{34}$ by calculating dissolution reaction rate at the hydrate-water interface. Another elementary model has been proposed by Nihous and Masutani ${ }^{35}$ to explain the dissolution of pure hydrate in undersaturated seawater. The model is based on a combination of a decomposition reaction within a desorption layer surrounding the hydrate and diffusion of the gas molecules through a diffusive boundary layer. They suggest that the concentration of the guest species in water plays an important role in providing the necessary fugacity gradient for the dissolution. They applied this model to the methane hydrate data obtained from the experiments by Rehder et al. on dissolution rates of methane and $\mathrm{CO}_{2}$ hydrates in undersaturated seawater on the seafloor. The model predicted that the desorption layer should be undersaturated with respect to methane for the dissolution to proceed. The concentration of methane in the desorption layer was approximately found to be half the equilibrium solubility of methane in the ambient water. But, the model could not explain deep sea observations related to the dissolution of $\mathrm{CO}_{2}$ hydrates. The model predicted a much lesser degree of undersaturation in the desorption layer with respect to $\mathrm{CO}_{2}$ when compared to experimental observations. All these models could make closer predictions to explain the behavior of methane and $\mathrm{CO}_{2}$ hydrates in undersaturated seawater.

Seafloor methane hydrate outcrops have been found to show considerably longer lifetimes than that predicted by all these models. Also, the slow rate of dissolution of methane hydrate reported 
by Rehder et al. ${ }^{31}$ from their insitu experiments implies that the longevity of sea floor methane hydrate outcrops observed today should be possible only by the supply of sufficient $\mathrm{CH}_{4}$ to maintain boundary layer saturation or a continuous hydrate regrowth. Hester et al. ${ }^{36}$ conducted in situ experiments on two distinct natural hydrate samples to determine their dissolution rates, unlike those done for synthetic samples by Rehder et al. ${ }^{31}$. Analyses gave similar results as those done for synthetic samples. On the other hand, though rapid dissolution rates of carbon dioxide hydrate were reported by Rehder et al. ${ }^{31}$, it is necessary to understand the factors affecting the dissolution phenomenon to assess the long term stability of $\mathrm{CO}_{2}$ hydrate deposit. It is yet to be known why there is a difference between the theoretical model predictions and the field observations in the sea. But, it can be understood that the concentration of the gas forming hydrate in both water and hydrate phase has a key role in providing the necessary driving force for the dissolution of their hydrates. It is required to study the dissolution behavior of the hydrates by varying the concentration of the guest species in water and the hydrate phases.

\subsubsection{Dissolution and dissociation studies using MD simulations}

Molecular dynamic (MD) simulations have proved to be useful for predicting various properties of methane hydrate. English et al. ${ }^{37}$ used MD simulations to validate the experimental values of thermal conductivity determined by them. They were also used to know the possible reason for a lower thermal conductivity of methane hydrate compared to ice ${ }^{38}$. There have been several studies on hydrate formation, nucleation and dissociation and also on phase interface behavior of hydrate and water using MD and Monte Carlo simulations ${ }^{39-43}$. There have been a limited number of molecular dynamic investigations into hydrate dissociation and dissolution in particular, while most of them were done on methane hydrate. 
Baez and Clancy ${ }^{39}$ carried out MD simulations to study the dissolution of spherical methane hydrate crystal in presence of water using non-polarizable SPC/E model for water at $270 \mathrm{~K}$ and 40 bar, where the hydrate crystallite of radius $12 \AA$ had around 250 molecules of water and 32 molecules of methane in the hydrate phase. They found that the crystallite dissolved in $146 \mathrm{ps}$ and the melting occurred in a stepwise manner. The interface formed between the hydrate crystal and the surrounding liquid phase consisted mainly of partial cages which survived for long times keeping the structure stable before it dissolved completely. They also noted that the size of the crystallite, initially or during the dissociation, did not affect the rate of dissociation. English et al. $^{40}$ also studied dissolution of spherical hydrate crystallites in water at $277 \mathrm{~K}$ and 68 bar using TIP4P-FQ water model. The crystallites were found to dissociate within 400 ps. The dissolution rates were found not to be affected by the methane composition of the hydrate phase between 80$100 \%$, but the empty hydrate clusters were found to dissolve rapidly. The size of the crystallite or the size of the liquid phase was not found to influence the dissolution rates, but an increase in the size of the liquid phase reduced the initial delay in the dissolution process.

It has to be noted that the temperature and pressure conditions at which the simulations were carried out by both Baez et al. ${ }^{39}$ and English et al. ${ }^{40}$ are within the hydrate stability zone. Although the liquid phase considered is unsaturated with respect to methane, hydrate dissolution caused by the concentration difference of methane between the hydrate and the liquid phases is supposed to be a slow process and cannot occur in very short timescales as those observed by these authors. So, it is more likely that the dissolution occurred because the crystallites considered were subcritical in size. The critical size of a hydrate cluster for nucleation has been estimated by Radhakrishnan et al. ${ }^{41}$ to be between $10-14 \AA$ in a linear dimension. So, the size of 
the hydrate phase has to be more than the critical size of nucleation to remain stable and have a continuous growth.

Rodger et al. ${ }^{42}$ studied the behavior of methane hydrate-methane gas interface at temperatures 15-20 K above the theoretical melting temperature using SPC water model. Analysis based on a new set of order parameters to identify the water in different phases helped them observe ice and hydrate like structures in the water phase. But clustering of these structures was not observed. Myshakin et al. ${ }^{43}$ performed molecular dynamic studies on methane hydrate dissociation at 277 $\mathrm{K}$ and 68 bar. They observed that the dissociation rate depends on the hydration number and found that a decrease in cage occupancy from $100 \%$ to $95 \%$ causes a greater change in the dissociation rate than for a decrease from $95 \%$ to $85 \%$. They note that the presence of empty cages destabilizes the hydrate lattice and stimulates the dissociation process. They state that the decomposition rates of the hydrate lattice are constant during the first several nanoseconds and then demonstrate oscillating behavior. The oscillatory behavior was attributed to a regrowth of the hydrate cages at the interface. In most of the above simulations done on dissociation or dissolution of hydrates in to water, there has been a mention of possible regrowth of the hydrate clusters due to the presence of the hydrate-like water structures in the liquid phase, which is referred as the memory effect. Such phenomena also increase the longevity of a hydrate.

There have been very few studies on $\mathrm{CO}_{2}$ hydrate using MD simulations. Hirai et al. $^{44}$ studied the stability of $\mathrm{CO}_{2}$ hydrate using $\mathrm{MD}$ simulations using an interatomic potential function based on a model given by Kumagai et al. ${ }^{45}$ for both $\mathrm{CO}_{2}$ and water. They found that it is unstable compared to both empty and Argon clathrate hydrates. This was attributed to the destabilizing effect caused by the repulsive force acting between the $\mathrm{O}$ atoms of $\mathrm{CO}_{2}$ and $\mathrm{O}$ atom in water on 
the lattice structure. Kvamme et al. ${ }^{46}$ performed MD simulations to study the $\mathrm{CO}_{2}$ hydrate-water interface at conditions within the hydrate stability zone using SPC/E water model. They evaluated the steady state interface thickness using different analyses like the hydrogen density profiles and radial distribution functions. To the best of our knowledge, the dissociation and dissolution of $\mathrm{CO}_{2}$ hydrates have not been studied using MD simulations.

\subsection{Thesis objectives and Significance}

The objective of this study is focused mainly on the different aspects of methane and carbon dioxide hydrates related to the dissociation and dissolution of hydrates and to determine the small driving forces which could affect hydrate dissolution such as concentration of the hydrate forming gases in the hydrate and water phases.

The main objective of this thesis is to determine the effect of changing the concentration of hydrate-forming gas in the hydrate and the liquid phase on the dissolution phenomenon of methane and $\mathrm{CO}_{2}$ hydrates in water and understand the importance of the gas concentration in driving the hydrate dissolution process. The overall objective of this study is to study and compare the dissolution behavior of methane and $\mathrm{CO}_{2}$ hydrates by varying

- the cage occupancy of gas in the hydrate between $100 \%$ and $0 \%$

- the level of undersaturation of the gas in the liquid phase at $100 \%, 75 \%$, $50 \%$ and $0 \%$

\subsubsection{Expected Significance}

This molecular dynamic study of the two major phenomena related to gas hydrates, dissociation and dissolution can help us relate the predictions of the dissolution models and the deep sea 
observations of these phenomena on hydrate outcrops. This relationship can help us understand know why the seafloor hydrate outcrops are more stable than that predicted by the dissolution models. This work, done at a nanoscale, can also help us investigate and find factors that influence the dissolution rates of the gas hydrates such as the hydrate cage occupancy and the level of undersaturation.

Direct experiments to study the dissolution of hydrates on the seafloor have already shown that $\mathrm{CO}_{2}$ hydrates dissolves much faster compared to methane hydrates. This study tries to bring a comparison between $\mathrm{CO}_{2}$ and methane hydrates on the same aspect in the presence of small driving forces to understand the feasibility of $\mathrm{CO}_{2}$ sequestration in the form of gas hydrates. Most of the previous work done studying hydrate dissociation and dissolution using MD studies were done on methane hydrates, but not on $\mathrm{CO}_{2}$ hydrates. This work is also different from previous studies in that, it involves larger simulation boxes and simulations run for much longer timescales up to $36 \mathrm{~ns}$. A bigger simulation box gives a more realistic picture to this study eliminating edge effects. The importance of having a bigger simulation box in studying hydrate dissolution was also studied by considering two different sizes of hydrate in the simulation box. 


\subsection{References:}

1. Davy, H. "The Bakerian Lecture: On Some of the Combinations of Oxymuriatic Gas and Oxygene, and on the Chemical Relations of These Principles, to Inflammable Bodies." Phil. Trans .Roy. Soc. London. 1811, 101, 1.

2. Makogon, Y. F. Hydrates of Hydrocarbons. 1997.

3. Wroblewski, S. "On the Composition of the Hydrate of the Carbonic acid." Acad. Sci. Paris, ibid., 1882b, 954.

4. Hammerschmidt, E. G. "Formation of Gas Hydrates in Natural Gas Transmission Lines" Ind. Eng. Chem. 1934, 26, 851.

5. Kvenvolden, K. A. "Methane Hydrate - A Major Reservoir of Carbon in the Shallow Geosphere." Chem. Geol. 1988, 71, 41.

6. Lorenson, T. D.; Kvenvolden, K. A. "Global Occurrences of Gas Hydrate." Geophysical Monograph. 2001, 124, 3.

7. Trofimuk, A. A.; Makogon, Y. F.; Tolkachev, M. V. "Gas Hydrate Accumulations- New Reserve Of Energy Sources." Geologiya nefti I Gaza. 1981, 10, 15.

8. Soloviev, V. A. "Global estimation of gas content in submarine gas hydrate accumulations." Russian Geol.Geophys. 2002, 43, 648.

9. National Energy Technology Laboratory http://www.netl.doe.gov/technologies/oilgas/FutureSupply/MethaneHydrates/maincontent.htm, 08/07/2009

10. Holder, G.D.; John, V. T.; Yen, S. "Geological Implications of Gas Production from In-Situ Gas Hydrates." SPE/DOE symposium on unconventional gas recovery.1980.

11. Kvenvolden, K. A. "Gas Hydrates as a Potential Energy Resource." U.S. Geological Survey Professional paper. 1993, 1570, 555.

12. Sloan, E. D.; Koh, C. A. Clathrate hydrates of natural gases, $3^{\text {rd }}$ Ed, 2007.

13. IPCC, 2007, Pachauri R. K.; Reisinger A. (Eds), The Synthesis report, Contribution of Working Group I,II and III to the Fourth Assessment Report of the IPCC, Cambridge University Press, United Kingdom, 104 pp.

14. IPCC, 2007, Solomon, S.; Qin, D.; Manning, M.; Marquis, M.; Averyt, K. B.; Tignor, M. M. B.; Miller, H. L.; Chen, Z., Climate change 2007: The Physical Science Basis, Contribution of Working Group I to the Fourth Assessment Report of the IPCC, Cambridge University Press, United Kingdom, 996 pp.

15. John Houghton, "Global warming”, Rep. Prog. Phys. , 2005, 68, 1343.

16. MacDonald G. T.,"Role of methane clathrates in past and future climates", Clim. Change, $1990,16,247$.

17. Archer, D. "Methane Hydrate Stability and Anthropogenic Climatic Change." Biogeosciences, 2007, 4, 521.

18. Hovland, M.; Judd, A. G. Seabed Pockmarks and Seepages. Graham \& Trotman, New York, 1988.

19. Kennett, J.P.; Stott, L.D. "Abrupt deep-sea warming, Palaeoceanographic changes and benthic extinctions at the end of the Palaeocene." Nature, 1991, 353, 225.

20. Gas hydrates, http://mysite.du.edu/ jcalvert/econ/hydrates.htm, 08/04/2009 
21. Tripati, A.; Elderfield, H. "Deep-Sea Temperature and Circulation Changes at the PaleoceneEocene Thermal Maximum". Science, 2005. 308 (5730), 1894

22. Storey, M., Duncan, R. A., Swisher, C. C. I. "Paleocene-Eocene Thermal Maximum and the opening of the Northeast Atlantic" Science, 2007, 316, 587.

23. Sowers T. "Shooting methane blanks" Science, 2006, 311, 838.

24. Sakai, H. Y.; Gamo, E. -S.; Kim, M.; Tsutsumi, T.; Tanaka, T.; Ishibashi, J.; Wakita, H.; Yamano, M.; and Omori, T. "Venting of carbondioxide-rich fluid and hydrate formation in mid-Okinawa Trough backarc basin." Science, 1990, 248, 1093.

25. Giavarini, C.; Maccioni, F.; Politi, M.; Santarelli, M. L. " $\mathrm{CO}_{2}$ Hydrate: Formation and Dissociation compared to methane hydrate." Energy Fuels, 2007, 21, 3284.

26. Brewer, P. G.; Friedrich, G.; Peltzer, E. T.; Orr, F. M. Jr. "Direct experiments on the ocean disposal of fossil fuel $\mathrm{CO}_{2}$." Science, 1999, 284, 943.

27. Rehder, G.; Leifer, I.; Brewer, P.G.; Friederich, G.; Peltzer, E.T. "Controls on methane bubble dissolution inside and outside the hydrate stability field from open ocean field experiments and numerical modeling." Marine Chemistry, 2009, 114, 19.

28. Aya, I.; Yamane, K.; Nariai, H. "Solubility of $\mathrm{CO}_{2}$ and density of $\mathrm{CO}_{2}$ hydrate at $30 \mathrm{MPa}$." Energy, 1997, 22, 263.

29. Kojima, R.; Yamane, K.; Aya, I. "Dual nature of $\mathrm{CO}_{2}$ solubility in hydrate forming regions." Presented at the 6th International Conference on Greenhouse Gas Control Technologies. 2002.

30. Seo, Y.; Lee, H. "Hydration number and two-phase equilibria of $\mathrm{CH}_{4}$ hydrate in the deep ocean sediments." Geophys. Res. Lett. 2002, 29, 10.

31. Rehder, G. ; Kirby, S.H.; Durham, W.B.; Stern, L.A.; Peltzer, E.T.; Pinkston, J.; Brewer, P.G. "Dissolution rates of pure methane hydrate and carbon-dioxide hydrate in undersaturated seawater at 1000-m depth." Geochimica et Cosmologica Acta, 2004, 68, 285.

32. Handa, Y.P. Effect of hydrostatic pressure and salinity on the stability of gas hydrates. J. Phys. Chem., 1990, 94, 2652.

33. Gabitto, J.; Tsouris, C. "Dissolution mechanisms of $\mathrm{CO}_{2}$ hydrate droplets in deep seawaters", Energy conversion and management, 2006, 47, 494.

34. Shindo, Y.; Hakuta, T.; Fujioka Y.; Takeuchi, K.; Komiyama, H. "Controlling effect of $\mathrm{CO}_{2}$ hydrate membrane on $\mathrm{CO}_{2}$ dissolution into water from the surfaceof liquid $\mathrm{CO}_{2}$ ", Energy conversion and management, 1995, 36, 479.

35. Nihous, G.C.; Masutani, S.M. "Notes on the dissolution rate of gas hydrates in undersaturated water", Chemical Engineering Science, 2006, 61, 7827

36. Hester, K. C.; Peltzer, E. T.; Dunk, R. M.; Walz, P. M.; Brewer, P. G. "Can Hydrate Dissolution Experiments Predict the Fate of a Natural Hydrate System?", Proceedings of the 6th International Conference on Gas Hydrates, Vancouver, BC, Canada, 2008.

37. Rosenbaum, E. J.; English, N. J.; Johnson, J. K.; Shaw, D. W.; Warzinski, R. P. "Thermal Conductivity of Methane Hydrate from Experiment and Molecular Simulation." J. Phys. Chem. B, 2007, 111, 13194.

38. Jiang, H.; Myshakin, E. M.; Jordan, K. D.; Warzinski, R. P. "Molecular Dynamics Simulations of the Thermal Conductivity of Methane Hydrate." J. Phys.Chem. B 2008, 112, 10207. 
39. Ba'ez, L. A.; Clancy, P. "Computer Simulation of the Crystal Growth and Dissolution of Natural Gas Hydrates.” Ann. N.Y. Acad. Sci. 1994, 715, 177.

40. English, N. J.; Johnson, J. K. "Molecular -dynamic simulations of methane hydrate dissociation."'J. Chemical physics. 2005, 123, 244503.

41. Radhakrishnan, R.; Trout, B. L. "A new approach for studying nucleation phenomena using molecular simulations: Application to $\mathrm{CO}_{2}$ hydrate clathrates", J. Chem. Phys., 2002, 117 (4), 1786

42. Westacott, R. E.; Rodger, P. M. "Full-coordinate free-energy minimisation for complex molecular crystals: type I hydrates.” Chem. Phys. Lett. 1996, 262, 47.

43. Myshakin, E., Jiang, H., Warzinski, R., Jordan, K., in review, "Molecular Dynamics Simulations of Methane Hydrate Decomposition", J. Phys. Chem. 2009, 113, 1913.

44. Hirai, S.; Okazaki, K.; Tabe, Y.; Kawamura, K. "Study for the stability of $\mathrm{CO}_{2}$ clathratehydrate using molecular dynamic simulations." Energy Convers.Mgmt, 1996, 37, 1087.

45. Kumagai, N.; Kawamura, K.; Yokokawa, T., Molecular Simulation. 1994, 12,177.

46. Kvamme, B.; Kuznetsova, T. "Investigation into stability and interfacial properties of $\mathrm{CO}_{2}$ Hydrate-Aqueous Fluid system", Lecture series on computer and computational sciences, 2005, 4, 307

47. M.E. Katz, D.K. Pak, G.R. Dickens and K.G. Miller, "The source and fate of massive carbon input during the Latest Paleocene Thermal Maximum”, Science ,1999, 286, 1531. 


\section{Theoretical Background}

\subsection{Hydrate Structures}

Hydrates, as well as ice are formed due to the ability of water to form hydrogen bonds. A water molecule consists of an oxygen atom covalently bonded to 2 hydrogen atoms. The $\mathrm{H}-\mathrm{O}-\mathrm{H}$ angle between the atoms is $104.5^{\circ}$. There are two unbound electrons on the oxygen atom, which gives it a partial negative charge resulting in an attracting force between the oxygen atom of one molecule and the hydrogen atom of another molecule. This attractive force is called the hydrogen bond. Unlike ice, where the hydrogen bonded water molecules form the six-membered rings, in a hydrate, water molecules arrange in to four, five, or six-membered rings, which, in turn, form structural cavities enclathrating the gas molecules. The specific volume of water during its transition into hydrate state increases by $26-32 \%$, but during the freezing in to ice the increase is just $9 \%^{2}$.

The three most common structures are structure I, structure II, and structure H categorized based on the combination of different polyhedral cavities that can be formed. There are five other structures that have been suggested to be formed by hydrates ${ }^{1}$. Jeffrey ${ }^{3}$ suggested the nomenclature description $\left(N^{M}\right)$, for these polyhedral cavities, where $N$ is the number of edges and $M$ is the number of faces with $N$ edges. Hydrate structures are composed of five basic polyhedral cavities formed by hydrogen-bonded water molecules. The pentagonal dodecahedron $\left(5^{12}\right)$ has 12 pentagonal faces with equal edge lengths and angles. The tetrakaidecahedron $\left(5^{12} 6^{2}\right)$ has 12 pentagonal and 2 hexagonal faces. Three other polyhedral cavities are the hexakaidecahedran 
$\left(5^{12} 6^{4}\right)$, the irregular dodecahedron $\left(4^{3} 5^{6} 6^{3}\right)$, and the icosahedron $\left(5^{12} 6^{8}\right)$. Since the cavities are expanded relative to ice, hydrate cavities are stabilized by the repulsive presence of guest molecules in the cavity. The size of the guest gas molecule and the properties of the guest gas determine the structure of the gas hydrate ${ }^{1}$. Structure I and II hydrates are known to occur commonly in nature while structure $\mathrm{H}$ hydrate is a rare kind of hydrate known to exist where there is a source of thermogenically produced gases containing hydrocarbons ${ }^{4}$. Structure I and II gas hydrates are usually formed by gas molecules of smaller size and can be stabilized by filling $70 \%$ of the cavities by a single guest molecule, unlike structure $\mathrm{H}$ which requires the cooperation of two guest gas molecules, one large and one small to be stable. Different cavities which combine to form the three different structures are shown in Figure 2.1 and Figure 2.2. The specifications of each type of cavity in all the three structures are given in Table 2.1.

Table 2. 1 Description of three different hydrate structures

\begin{tabular}{|c|c|c|c|c|c|c|c|}
\hline Property & \multicolumn{2}{|c|}{ Structure I } & \multicolumn{2}{c|}{ Structure II } & \multicolumn{3}{c|}{ Structure H } \\
\hline Cavity & Small & Large & Small & Large & Small & Medium & Large \\
\hline Description & $5^{12}$ & $5^{12} 6^{2}$ & $5^{12}$ & $5^{12} 6^{4}$ & $5^{12}$ & $4^{3} 5^{6} 6^{3}$ & $5^{12} 6^{8}$ \\
\hline Cavities/unit cell & 2 & 6 & 16 & 8 & 3 & 2 & 1 \\
\hline Water molecules/unit cell & \multicolumn{2}{|c|}{46} & \multicolumn{3}{|c|}{136} & & \multicolumn{2}{c|}{34} \\
\hline Average cavity radius (̊) & 3.95 & 4.33 & 3.91 & 4.73 & 3.94 & 4.04 & 5.79 \\
\hline
\end{tabular}




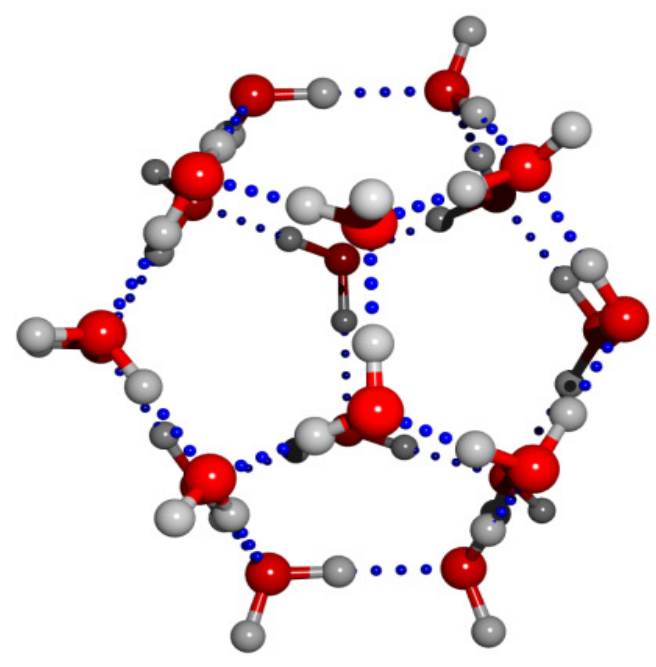

(a)

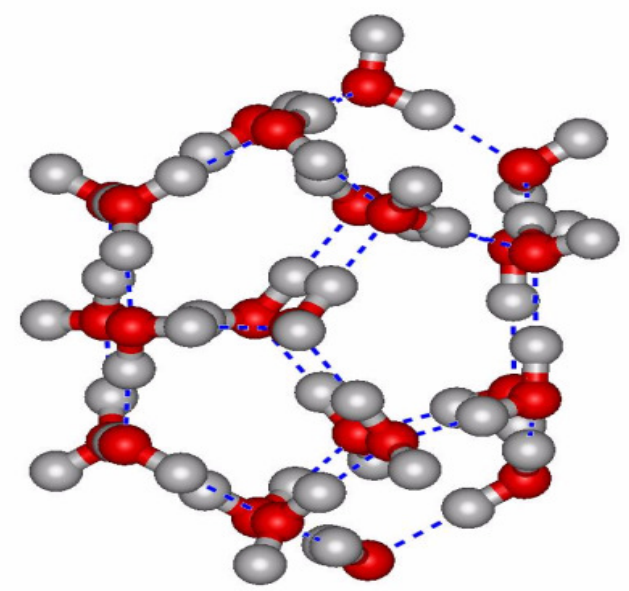

(b)

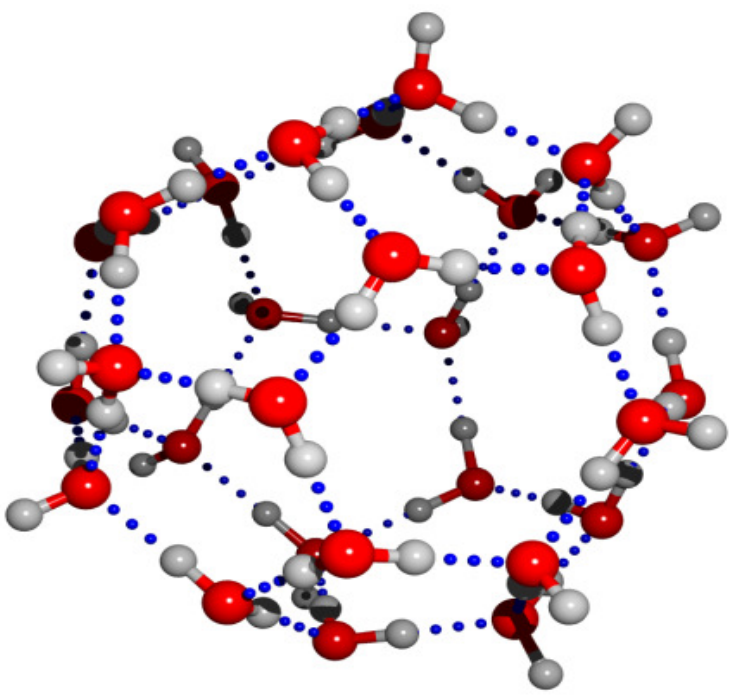

(c)

Figure 2. 1 Cavities of hydrate structures: (a) Pentagonal dodecahedron $\left(5^{12}\right)(b)$ Tetrakaidecahedron $\left(5^{12} 6^{2}\right)$ (c) Hexakaidecahedran $\left(5^{12} 6^{4}\right)$ 


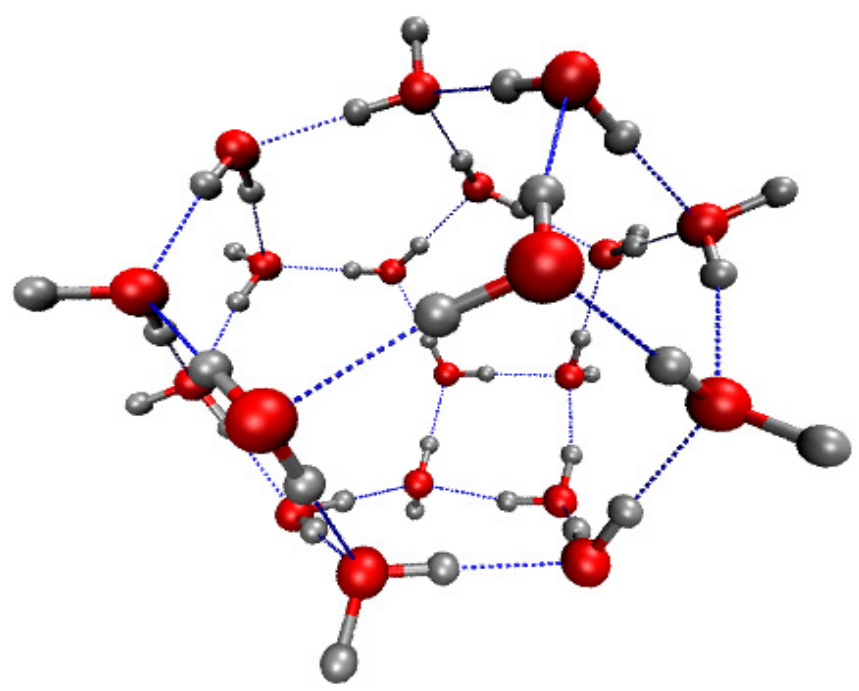

(a)

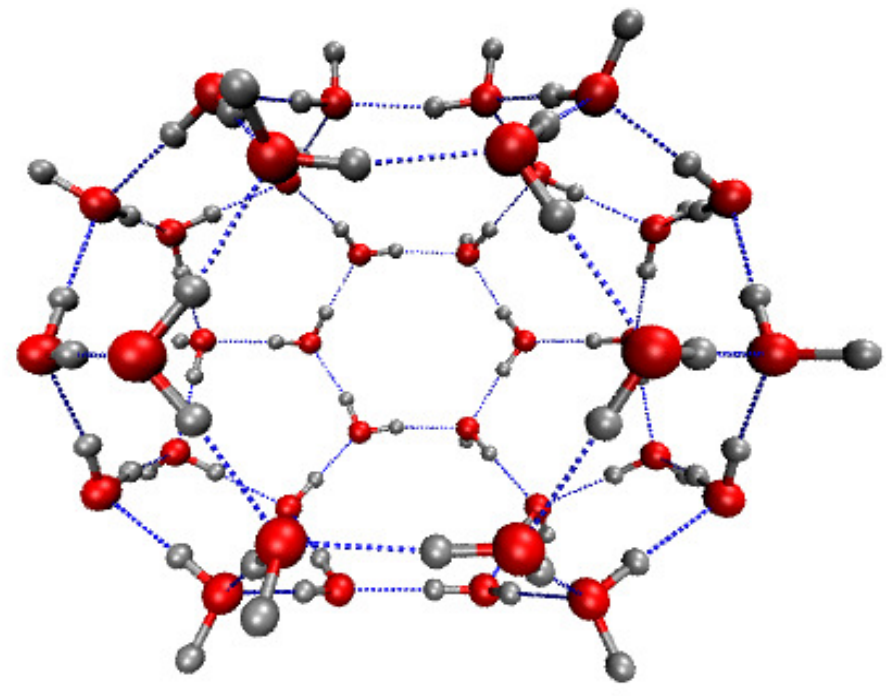

(b)

Figure 2. 2 Cavities of different hydrate structures (a) Irregular dodecahedron $\left(4^{3} 5^{6} 6^{3}\right)$ (b) Icosahedron $\left(5^{12} 6^{8}\right)$ 


\section{Structure I}

Definitive x-ray diffraction data on structure I was first obtained for ethylene oxide hydrate by McMullan and Jeffrey ${ }^{5}$. It is a primitive cubic lattice structure with a lattice constant of approximately $12 \AA$. It has two kinds of cages one of them larger than the other. A unit cell of this hydrate has two small pentagonal dodecahedron $\left(5^{12}\right)$ and six large tetrakaidecahedron $\left(5^{12} 6^{2}\right)$ cages. Each cage is occupied by a non-hydrogen gas molecule and 20 water molecules if it is a small cage or 24 water molecules if it is a large cage. There are 46 water molecules in a unit cell and the ideal unit cell formula for structure I hydrate can be written as $6\left(5^{12} 6^{2}\right) \cdot 2\left(5^{12}\right) \cdot 46 \mathrm{H}_{2} \mathrm{O}$. Smaller molecules like methane, ethane, carbon dioxide and hydrogen sulfide form this structure of hydrate. Figure 2.3 shows a structure I hydrate.

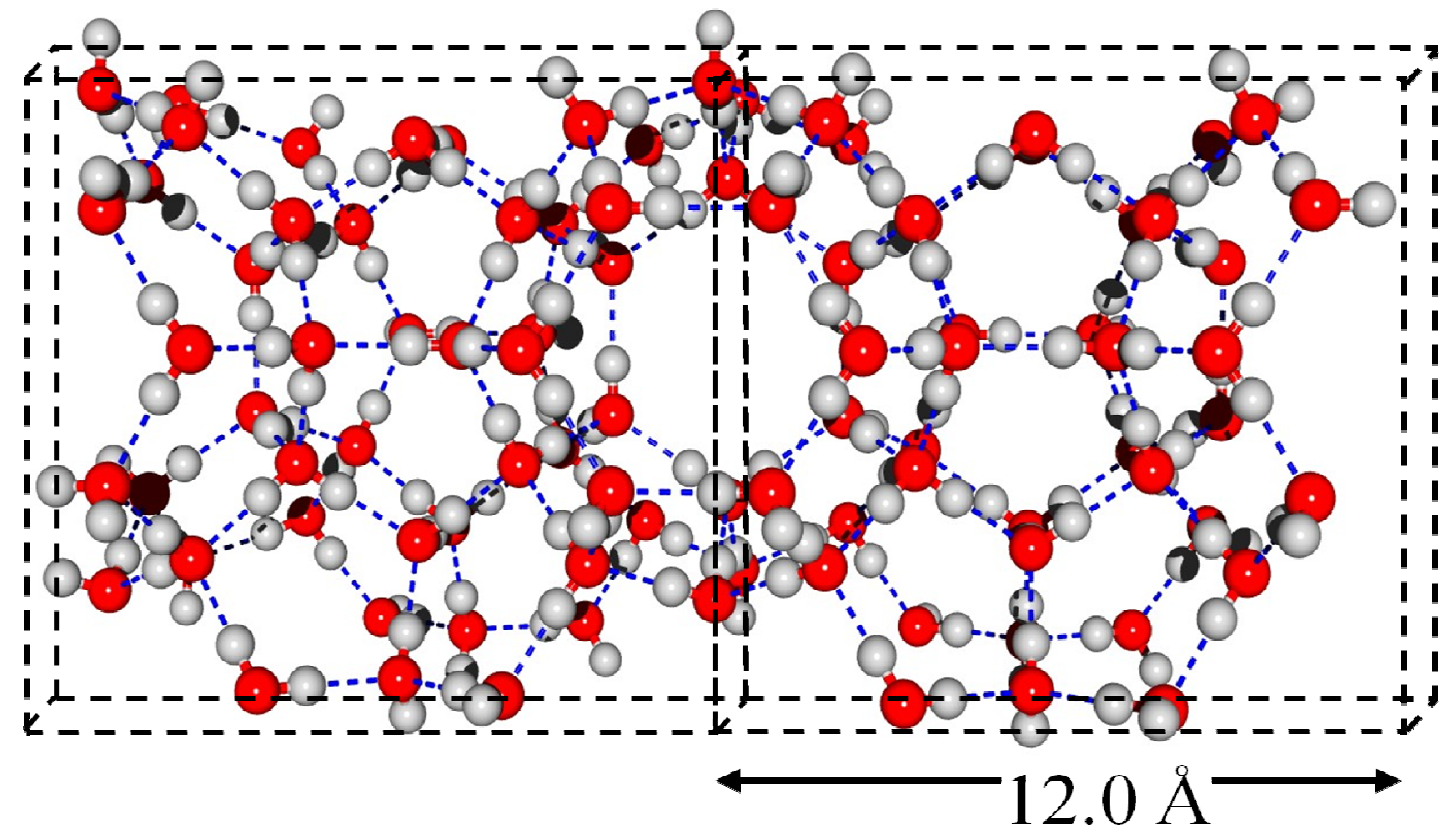

Figure 2. 3 Struture $I$ hydrate in 2 adjacent unit cells in $x$-direction 


\section{Structure II}

A study of x-ray diffraction data of tetrahydrofuran/hydrogen sulphide hydrate by McMullan et al. yielded the geometry of the structure II hydrate ${ }^{6}$. It is a face-centered cubic lattice structure with a lattice constant of $17.3 \AA$. It is formed by two kinds of cages pentagonal dodecahedron $\left(5^{12}\right)$ and hexakaidecahedron $\left(5^{12} 6^{4}\right)$ the latter being larger than the first. While a small cage consists of 20 water molecules, the large cage has 28 water molecules with a single guest molecule. A unit cell of this structure has 16 small cages and 8 large cages having 136 water molecules. Its unit cell formula can be written as $8\left(5^{12} 6^{4}\right) \cdot 16\left(5^{12}\right) \cdot 136 \mathrm{H}_{2} \mathrm{O}$. Larger molecules like propane and isobutane form this kind of a hydrate. Figure 2.4 shows a structure II hydrate.

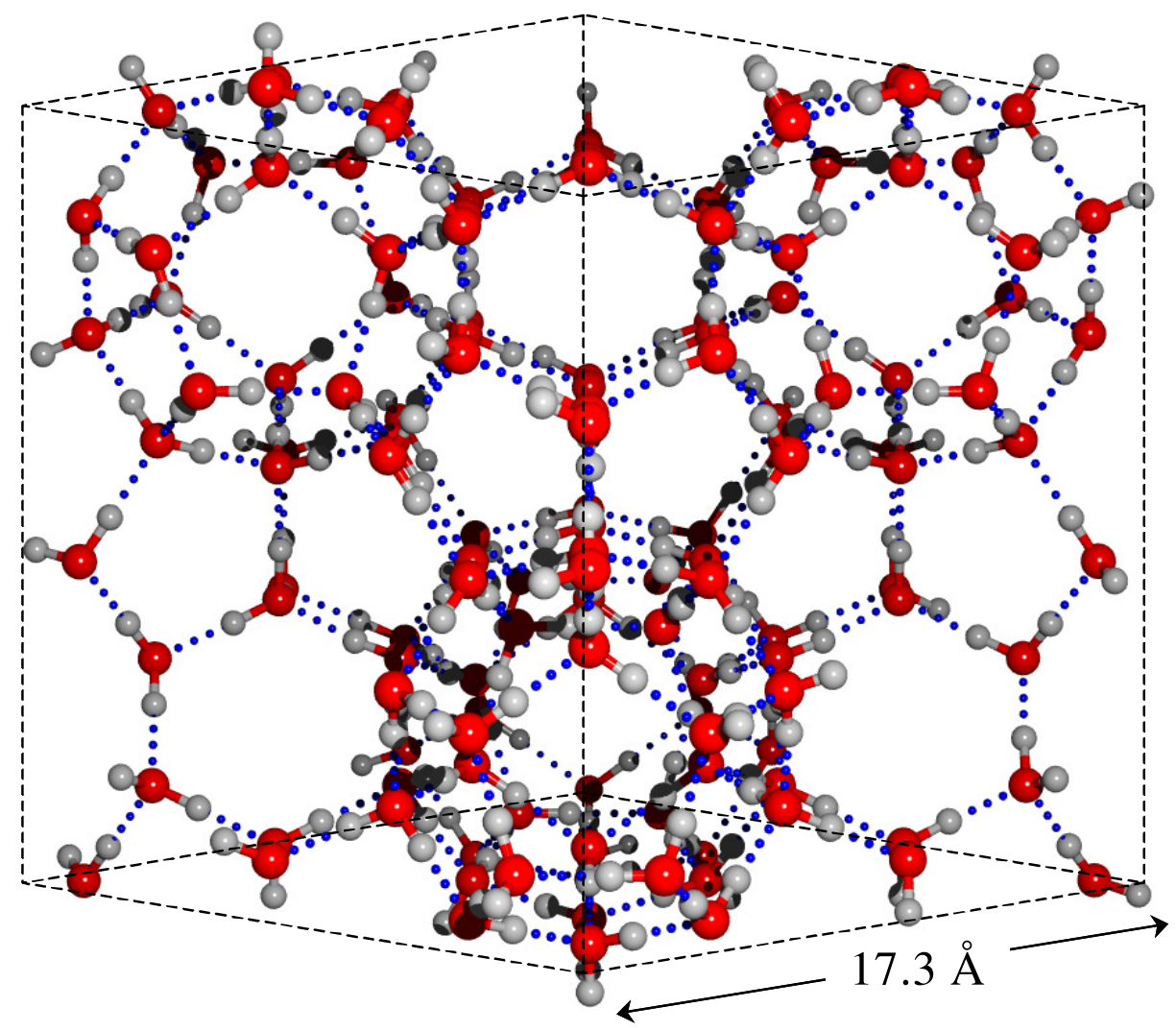

Figure 2. 4 Struture II hydrate in one unit cell of cubic structure. 


\section{Structure H}

Ripmeester et al. ${ }^{7}$ first reported structure $\mathrm{H}$ with evidence provided by NMR spectroscopy and xray powder diffraction. It is composed of 3 different types of cages. In the order of increasing size they are pentagonal dodecahedron $\left(5^{12}\right)$, irregular dodecahedron $\left(4^{3} 5^{6} 6^{3}\right)$ and icosahedron $\left(5^{12} 6^{8}\right)$. A unit cell of a hydrate of this structure accommodates 3 small, 2 medium and 1 large cages with 34 water molecules and has a hexagonal lattice structure. The large cage is occupied by large molecules like butane and other larger hydrocarbons while the other two smaller cages are occupied by smaller gas molecules like methane. Figure 2.5 shows a structure $\mathrm{H}$ hydrate

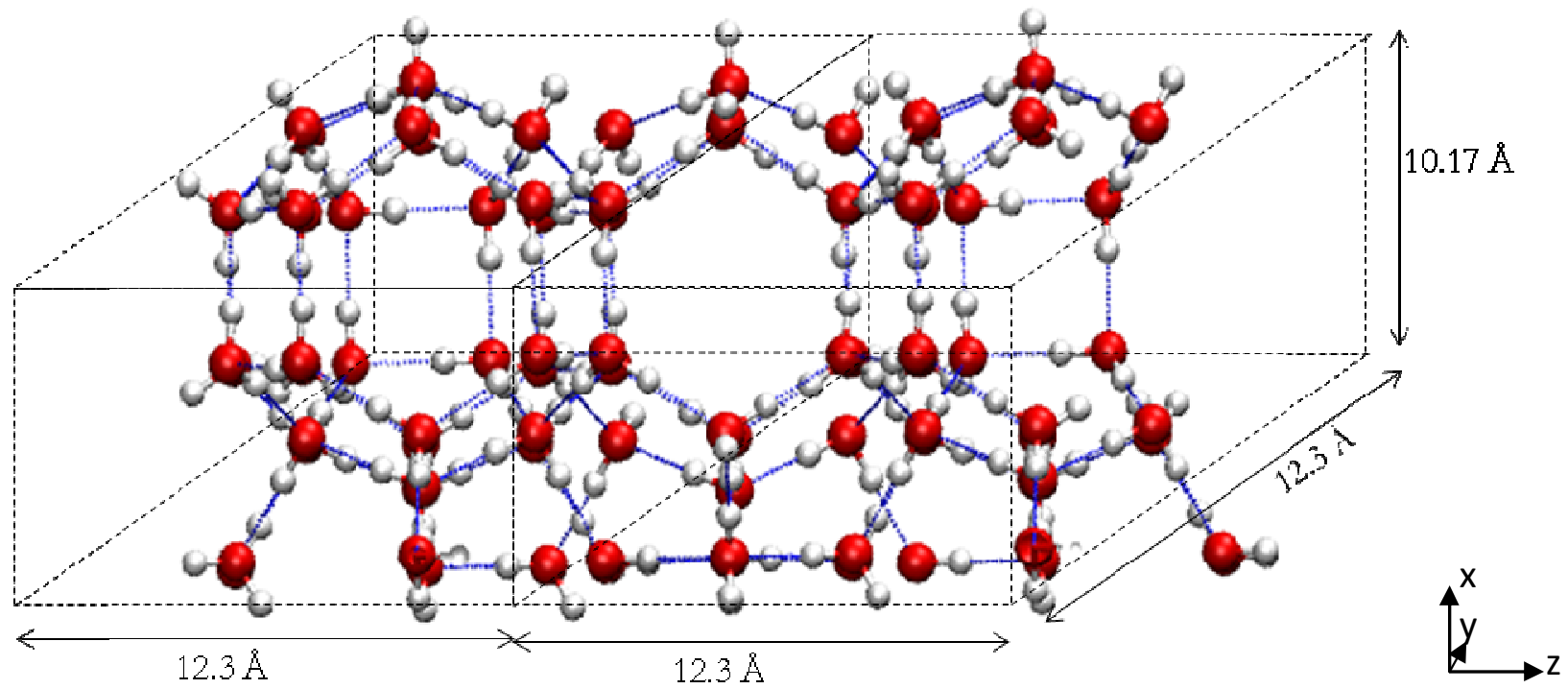

Figure 2. 5 Struture $\mathbf{H}$ hydrate in 2 adjacent unit cells of hexagonal structure in $\mathbf{x}$-direction. (The $\mathbf{y}$-axis is perpendicular to the plane of the paper) 


\subsection{Stability}

Natural gas hydrates are stable at conditions of low temperatures and high pressures. The phase diagram for a methane hydrate in Figure 2.6 shows the combination of temperatures and pressures which mark the phase transition from a system of water/ice and methane hydrate to coexisting gas and water. The range of subsurface depths in which the prevailing temperature and pressure conditions keep a gas hydrate stable is called the hydrate stability zone (HSZ). In the ocean, the hydrate stability zone starts at a depth of approximately 450 meters. The range of depths in which the temperature gradient is to the left of the phase boundary indicates the hydrate stability zone which is different for permafrost and ocean settings. This graph shows the hydrate stability zone for the ocean settings.

In addition to temperature and pressure, the composition of both water and gas are important to determine the stability of gas hydrates in specific settings. Natural subsurface environments exhibit variations in formation water chemistry, and these changes create local shifts in the phase boundary ${ }^{8}$. Local conditions and the zone's geologic history determine whether the hydrates will occur within the stability zone. Higher salinity restricts hydrate formation causing the phase boundary in the Figure 2.6 to shift to its left $^{8}$. Similarly, the presence of other gases such as carbon dioxide, hydrogen sulphide and high molecular weight hydrocarbons will increase the stability of the hydrate, shifting the phase boundary to its right. 


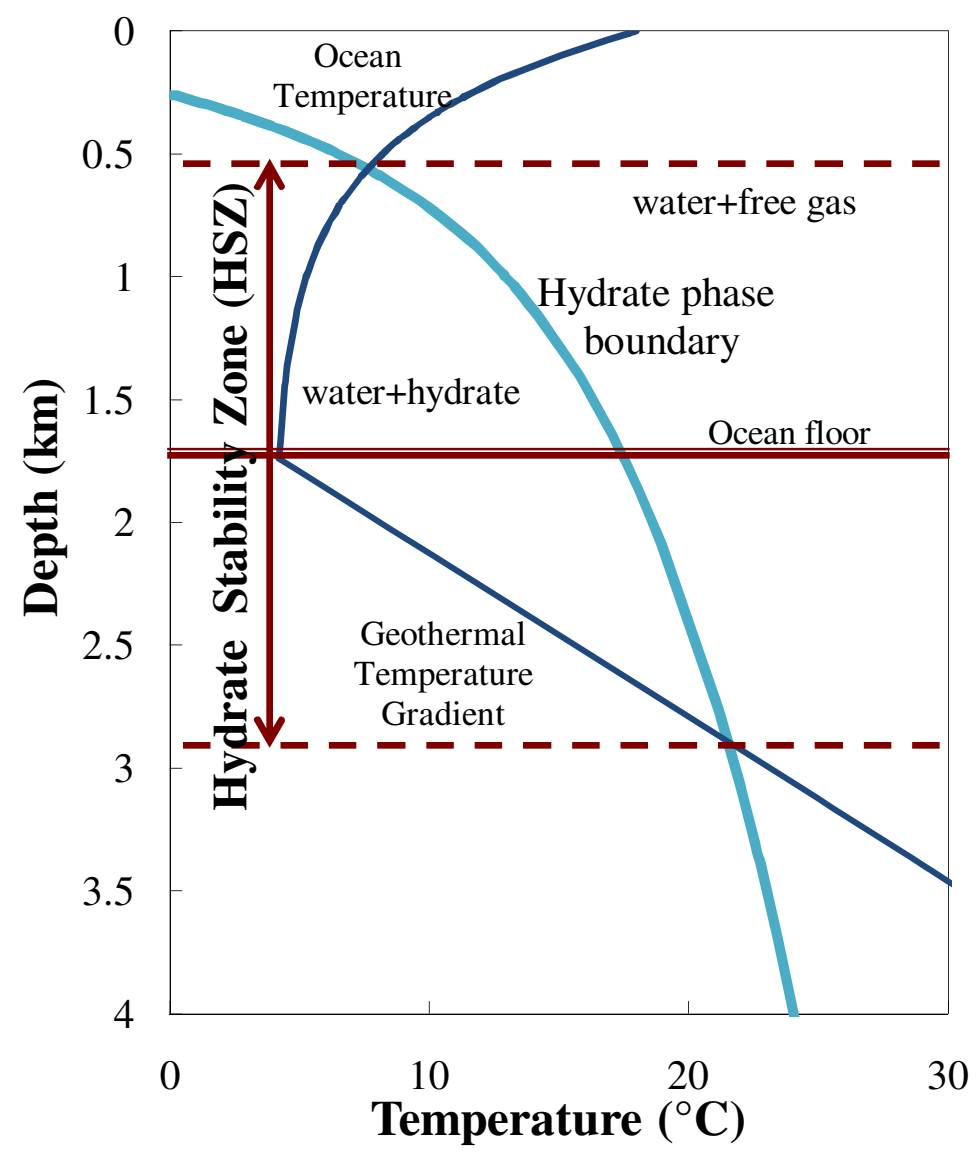

Figure 2. 6 Phase diagram for methane hydrate showing hydrate stability zone in the ocean settings

\subsection{Hydrate nucleation, growth and dissociation}

The three important phenomena which describe the life cycle of a gas hydrate are hydrate nucleation, growth and dissociation. As governed by thermodynamics, these phenomena indicate the phase stability of gas hydrates. They determine the reaction of gas hydrates when it is in a state of disequilibrium with the gas phase or liquid water phase. In order to understand these processes related to hydrate evolution, it is important to understand the properties of supercooled water responsible for a gas hydrate formation. Water is considered to be supercooled when it 
exists as a liquid at temperatures below its melting point, where it is metastable ${ }^{1}$. Water in this state is structured by hydrogen-bonded water networks or water clusters that initiate hydrate formation. This network is also responsible for the anomalous behavior of water, giving a microscopic basis to the negative thermal expansion of water at temperatures below $4^{\circ} \mathrm{C}^{1}$. $\mathrm{A}$ build of these hydrogen bonded water networks leads to a hydrate nucleation and growth while a rupture of these hydrogen bonds result in hydrate dissociation or dissolution.

Nonpolar gases are usually found to form hydrates. This is attributed to the low solubilities of these gases in water, large negative entropy and high positive heat capacity changes of the aqueous solutions of these gases with decreasing temperature ${ }^{1}$. Solubility of a hydrate-forming gas in water has a key role to play in determining the necessary concentration gradient for a hydrate dissolution process. The maximum amount of gas that can be dissolved in a liquid at a certain temperature and pressure is considered to be its solubility at those conditions ${ }^{9}$. In this context, solubility of gas can also be referred as the equilibrium gas concentration required for the hydrate stability. The solubility profile of methane in the marine sediments has also been found to have an effect on the vertical distribution of methane hydrates under the ocean floor and the diffusion of methane from the hydrate located sites ${ }^{10}$. The trend of solubility changes of methane and $\mathrm{CO}_{2}$ in the hydrate stability zone has been found to be opposite to that outside the stability zone. Solubility of these gases in water decreases with decrease in temperature in the hydrate stability region, while it increases with decrease in temperature outside the stability region ${ }^{11}$. In this work, solubility of methane and $\mathrm{CO}_{2}$ in water is useful to determine the saturation point and maintain the required level of undersaturation of these gases in the water phase thereby study the influence of the undersaturation on the dissolution phenomenon. 
Stability of gas hydrates in seawater is largely influenced by the rates of two phenomena dissociation and dissolution of hydrates as mentioned in the previous chapter. But it was evident from one of the previous works by English et al. ${ }^{12}$ on dissolution of methane hydrate crystallites discussed in the previous chapter that the effect of the crystallite being subcritical in size also influences their lifetime in water. A hydrate crystal that is subcritical in size is not a stable form of hydrate and should not be used to study the dissolution phenomenon because it causes the hydrate to dissociate faster. To study the dissolution process, the size of the hydrate crystal to be simulated has to be above a critical size which is same as the critical size of nucleation required for a continuous growth of the hydrate during its formation. So, although this study is concerned primarily with hydrate dissociation and dissolution, it is also important to understand the phenomenon of hydrate nucleation and growth.

\subsubsection{Hydrate Nucleation}

Hydrate nucleation is a process during which small clusters of water and gas grow and disperse trying to achieve a critical size for continued growth to form a stable hydrate ${ }^{1}$. After an initial induction time or a state of metastability, a gas hydrate starts to grow rapidly in hydrate forming conditions of temperature and pressure. Several hypotheses have been proposed to describe the phenomenon of hydrate nucleation. Sloan ${ }^{13}$ proposed a "labile cluster hypothesis" in which water molecules instantly form small cages, also called labile clusters, around the gas molecules. These clusters then group up to form a hydrate nucleus of a critical size before a rapid growth, where not all the configurations of the assembly would lead to a correct hydrate structure.

Nucleation at the interface hypothesis has been proposed by Long and Kvamme ${ }^{14}$ in which gas molecules are transported to the interface at hydrate forming conditions followed by an 
adsorption of these gas molecules on the aqueous surface through surface diffusion. This results in a formation of labile clusters which join and grow on the vapor side of the interface until a critical size is achieved. Radhakrishnan and Trout ${ }^{15}$ employed a Landau-Ginzburg free energy method to calculate the free energy of nucleation of a $\mathrm{CO}_{2}$ hydrate as a function of spatially varying order parameters defined based on geometrical arrangements of the guest-host molecules. "Local structuring hypothesis" was proposed by them based on their analysis of the free energy along each of the order parameters and observations of the hydrate structures from their simulations. It states that the local geometrical arrangement of gas molecules in water with a similar positioning as in a hydrate leads to the formation of the critical nucleus. It was proposed

that thermal fluctuations are responsible for such an arrangement. Moon et al. ${ }^{16}$ proposed a similar model on the basis of MD simulations of methane hydrate nucleation. So, all these hypotheses proposed the path that a hydrate could take after an initiation to form a hydrate nucleate and proceed towards a continuous growth. A failure of forming a critical nucleus would result in a dissociation of the hydrate.

\subsubsection{Hydrate Dissociation and Dissolution}

Disequilibrium between two phases can be caused by a difference in temperature, pressure or chemical potential of a particular chemical component in both the phases. These are the major factors which drive the instability of gas hydrates in deep oceans and the sediments under the ocean floor, which would result in hydrate dissociation or dissolution. It has been mentioned in the previous chapter that if the gas hydrate is unstable due to the existing temperature and pressure conditions, the phenomenon of decomposition of the gas hydrates is called hydrate dissociation. The process of decomposition of the hydrates which are stable at the prevailing 
temperature and pressure conditions, and are caused by the concentration differences of gas forming hydrate between the hydrate and surrounding liquid water phase is called hydrate dissolution ${ }^{17}$. So, dissolution occurs because the liquid water phase surrounding the hydrates is undersaturated.

Hydrate dissociation causes the hydrate phase to split into water and free gas while dissolution causes it to separate as water and gas dissolved in the water phase without any bubble formation. Unlike the dissolution process, dissociation does not require an external water phase, but the presence of water may decrease its rate which has been studied in this work. Dissolution is lead by mass transfer while dissociation is driven by heat transfer and because the heat transfer rate is faster than the mass transfer rate, dissociation is expected to be much faster compared to dissolution with respect to kinetics ${ }^{17}$. In fact, dissociation requires both heat and mass transfer. But, dissolution of a hydrate requires mass transfer of the gas within the hydrate or liquid phase and a dissolution reaction at the hydrate-water interface.

Dissolution is controlled by the mass transfer, when the diffusion of gas from the interface in to the bulk water phase is slower compared to the interface reaction. It is rather controlled by dissolution reaction at the interface, if the diffusion of gas in the liquid water phase is faster than the interface reaction. The dissolution reaction rate depends on the type of the guest gas, as it depends on the bond strength of the hydrate crystal which depends on the type of guest gas molecule forming the hydrate. But as the diffusion co-efficients of different solutes in water do not vary significantly, mass transfer or the diffusion of gas in the liquid phase is independent of the type of the guest gas molecule ${ }^{16}$. There have been several models, as discussed in the previous chapter, proposed to describe the dissolution process and have also been applied to 
related experimental work. This work has been done to understand the influence of the concentrations of the guest gas in the liquid and the hydrate phases on the dissolution process using MD simulations.

The majority of the molecular dynamic studies, previously performed on methane hydrate dissociation, have stated a possibility of hydrate regrowth as a reason for the hydrate-like water structures observed in the liquid water phase after the dissociation of the hydrate. If the hydrate is present in hydrate forming conditions, the observed hydrate-like structures could rearrange to result in a regrowth of the hydrate phase. This is called the memory effect ${ }^{1}$. There have been experimental observations of another similar phenomenon of gas hydrate mentioned below, by which it would remain stable outside the hydrate stability region, called the anomalous self preservation effect. Such phenomena need to be investigated because they can increase the stability of gas hydrates in the ocean sediments.

\subsubsection{The Memory Effect phenomenon}

Hydrate researchers believe that hydrates retain the memory of their structure even after their dissociation at moderate temperatures ${ }^{1}$. Hydrates are observed to form more readily from the melted hydrate. But, if the hydrate system is heated sufficiently above the hydrate formation

temperature, the "memory effect" will be destroyed. It has been observed by Lee et al. ${ }^{18}$ that the induction times decrease when hydrate is reformed from hydrate decomposed for 1hour compared to 12 hours. 


\subsubsection{Anomalous Self-preservation}

Self-preservation is the phenomenon where hydrates can remain stable for extended periods outside the hydrate stable region. This has been experimentally first observed by Davidson et al. ${ }^{19}$ in 1986 . This phenomenon of the hydrates is desirable for gas storage applications where it stabilizes the hydrate even at atmospheric conditions. This is observed over a temperature range of 242-271 $\mathrm{K}$ on rapid depressurization to $0.1 \mathrm{MPa}$. The cause of this behavior is not well understood, but it was suggested that the ice-shielding could explain this behavior.

\subsection{Molecular dynamic simulations}

A statistical sampling of microscopic or molecular properties (e.g., cavities and their filling by gas molecules) enables the prediction of properties which are macroscopic or measurable with normal tools such as pressure gauges and thermocouples ${ }^{1}$. For the first three-quarters of the last century, statistical thermodynamics was the only bridge available between the molecular and the macroscopic domains ${ }^{20}$. However, the availability of large, fast digital computers has enabled the use of computer simulations into this area.

Computer simulations serve as a means to understand the properties of a group of molecules in terms of their structure and the behavior of molecules at different conditions of the simulations ${ }^{2}$. They can be used to test both theoretical models and the experimental results so as to bring a comparison between them. It has been said by Allen et al. ${ }^{20}$ that "Computer simulations can act as a bridge between the microscopic length and time scales and the macroscopic world of the laboratory". Experiments cannot give an insight into many processes which require a microscopic level of understanding. They also cannot be used for abnormal conditions like very high temperatures or pressures which are not easy to handle in a realistic system. Simulations 
help us know the feasibility and practicality of such processes. They can complement the experimental work and help us understand the phenomena involved under microscopic level, which cannot be found in other ways. For example, phenomena like the memory effect that has been discussed previously can be better observed and understood through computer simulations than any other methods. Two important simulation techniques commonly used are molecular dynamics and Monte Carlo simulations. The advantage of molecular dynamics over Monte Carlo simulations is that it gives a route to determining the dynamical properties of the system like the time dependent responses to perturbations ${ }^{20}$.

Molecular dynamics is a convenient tool which helps simulate a number of molecules covering time periods up to a nanosecond, clearly within the length and the timescales necessary to observe important phenomena pertaining to the hydrate like nucleation, growth and dissociation. They are initiated with a starting configuration and a guess of the interactions between the molecules to determine the properties of the assembly of molecules. If the starting configuration is far from equilibrium, the forces are excessively large resulting in a failure of the simulation in which case an energy minimization is required.

The molecular dynamic technique has been validated for water structures through comparison of calculated properties with experimental thermodynamic data for water, such as the density maximum and the high heat capacity ${ }^{20}$. Since the first applications of molecular simulations to hydrates by Tester et al. ${ }^{21}$ in 1972, the tool has been widely used to analyze the physical behavior of the hydrates. Molecular simulations have been successfully used in many hydrate research areas such as stability, nucleation, kinetic inhibitors, interfacial properties, spectral properties and other anomalous properties like thermal expansion and thermal conductivity ${ }^{20}$. 
MD simulations solve Newton's equation of motion for a system of $\mathrm{N}$ interacting atoms while the forces $F_{i}$ are the negative derivatives of the potential functions $V\left(r_{1}, r_{2}, \ldots, r_{N}\right)^{22}$

$$
\begin{gathered}
m_{i} \frac{\partial^{2} r_{i}}{\partial t^{2}}=F_{i}, \quad i=1 \ldots N \\
F_{i}=-\frac{\partial V}{\partial r_{i}}
\end{gathered}
$$

The equations are solved simultaneously in small time steps. The temperature and pressure of the system are kept constant and the coordinates of the atoms are written to an output file at regular intervals. The coordinates as a function of time represent the trajectory of the system. After the system reaches equilibrium, many macroscopic properties can be extracted from the output file of the trajectory. The integration of forces between all molecules over several thousand timesteps produces particle trajectories from which time-averaged macroscopic properties can be computed. In a simulation work related to gas hydrates, many properties related to hydrate crystal can be evaluated like the dimensions of the simulation box, pressure, density, temperature, energy, viscosity, bond angles etc. The change in these properties with respect to time studied up to a nanoscale will help in getting a better understanding of the behavior of the hydrate under various conditions. For example a molecular density plot of the simulation cell across the box obtained as a result of these simulations gives an indication of the number of gas molecules moving out of the hydrate phase and also the rate at which they are moving out of the hydrate phase. In molecular dynamics, the simulation is limited by the computer storage and speed. So, the study of long-lived phenomena like nucleation of a hydrate requires a computer with higher storage capacity and speed. Dissolution process is also a slow process compared to dissociation and so requires a computer with higher storage and speed. 
However, there are certain limitations of MD simulations and it will therefore be necessary to perform certain checks on the experimental properties to assess the accuracy of the simulation ${ }^{22}$. The approximations are

1. The simulations use classical mechanics to describe the motion of atoms but do not consider the quantum mechanical dynamics. Classical mechanics are not applicable for many hydrogen bonded motions and the bond angle vibrations, for which the bonds are treated as constraints in the equation of motion.

2. Electronic motions are not considered in these simulations and it is assumed that the electrons are in the ground state.

3. The force field is approximate with their parameters user-modified. In this work, different force fields were used for each type of the molecules obtained by changing the LennardJones parameters. The force fields are also pair-additive which means that all the non bonded interactions result from the sum of non-bonded pair interactions.

4. Periodic boundary conditions are used to avoid real phase boundaries and are more convenient simulating bulk systems compared to smaller systems. When surface effects are not of particular interest, periodic boundary conditions need to be used. It can be applied by creating infinite lattice box, which is a replicate of the basic simulation box considered throughout the space. So, in the course of the simulation, if an atom leaves the basic simulation box, attention can be switched to its incoming periodic image in the neighboring box as shown in the Figure 2.7. Periodic boundary conditions have been used in this work, because we are dealing with bulk phases. 
5. Long range interactions are cut-off to avoid expensive calculations and the choice of this cut-off radius depends on the lattice parameter and cannot exceed half the shortest box vector. According to the minimum image convention, each individual particle in the simulation box would interact with particles within this radius around it, which could be either the particles within the simulation box or their closest periodic images. This is shown in the Figure 2.7 by a dotted circle around one of the particles in the central simulation box.

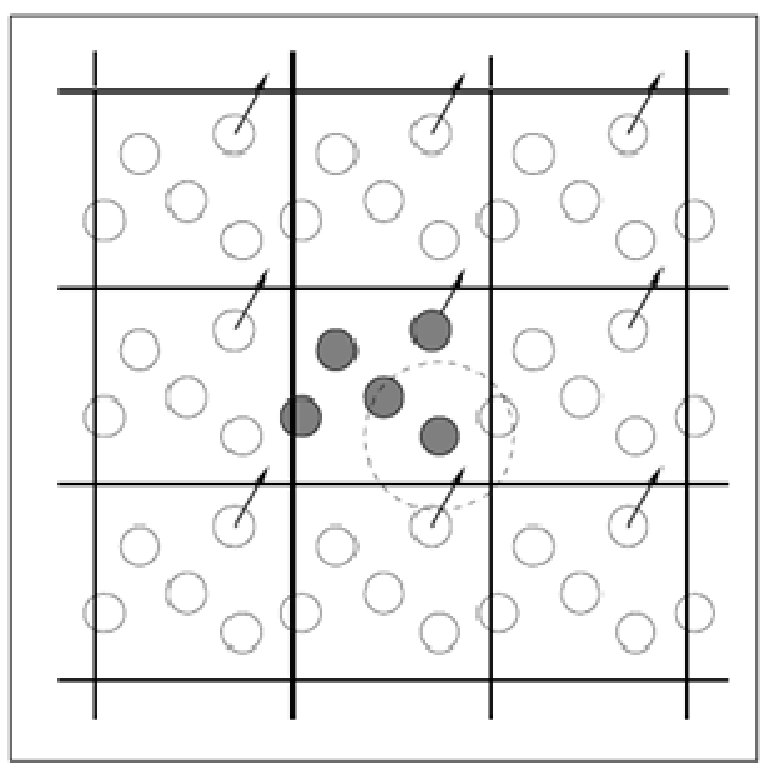

Figure 2. 7 Periodic boundary conditions ${ }^{20}$. This figure is taken from Allen, Comp. S. Matter, NIC series, 2004, 23,1

\subsubsection{Energy Minimization}

A molecular dynamic simulation can fail if the starting configuration of the system is far away from the equilibrium causing the forces to be very high. Even in this work, this was observed frequently when it is required to simulate a cell which has two different phases of molecules 
joined or when some new molecules are required to be inserted in to a group of molecules. This is when energy minimization of the system is necessary. It also helps in removing vacuum if created at the hydrate-water interface during the concatenation of the simulation boxes of hydrate and water phases readjusting the positions of the molecules in the cell. The forces among the molecules depend on the energy function of the system while a potential energy function of a molecular system is a very complex landscape in a number of dimensions ${ }^{22}$. It has one deepest point, the global minimum and very large number of local minima, where all the derivatives of the potential energy function with respect to the coordinates are zero and the second order derivatives are nonnegative. The matrix of second order derivatives, which is called the Hessian matrix, has nonnegative eigen values.

Knowledge of all local minima, the global minimum and all the saddle points in between the local minima helps in describing the relevant structures and conformations and their free energies, as well as the dynamics of the structural transitions ${ }^{22}$. There is no minimization method which guarantees the determination of a global minimum in a practical amount of time. However, given a starting configuration, it is possible to find the nearest local minimum. The method that is considered is required to search and reach the minimum by systematically moving down the steepest local gradient. The best search method is that which allows excursions into the four-dimensional space. The most popular methods known for the energy minimization are steepest descent method and conjugate gradient $\operatorname{method}^{22}$. The steepest descent method takes a step in the direction of the negative gradient irrespective of its history in the previous steps and so gets closer to the nearest minimum very quickly. The conjugate gradient method uses the gradient information of the previous steps and therefore gets much closer to the nearest 
minimum. Energy minimization for all the simulations in this work was done using the steepest descent method.

\subsubsection{Interaction functions and force field}

A force field is built up from a set of equations called potential functions which are used to generate the potential energies and their derivatives, the forces ${ }^{22}$. Within one set of equations various sets of parameters can be used which are user modified. These parameters vary based on the type of molecule and determine interactions between the molecules. Three types of molecules have been used in this work namely methane, $\mathrm{CO}_{2}$ and water. The behavior of the molecules and so some of their properties depend on the force field used for each type of molecule. Different force fields were used for each of these molecules explained in the next section and the results were compared. These potential functions can be subdivided in to three parts ${ }^{22}$.

1. Non-bonded interactions are computed on the basis of a neighbor list, a list of non bonded atoms within a certain radius. The non- bonded interactions contain a repulsion term, a dispersion term and a Coulomb term. The Lennard Jones potential between two atoms is given by

$$
V_{L J}\left(r_{i j}\right)=\frac{C_{i j}^{(12)}}{r_{i j}^{12}}-\frac{C_{i j}^{(6)}}{r_{i j}^{6}}
$$

where the parameters $C_{i j}^{(12)}$ and $C_{i j}^{(6)}$ depend on pairs of atom types.

The Colulomb interaction between the charge particles is given by

$$
V_{c}\left(r_{i j}\right)=f \frac{q_{i} q_{j}}{\varepsilon_{r} r_{i j}} ; f=\frac{1}{4 \pi \varepsilon_{0}}
$$

where $\varepsilon_{r}$ is the relative dielectric constant. 
The Lennard-Jones potential is the commonly used potential which includes the repulsion and the dispersion terms while appropriate Coulomb potentials are added if electrostatic charges are present.

2. Bonded interactions are based on a fixed list of atoms. They include bond stretching (2body), bond angle (3-body), and dihedral angle (4-body) interactions. A special type of dihedral interaction called improper dihedral is used to force atoms to remain in a plane or to prevent transition in to its mirror image.

3. Restraints are potentials used for imposing restraints on the motion of the system, either to avoid disastrous deviations, or to include information obtained from the experimental data. They usually include position restraints, angle restraints, distance restraints, orientation and dihedral restraints, all based on fixed lists. 


\subsection{References:}

1. Sloan, E. D.; Koh, C. A. Clathrate hydrates of natural gases, $3^{\text {rd }} \mathrm{Ed}, 2007$.

2. Makogon, Y. F. Hydrates of Hydrocarbons. 1997.

3. Jeffery, G. A. Hydrate Inclusion Compounds. Academic Press. 1984.

4. Roger Sassen, Ian R. MacDonald, "Evidence of structure H hydrate, Gulf of Mexico continental slope", Organic Geochemistry, 1994,22(6), 1029

5. McMullan, R. K.; Jeffery, G. A. "Polyhedral Clathrate Hydrates. IX. Structure of Ethylene Oxide Hydrate." J. Chem. Phys. 1965, 42, 2725.

6. Mak, T. C. W.; McMullan, "Polyhedral Clathrate Hydrates. X. Structure of the Double Hydrate of Tetrahydrofuran and Hydrogen Sulfide." J. Chem. Phys. 1965, 42, 2732.

7. Ripmeester, J. A.; Tse, J. S.; Ratcliffe, C. I.; Powell, B. M. "A New Clathrate Hydrate Structure." Nature, 1987, 352, 135.

8. National Energy Technology Laboratory, http://www.netl.doe.gov/technologies/oilgas/futuresupply/methanehydrates/about-hydrates/conditions.htm , 08/04/2009.

9. Lekvam, K.; Bishnoi, P. R., "Dissolution of methane in water at low temperatures and intermediate pressures", Fluid phase Equilibria, 1997, 131, 297.

10. Davie, M. K.; Buffett, B. A., "A numerical model for the formation of gas hydrate below the seafloor", J. Geophys. Res., 2001, 106, 497.

11. Rehder, G. ; Kirby, S.H.; Durham, W.B.; Stern, L.A.; Peltzer, E.T.; Pinkston, J.; Brewer, P.G. "Dissolution rates of pure methane hydrate and carbon-dioxide hydrate in undersaturated seawater at 1000-m depth." Geochimica et Cosmologica Acta, 2004, 68, 285.

12. English, N. J.; Johnson, J. K. "Molecular -dynamic simulations of methane hydrate dissociation."J. Chemical physics. 2005, 123, 244503.

13. Christiansen, R.L., Sloan, E.D., "Mechanisms and Kinetics of Hydrate Formation." Proceedings of the First International Conference on Natural Gas hydrates, Ann. N.Y. Acad. Sci., New Paltz, NY, 1993.

14. Kvamme, B., "A New Theory for the Kinetics of Hydrate Formation." Proceedings of the Second International Conference on Natural Gas hydrates, Toulouse, France, 1996, 139.

15. Radhakrishnan, R.; Trout, B. L. "A new approach for studying nucleation phenomena using molecular simulations: Application to $\mathrm{CO}_{2}$ hydrate clathrates", J. Chem. Phys., 2002, 117, 1786.

16. Moon, C.; Taylor, P. C.; Rodger, P. M. "Molecular Dynamics Study of Gas Hydrate Formation" J.Am.Chem.Soc., 2003, 125, 4706.

17. Zhang, Y.; Xu, Z., "Kinetics of convective crystal dissolution and melting, with applications to methane hydrate dissolution and dissociation in seawater", Earth and Planetary Science letters, 2003, 213, 133.

18. Lee, J.D.; Susilo, R.; Englezos, P., "Methane-Ethane and Methane-Propane Hydrate Formation and Decomposition on Water Droplets." Proceedings of the Fifth International Conference on Natural Gas hydrates, Trondheim, Norway, 2005, 1034. 
19. Davidson, D. W.; Garg, S. K.; Gough, S. R.; Handa, Y. P.; Ratcliffe, C. I.; Ripmeester, J. A.; Tse, J. S.; Lawson, W. F. "Laboratory Analysis of a Naturally Occurring Gas Hydrate from Sediment of the Gulf of Mexico" Geochim. Cosmochim. Acta, 1986, 50, 619.

20. Allen, M. P. "Introduction to Molecular Dynamics Simulation" published in Computational Soft Matter; NIC Series, 2004, 23, 1.

21. Tester, J. W.; Bivins, R. L.; Herrick, C. C., "Use of Monte Carlo in calculating the thermodynamic properties of water clathrates", AIChE J.,1972, 18(6), 1220.

22. Van der Spoel, D.; Lindahl, E.; Hess, B.; van Buuren, A.; Apol, E.; Tieleman, P.; Meulenhoff, P.; Sijbers, A.; Feenstra, A.; Drunen, R.;Berendsen, H. "Gromacs User Manual, version 3.3" www.gromacs.org, 2005. 


\section{Molecular dynamic simulations on methane and $\mathrm{CO}_{2}$ hydrates}

\subsection{Simulation details}

\subsubsection{Initial conditions and force fields used in this study}

All the simulations in this work were done in an NPT ensemble. In this study, the very popular TIP4P $\mathrm{P}^{1}$ force field has been used for water in both methane hydrate/water and $\mathrm{CO}_{2}$ hydrate/water simulations. Three different potentials namely $\mathrm{OPLS}^{2}$, GROMACS$^{3}$ and the Anderson et al. ${ }^{4}$ model have been used for methane in order to perform a comparison among them with respect to the dissociation properties of hydrates. The Harris and $\mathrm{Yung}^{5}$ potential has been used for $\mathrm{CO}_{2}$ in all the simulations. The charges and the Lennard Jones parameters of methane or $\mathrm{CO}_{2}$ for each of the potentials have been taken from the corresponding references provided. Periodic boundary conditions were used in all the directions for all the simulations. The Lorentz-Berthelot combination $^{6}$ rules were used to calculate the Lennard-Jones parameters between the water and gas molecules. The cutoff radius for the LJ interactions was chosen to be $9 \AA$ for all the systems. Ewald summation $^{7}$ was used to account for the long range electrostatic interactions. The Berendsen coupling scheme has been used for the temperature coupling of the system. The system is coupled to a Berendsen pressure coupling for controlling the pressure. The GROMACS $^{8}$ package was used to perform the MD simulations.

\subsubsection{Methodology}

Hydrate crystals for both methane and $\mathrm{CO}_{2}$ hydrates were constructed using programs in GROMACS package, based on the lattice structure of a unit cell of the hydrate for structure I and II which is shown in Table 3.1. Table 3.1, Table 3.2 and Table 3.3 show the relative positions of 
Table 3.1 Relative positions of all cavities in a unit cell of S-I hydrate showing the cavity centers.

\begin{tabular}{|c|c|c|c|c|}
\hline \multicolumn{5}{|c|}{ Cavity centers in a unit cell } \\
\hline $\mathrm{mol}$ & cavity & $\mathrm{x}$ & $\mathrm{y}$ & $\mathrm{z}$ \\
\hline 1 & \multirow{2}{*}{ Small $\left(5^{12}\right)$} & 0 & 0 & 0 \\
\hline 2 & & 0.5 & 0.5 & 0.5 \\
\hline 3 & \multirow{6}{*}{ Large $\left(5^{12} 6^{2}\right)$} & 0.25 & 0.5 & 0 \\
\hline 4 & & 0 & 0.25 & 0.5 \\
\hline 5 & & 0.5 & 0 & 0.25 \\
\hline 6 & & 0.75 & 0.5 & 0 \\
\hline 7 & & 0 & 0.75 & 0.5 \\
\hline 8 & & 0.5 & 0 & 0.75 \\
\hline
\end{tabular}

Table 3.2 The cartesian coordinates of the atoms in a methane and $\mathrm{CO}_{2}$ molecule with respect to the central atom carbon in $\AA$.

\begin{tabular}{|c|c|c|c|}
\hline \multicolumn{4}{|c|}{ methane } \\
\hline atom & $\mathrm{x}(\AA)$ & $\mathrm{y}(\AA)$ & $\mathrm{z}(\AA)$ \\
\hline $\mathrm{C} 1$ & 0.0000 & 0.0000 & 0.0000 \\
\hline $\mathrm{H} 1$ & -0.1874 & 0.0417 & -1.0803 \\
\hline $\mathrm{H} 2$ & -0.9464 & -0.1051 & 0.5441 \\
\hline $\mathrm{H} 3$ & 0.6516 & -0.8528 & 0.2276 \\
\hline $\mathrm{H} 4$ & 0.4886 & 0.9257 & 0.3280 \\
\hline
\end{tabular}

\begin{tabular}{|c|c|c|c|}
\hline \multicolumn{4}{|c|}{$\mathrm{CO}_{2}$} \\
\hline atom & $\mathrm{x}(\AA)$ & $\mathrm{y}(\AA)$ & $\mathrm{z}(\AA)$ \\
\hline $\mathrm{CD}$ & 0.0000 & 0.0000 & 0.0000 \\
\hline $\mathrm{OO}$ & 1.163 & 0.0000 & 0.0000 \\
\hline $\mathrm{OO}$ & -1.163 & 0.0000 & 0.0000 \\
\hline
\end{tabular}

the cavities and the coordinates of the atoms in water molecules and the guest gas molecules (methane and $\mathrm{CO}_{2}$ ) in a unit cell of structure I hydrate. The guest gases $\mathrm{CO}_{2}$ or methane occupy the cavity centers. A unit cell of structure I hydrate has 8 cavities, 2 small and 6 large cavities, with 46 water molecules ${ }^{9}$. The coordinates of the atoms in this table are multiplied by the lattice constant of structure I hydrate which has been taken as $12.03 \AA$. This gives us the cartesian coordinates of all the atoms in the hydrate representing the geometry of the hydrate of 1 unit cell. 
Table 3.3 Relative positions of atoms of a water molecule in a unit cell of S-I hydrate

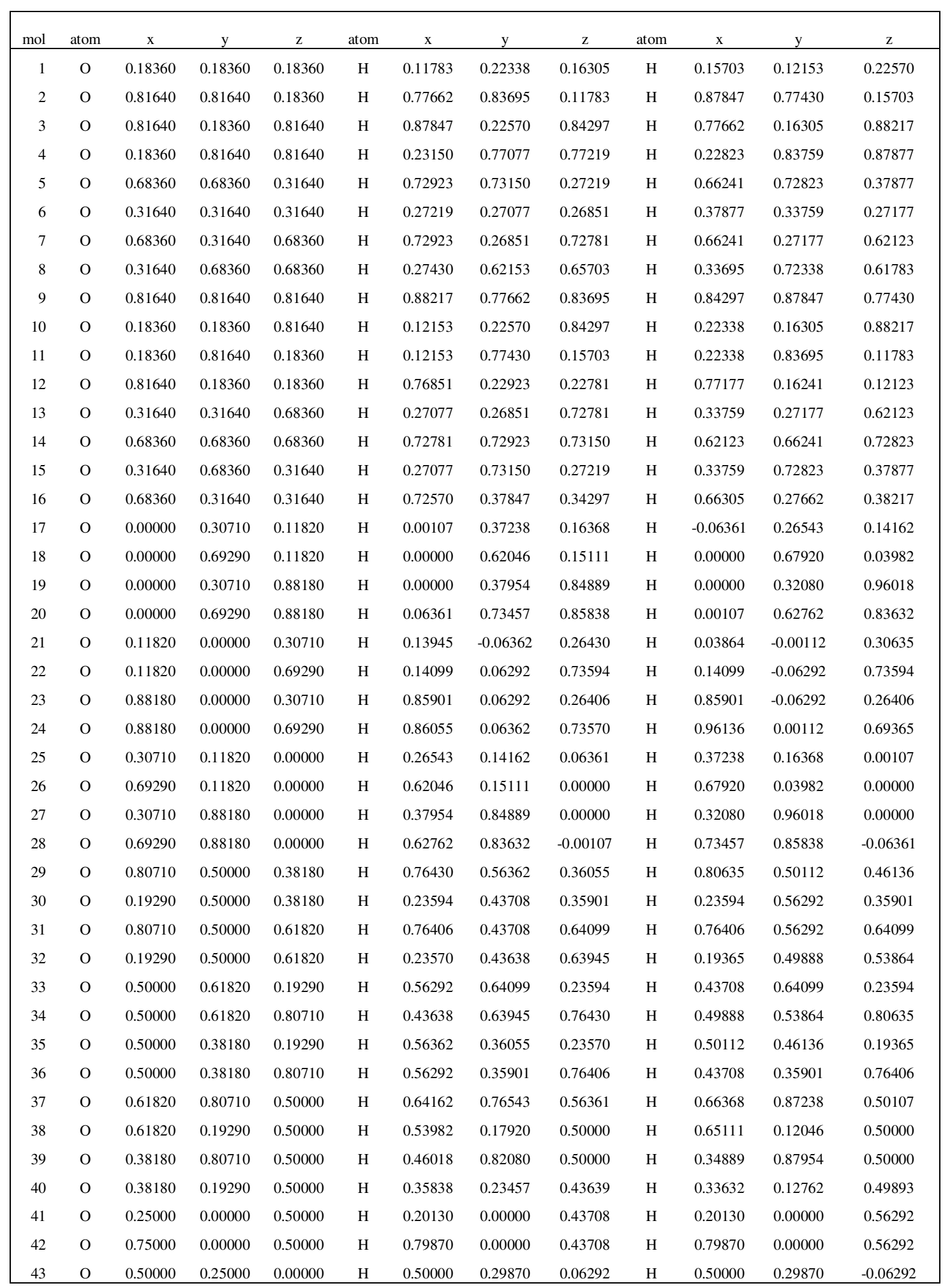




\begin{tabular}{|ccccccccccccc|}
\hline 44 & $\mathrm{O}$ & 0.50000 & 0.75000 & 0.00000 & $\mathrm{H}$ & 0.50000 & 0.70130 & 0.06292 & $\mathrm{H}$ & 0.50000 & 0.70130 & -0.06292 \\
45 & $\mathrm{O}$ & 0.00000 & 0.50000 & 0.25000 & $\mathrm{H}$ & 0.06292 & 0.50000 & 0.29870 & $\mathrm{H}$ & -0.06292 & 0.50000 & 0.29870 \\
46 & $\mathrm{O}$ & 0.00000 & 0.50000 & 0.75000 & $\mathrm{H}$ & 0.06292 & 0.50000 & 0.70130 & $\mathrm{H}$ & -0.06292 & 0.50000 & 0.70130 \\
\hline
\end{tabular}

\subsection{Analysis of the simulations}

Visual molecular dynamics (VMD) was used to view a movie of the entire simulation which helped get a clear vision of the hydrate structures and the movement of the molecules in the simulation box. It is required to estimate the rate at which the gas molecules move out of the hydrate phase in to the surrounding water as a result of the dissolution process. Analysis of all the simulations was done based on the density plots and energy plots of the simulation box. Energy plots gave the average total energy of the simulation box at different times during the course of simulation which helped to determine whether the simulation box reached equilibrium with respect to the dissolution or dissociation process.

Density plots of the simulation cell across the box in the z-direction helped estimate the number of gas molecules that are present in water and hydrate phases at different stages of the simulation and also observe the movement of the liquid-hydrate interface. These are plotted based on the data given by a program in GROMACS. The simulation cell is divided in to a fixed number of slabs of constant width in the z-direction to generate the density profile of the selected group of molecules across the simulation box. It plots density of the number of molecules in these small slabs as a function of length of the box in the z-direction. But, these profiles may also include the effects of the long range oscillations of the simulation box. So, it becomes difficult to get a closer estimation of the number of methane or $\mathrm{CO}_{2}$ molecules in water and hydrate phases. 


\subsubsection{Identification of hydrate and liquid phases}

It is important to identify in which phase these gas molecules are present at each stage of a simulation, especially the ones present at the hydrate-water interface. Therefore, a phase recognition code given by Baez and Clancy ${ }^{10}$ was used, in which they employed different criteria required to differentiate the water molecules among three phases, water, ice and hydrate. An angular parameter has been defined, which is calculated for each water molecule $i$, where $n_{i}$ is the number of nearest neighbors of molecule $i$.

$$
F_{i}=\sum_{j=1}^{n_{i}-1} \sum_{k=j+1}^{n_{i}}\left(\left|\cos \theta_{j i k}\right| \cos \theta_{j i k}+0.11\right)^{2}
$$

The nearest neighbor molecules of a molecule are considered to be those present within a distance that corresponds to the first minimum in the oxygen-oxygen pair correlation for the ice or hydrate. This distance was taken to be $3.5 \AA$. $\theta_{j i k}$ is the triplet angle between the $\mathrm{O}$ atoms of molecules $\mathrm{j}$, i and $\mathrm{k}$. For a molecule $i$ with $n_{i}$ neighbor molecules, there will be $n_{i}\left(n_{i}-1\right) / 2$ independent triplet angles with $i$ as central molecule. In ice and hydrate, the water molecules are tetrahedrally bonded. Therefore, they have 6 independent angles for each molecule $i$ and the cosine of each angle $\theta_{j i k}$ would be close to -0.33 . So, the value of $F_{i}$ of a particular water molecule gives the degree of deviation from being tetrahedrally bonded to its neighbors. If the value of $F_{i}$ is close to zero $\left(F_{i}<0.4\right)$, it indicates a tetrahedral bonding and the molecule is supposed to be in a ice-like or a hydrate-like region. Otherwise, it implies that the molecule is in water-like region.

The categorization between hydrate-like and ice-like water molecules is then done based on the identification of five-membered rings, observed only in hydrates. A water molecule in hydrate 
shares only four, five or six pentamers, unlike that observed in the liquid water. The angular order parameter and the number of five-membered rings in which the water molecule is present, in conjunction set the criteria required to categorize the water molecules among 3 different phases ice, water and hydrate. Therefore, a water molecule is considered to be ice-like if $F_{i}<0.4$ and no pentamers are identified, hydrate-like if $F_{i}<0.4$ and the molecule is found to form a part of four, five or six pentamers and liquid-like in all the other cases.

A reclassification of these water molecules is done based on the phase identity of its neighbor molecules. If a water molecule has three or more neighbors with different identity, it is reassigned to that identity. The hydrate-like water molecules are designated to clusters based on this reclassification. Clusters having less than eight water molecules are reassigned to liquid water. After the classification of all the water molecules, the methane molecules are assigned to

each cluster, if there are more than ten hydrate-like water molecules within a distance of $5.5 \AA$. This phase recognition algorithm has been tested on pure hydrate, pure water and also a completely dissociated hydrate in presence of water and was found to give correct phase recognition of the molecules in the simulation cell in all the cases.

\subsection{Comparison of lattice constants of methane hydrate for different}

\section{potentials of methane}

An 8 unit cell $(2 \times 2 \times 2)$ simulation box each of structure I and II methane hydrate was constructed as shown in the Figure 3.1. NPT simulations were carried out at 2 different potentials GROMACS and OPLS model for methane at temperatures ranging from $250 \mathrm{~K}$ to $400 \mathrm{~K}$ and a constant pressure of 1 bar for 200 ps. In all the simulations, a timestep of $1 \mathrm{fs}$ was used. This was 
done to validate the two potentials considered for methane. Lattice constant of the simulation cell of both structure I and II methane hydrates was determined from the simulations for 2 different force fields GROMACS and OPLS used for methane and compared to the experimental value. Simulations were carried out at a constant pressure of 1 bar and different temperatures ranging from $250 \mathrm{~K}-400 \mathrm{~K}$. These simulations were carried out for 200 ps. For each simulation, a plot of the box dimensions with respect to time was obtained from which lattice constant is evaluated. It was observed that the box dimensions and hence the lattice constant changes with time. It decreased to a near equilibrium value in not more than 20 ps. A time averaged value of the lattice constant of the simulation cell after equilibrium is reached is noted.

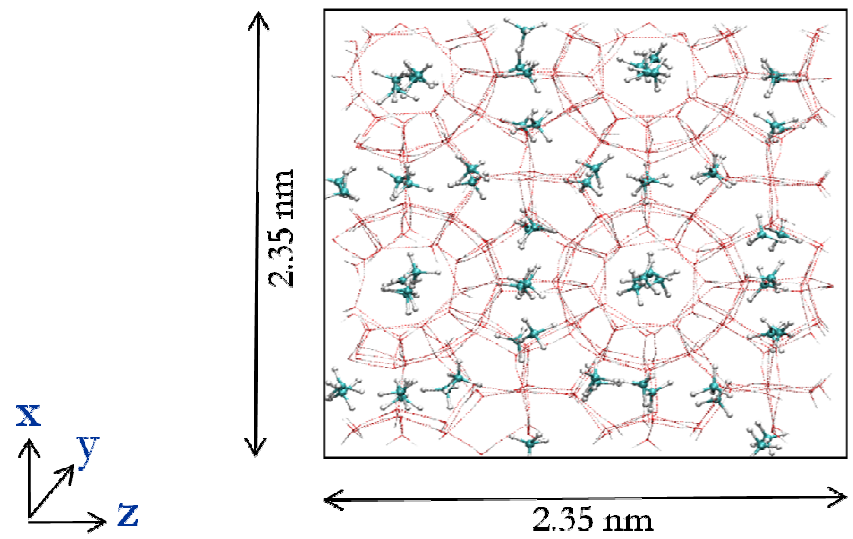

Figure 3.12 -dimentional view of an 8 unit cell $(2 \times 2 \times 2)$ simulation box of methane hydrate

\subsubsection{Effect of temperature on the lattice constant of the simulation box}

Simulation were done at different temperatures and the plot of the average lattice constant with respect to temperature for both the potentials of methane is as shown in the Figure 3.2 and Figure 3.3. The effect of temperature on the lattice constant of the simulation box was observed till a 
temperature was found where the hydrate dissociated completely. The average lattice constant of the simulation cell was found to increase with temperature from $250 \mathrm{~K}$ up to a point around 370 $\mathrm{K}$, which was observed to be little different for the two potentials. For any temperature above this point, the box dimensions were found to increase. Density plots and VMD movies showed that the hydrate structures no longer existed and dissociated in to free gas and water at these temperatures. Since there is no crystal structure after this temperature, there is no meaning for lattice constant at these temperatures. These simulations were run for very short timescales and it is possible that the hydrate dissociation can be observed at a lower temperature if the simulations were ran for longer timescales. It is also important to note that these simulations were carried out in the absence of a water phase. Therefore, the dissociation phenomenon of such a hydrate crystal could be better compared to the melting of a solid. So, the lattice constant of the hydrate crystal before dissociation can bring out a better comparison among different potentials of methane rather than the temperature at which hydrate was found to be completely dissociated. Similar simulations and analysis for structure II methane hydrate resulted in another plot. 


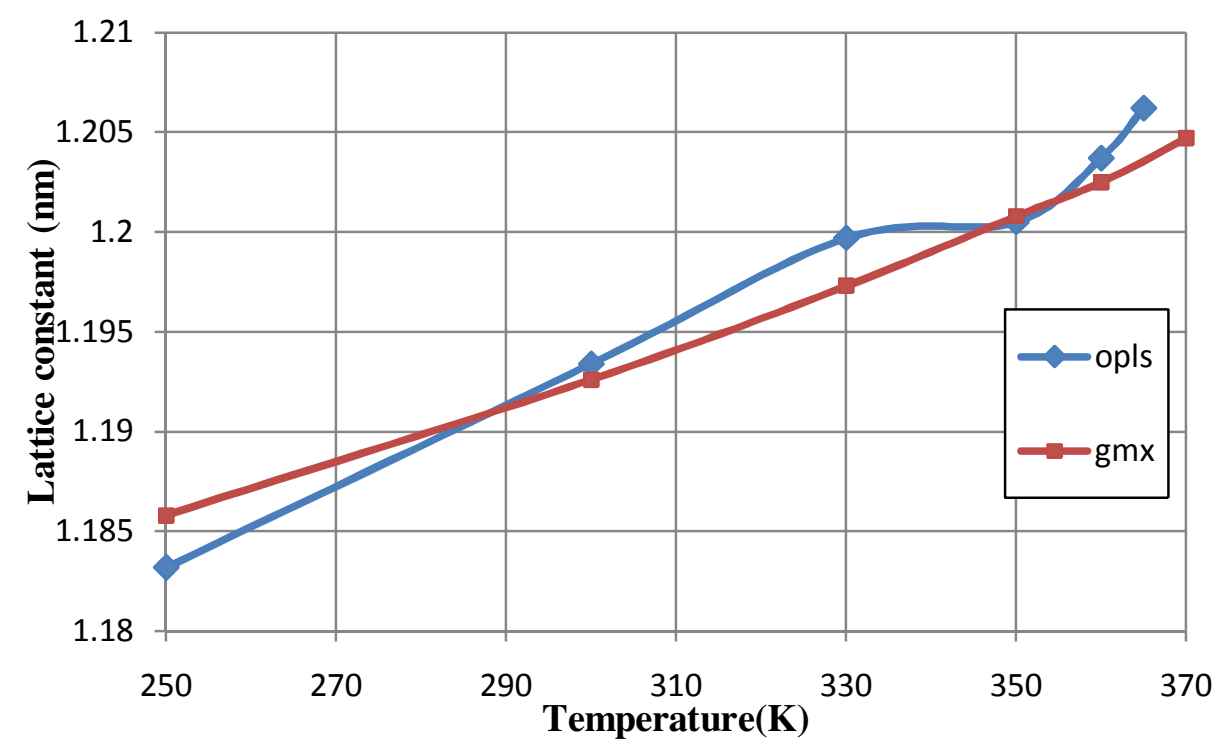

Figure 3.2 Effect of temperature on lattice constant of the structure-I methane hydrate for 2 potentials

Lattice constant of structure I methane hydrate at $273 \mathrm{~K}$ and 1 bar was noted to be $1.187 \mathrm{~nm}$ for OPLS and 1.189 for GROMACS potential from this plot and was found to be comparable to the experimental value ${ }^{12}$ of $1.2 \mathrm{~nm}$. Lattice constant of structure II methane hydrate at the same conditions were noted to be $1.705 \mathrm{~nm}$ for OPLS and $1.722 \mathrm{~nm}$ for GROMACS potential, which were also comparable to the experimental value ${ }^{12}$ of $1.73 \mathrm{~nm}$. The hydrate with GROMACS potential was observed to be more accurate in this case. This validates the 2 potentials considered for methane. 


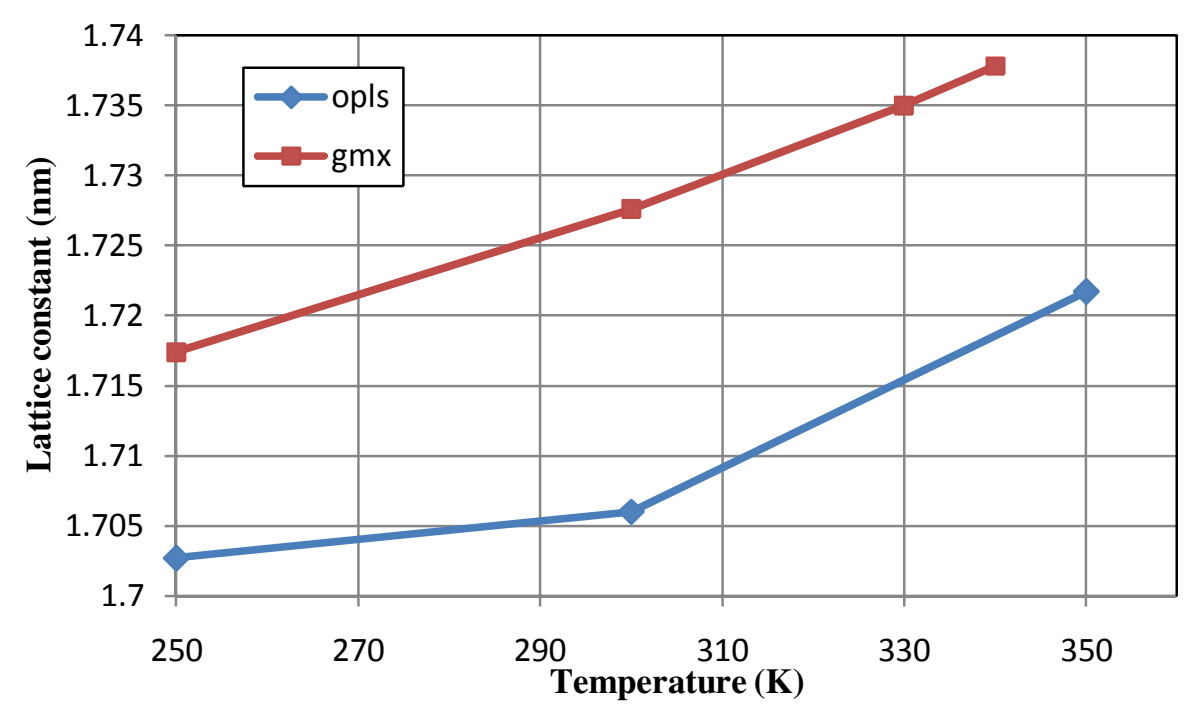

Figure 3.3 Effect of temperature on lattice constant of the structure-II methane hydrate for 2 potentials

\subsection{Hydrate Dissociation}

To study the dissociation of hydrate in presence of water, another simulation cell was constructed in which a cubic cell of water molecules has been appended to the hydrate crystal. A 32 unit cell $(4 \times 4 \times 2)$ simulation box of structure I methane hydrate has been constructed and a cell of 6917 water molecules has been appended to it making it a simulation cell of dimensions $4.7 \times 4.7 \times 7.2 \mathrm{~nm}$ as shown in the Figure 3.4. Energy minimization has been employed using GROMACS to equilibrate this simulation cell. This gives an equilibrated configuration of the molecules in the simulation cell. This procedure of equilibration was followed for all the simulations in this work. The resulting simulation cell has been simulated at a pressure of $1 \mathrm{bar}$ and different temperatures from $250 \mathrm{~K}$ till a point where it dissociates completely. All the simulations were carried out in an NPT ensemble allowing the simulation box to readjust its dimensions in response to an equilibration or a phase change. The dissociation temperature at 1 
bar has been noted and compared for three different potentials of methane the GROMACS model, OPLS and the Anderson et al. model. The temperatures chosen are well above the melting point of water for TIP4P model whose experimental value is $235 \mathrm{~K}(+/-10 \mathrm{~K})$.

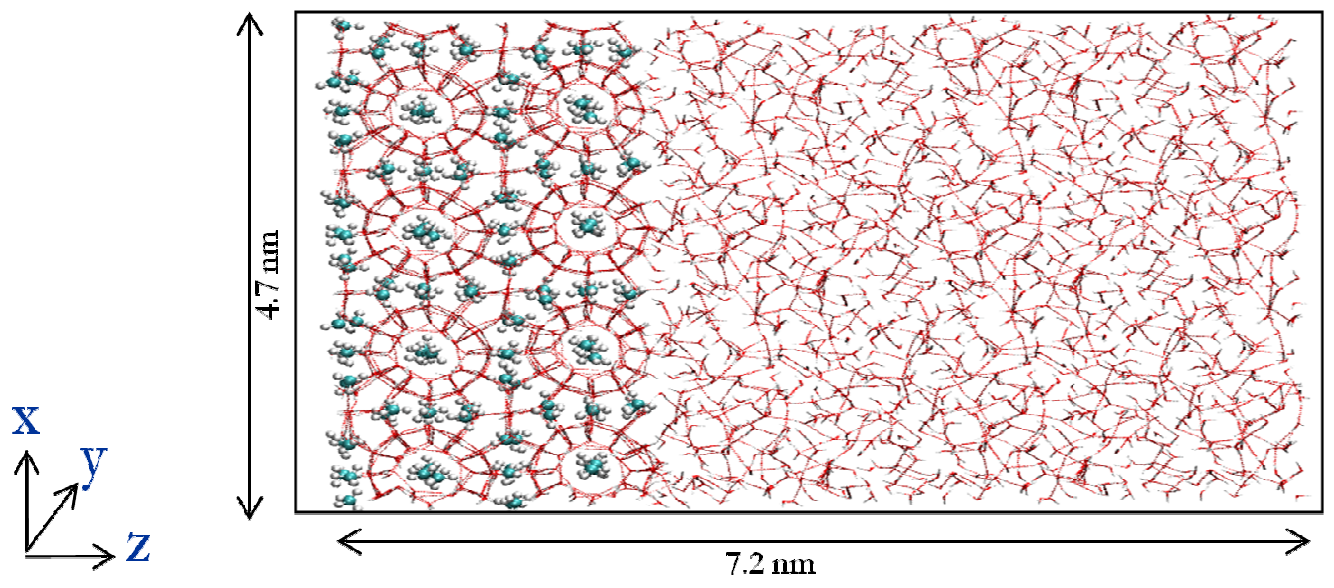

Figure 3.42 -dimentional view of a simulation cell with 32 unit cell $(4 \times 4 \times 2)$ box of $S$-I methane hydrate appended to water phase in z-direction.

This part of the study also helped us understand the effect of temperature and pressure on the dissociation process of the hydrate. This is different from the previous simulations determining the lattice constant of the simulation box in that here the dissociation was observed in the presence of water. A water phase has been appended to the simulation box on one side in only the z-direction. As the periodic boundary conditions are applied, we are actually studying an infinitely extended hydrate slab with a water phase on either sides of it. Simulations were run at a pressure of 1 bar and different temperatures starting from $250 \mathrm{~K}$ till we reached a temperature at which the hydrate completely dissociated in to the water. Each of these simulations was run for sufficiently longer time up to $20 \mathrm{~ns}$. It was observed that the presence of water phase decreases the energy barrier required for the hydrate dissociation process. It causes the hydrate to 
dissociate at a much lesser temperature than it does in the absence of water. The dissociation process was studied based on the number of gas molecules that moved out of the hydrate in to the water phase, which was obtained with the help of density plot across the simulation box as shown in the Figure 3.5. The density plot clearly shows how the hydrate shrinks in size before it completely dissociated.

At $250 \mathrm{~K}$ and $1 \mathrm{bar}$, the hydrate was found to be stable for the entire simulation run for $20 \mathrm{~ns}$. Then, simulations run at this temperature of $250 \mathrm{~K}$ and different pressures between 1 bar and 50 bar showed that the dissociation rates of the hydrate were not affected by a change in the pressure. But, it steadily increased with temperature. At $255 \mathrm{~K}$ and 1 bar, the hydrate did not completely dissociate till $20 \mathrm{~ns}$, but was found to be unstable and had a higher dissociation rate compared that at $250 \mathrm{~K}$. A further increase in temperature to $260 \mathrm{~K}$ and same pressure caused the hydrate to completely dissociate within $20 \mathrm{~ns}$. Hydrate at $265 \mathrm{~K}$ dissociated in $15 \mathrm{~ns}$, while it dissociated in $5 \mathrm{~ns}$ at $270 \mathrm{~K}$. The density plot and corresponding snapshot of the system of the simulation at $270 \mathrm{~K}$ and $1 \mathrm{bar}$ is also shown in Figure 3.6. The dissociation temperature of methane hydrate at 1 bar was noted to be $260 \mathrm{~K}$. This was for Anderson et al. model of methane.

These simulations were also done using the other two potentials for methane. Similar trends of dissociation rates of hydrates were observed for all the three potentials with changes in temperature and pressure. The dissociation temperature was noted to be $260 \mathrm{~K}$ for OPLS potential and $285 \mathrm{~K}$ for GROMACS potential. Hydrate with GROMACS potential for methane was found to withstand higher temperatures compared to OPLS and Anderson et al. model. The GROMACS intermolecular potential for methane seemed to be strong for molecules in a hydrate 
compared to other two potentials. Anderson et al model was used for methane in all the simulations done for dissolution of hydrates in water in this work.

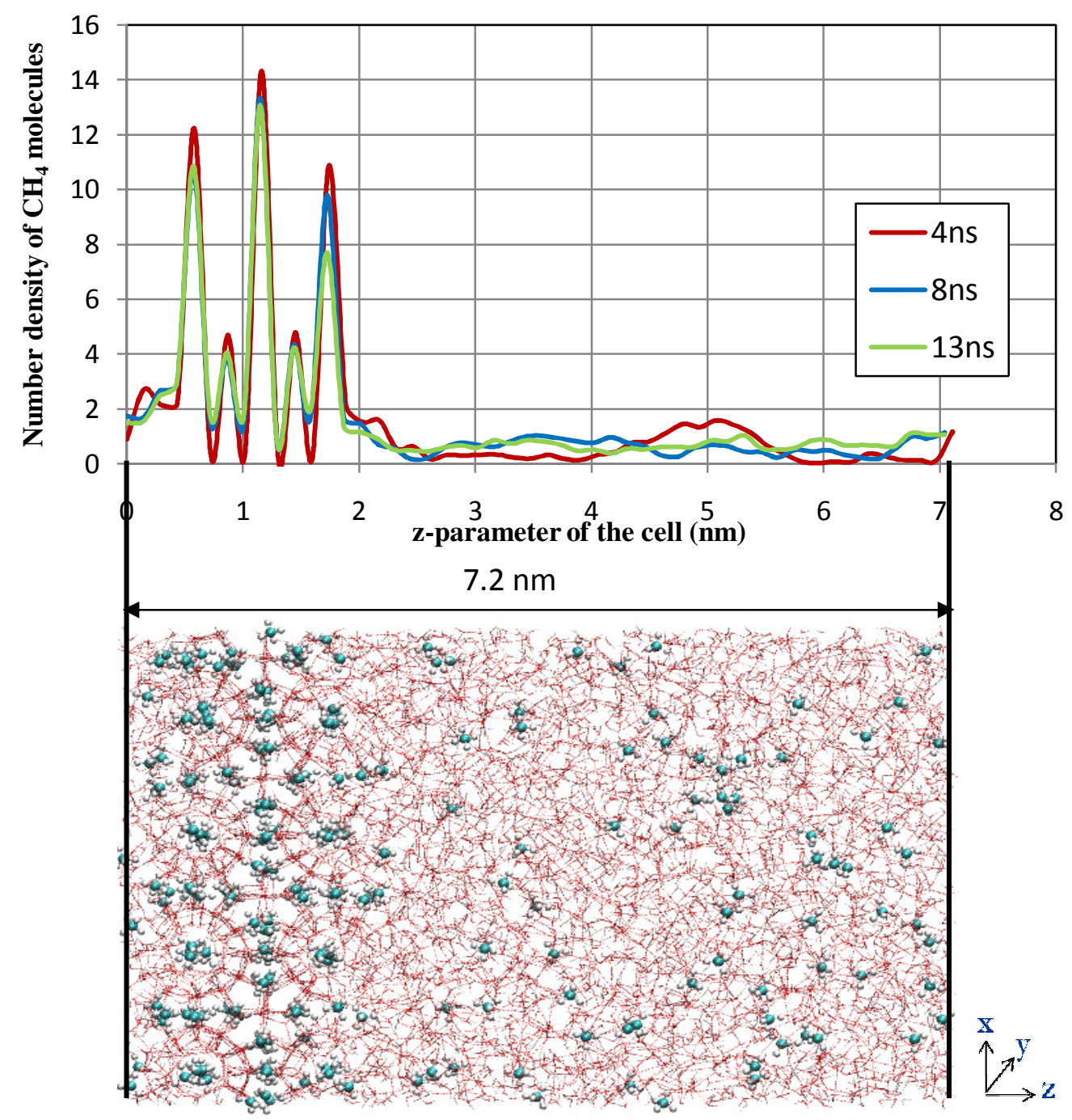

Figure 3.5 Density plot of $\mathrm{CH}_{4}$ molecules and snapshot of $\mathrm{S}$-I $\mathrm{CH}_{4}$ hydrate-water system which shows the dissociation of the hydrate at $265 \mathrm{~K}$ at $13 \mathrm{~ns}$ 


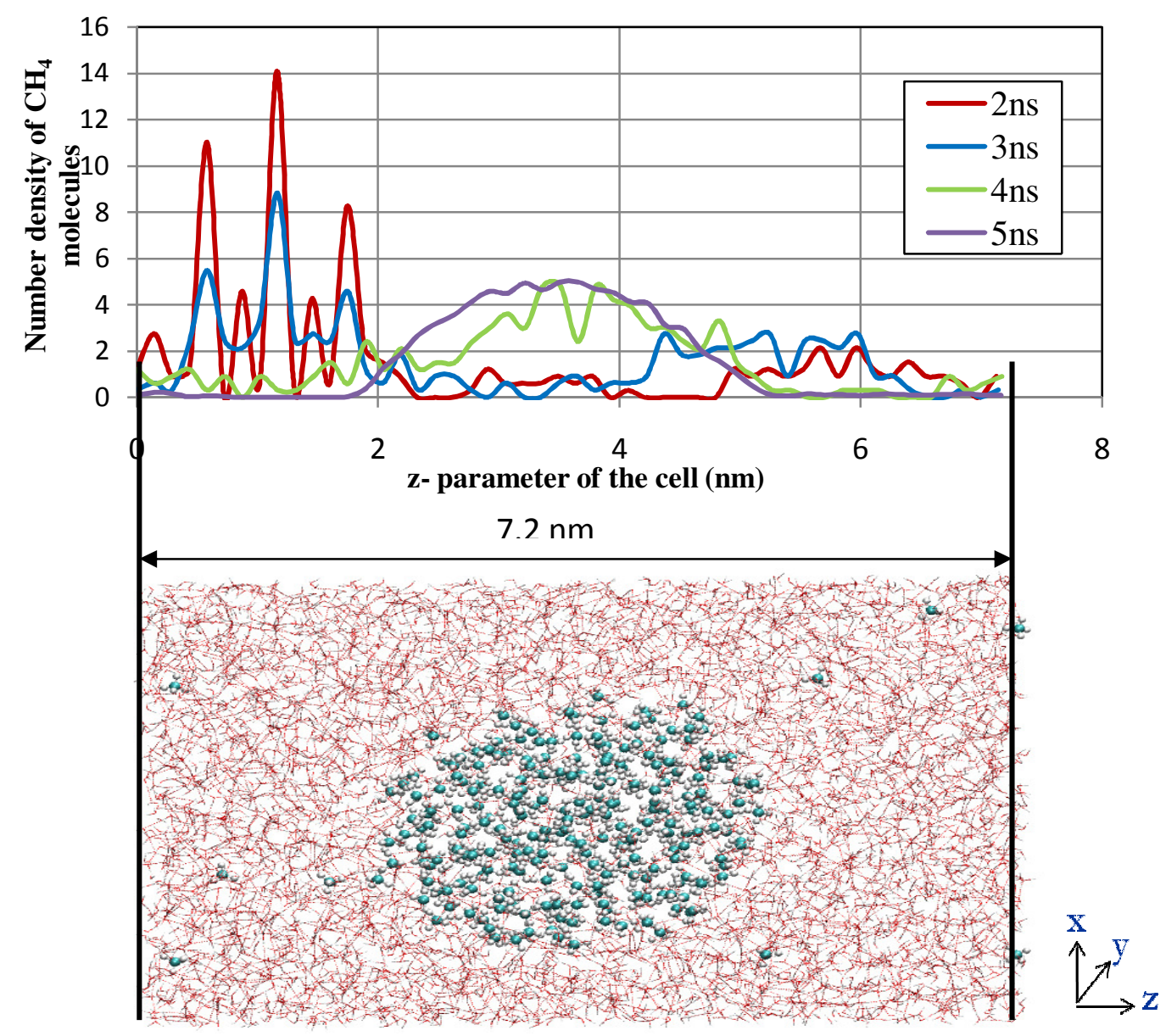

Figure 3.6 Density plot of $\mathrm{CH}_{4}$ molecules and a snapshot of S-I $\mathrm{CH}_{4}$ hydrate-water system which shows the dissociation of the hydrate at $270 \mathrm{~K}$ at $5 \mathrm{~ns}$.

\subsection{Simulation Configurations for Hydrate Dissolution}

Simulations on methane and $\mathrm{CO}_{2}$ hydrates to study their dissolution phenomenon were performed at a chosen temperature and pressure conditions $275 \mathrm{~K}$ and 50 bar which are within the hydrate stability zone for both the hydrates. Different combinations of temperature and pressure conditions were tried before choosing these conditions. The temperature was chosen so that it is within the hydrate stability zone but not too far from the hydrate dissociation point at the 
chosen pressure, so that considerable amount of dissolution is observed with both methane and $\mathrm{CO}_{2}$ hydrates. Hydrate dissolution was not found to be sensitive to change in pressure between $20-50$ bar at $275 \mathrm{~K}$. A pressure of 50 bar was chosen because it is a theoretically more stable pressure at $275 \mathrm{~K}$.

A 64 -unit cell $(4 \times 4 \times 4)$ simulation box of structure I hydrate was constructed for both methane and $\mathrm{CO}_{2}$ and a cell of 6917 water molecules has been appended to it to make it a simulation cell of dimensions $4.7 \times 4.7 \times 14 \mathrm{~nm}$ as shown in the Figure 3.7. The hydrate phase has 512 gas molecules $\left(\mathrm{CO}_{2}\right.$ or methane in the corresponding hydrates) and 2944 water molecules. NPT Simulations on each of these simulation cells have been carried out for longer timescales of $36 \mathrm{~ns}$ to determine the rate at which the gas molecules are coming out in to the liquid water phase as a result of the dissolution process.

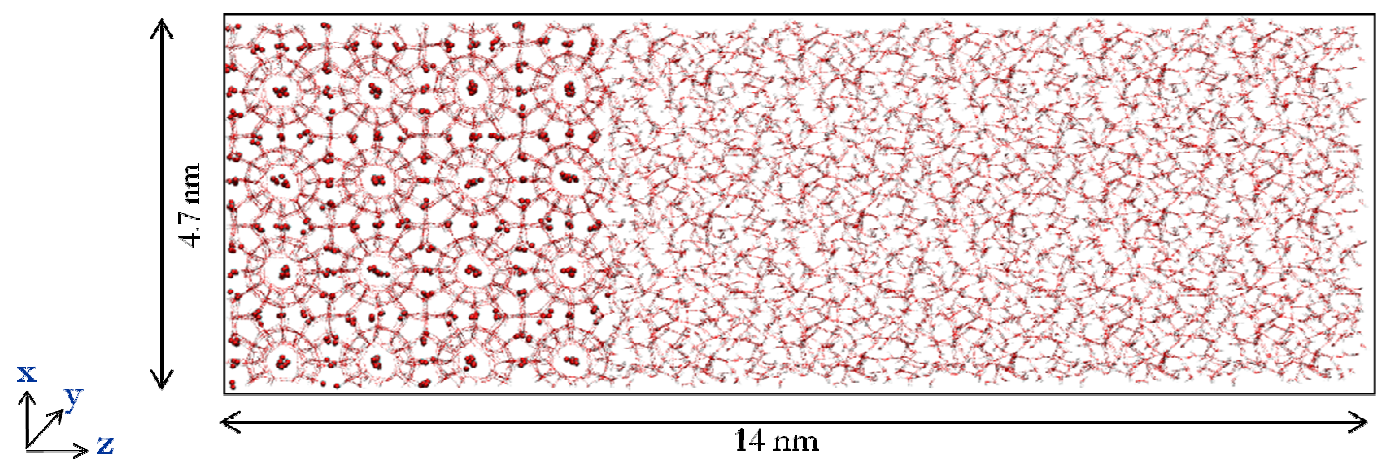

Figure 3.7 2-dimentional view of a simulation cell with 64 unit cell $(4 \times 4 \times 4)$ box of S-I $\mathrm{CO}_{2}$ hydrate appended to water phase in z-direction.

The next objective is the determination of the effects of various small driving forces like the changes in the concentration of the guest gas components $\left(\mathrm{CO}_{2}\right.$ or methane) in the hydrate and 
the liquid phases on the dissolution process of the hydrate individually. For this reason, different models of the simulation cells have been constructed varying the number of molecules and the concentration of the guest gas in both the phases.

\subsubsection{Effect of Cage occupancy}

The concentration of the guest gases in the hydrate phase has been changed by varying the cage occupancy of the gas molecules in the hydrate. Cage occupancy here refers to the percentage of hydrate cages that are occupied by the guest gas molecules. In this work, cage occupancy of only small cages has been varied keeping the large cages fully occupied. With the help of radial distribution functions and VMD the guest gas molecules present in the small cages were identified. As each unit cell of structure I hydrate has 2 small cages, a 64 unit cell hydrate phase would have 128 small cages. So, a hydrate phase that has $100 \%$ cage occupancy of all its small cages should have all the 128 small cages occupied by 128 gas molecules. Three models each for methane and $\mathrm{CO}_{2}$ hydrate have been constructed at $100 \%, 75 \%$ and $50 \%$ cage occupancies of the small cages in the hydrate while the large cages were completely occupied in all the cases.

\subsubsection{Effect of water undersaturation}

The concentration of the gas in the water phase has been varied according to the different levels of undersaturation. As solubility of these gases in water determines the saturation point of the gases in water, simulations have also been carried out to estimate the solubility of methane and $\mathrm{CO}_{2}$ in water at $275 \mathrm{~K}$ and 50 bar. A simulation box of 512 gas molecules $\left(\mathrm{CO}_{2}\right.$ or methane) and 6917 (6799 for methane) water molecules was created with gas phase on one side and water phase on the other side. When this simulation box was simulated, gas molecules were observed to come out in to the liquid phase and the simulation was continued till a near equilibrium was 
reached where no further gas molecules were seen to come out of the gas phase. Based on the number of gas molecules in the water phase, the solubilities of methane and $\mathrm{CO}_{2}$ in water were estimated. These values were used to create three models each of methane and $\mathrm{CO}_{2}$ hydrates at different levels of undersaturation $100 \%, 75 \%$ and $50 \%$.

Table 3.4 Number of molecules in each phase in each of the simulations on $\mathrm{CO}_{2}$ hydrate.

\begin{tabular}{|c|c|c|c|c|c|c|}
\hline \multicolumn{7}{|c|}{ Simulations on $\mathrm{CO}_{2}$ hydrate } \\
\hline & & \multicolumn{2}{|c|}{$\begin{array}{c}\text { Number of } \mathrm{CO}_{2} \\
\text { molecules }\end{array}$} & \multicolumn{2}{|c|}{$\begin{array}{c}\text { Number of water } \\
\text { molecules }\end{array}$} & \multirow[t]{2}{*}{$\begin{array}{l}\text { Total number } \\
\text { of molecules }\end{array}$} \\
\hline & & $\begin{array}{l}\text { Hydrate } \\
\text { phase }\end{array}$ & $\begin{array}{l}\text { Liquid } \\
\text { phase }\end{array}$ & $\begin{array}{l}\text { Hydrate } \\
\text { phase }\end{array}$ & $\begin{array}{l}\text { Liquid } \\
\text { phase }\end{array}$ & \\
\hline $\begin{array}{l}\text { Varying the size of } \\
\text { hydrate phase }\end{array}$ & $\begin{array}{l}\text { Number of unit } \\
\text { cells of hydrate }\end{array}$ & & & & & \\
\hline Model1 & 64 & 512 & & 2944 & 6917 & 10373 \\
\hline Model2 & 32 & 256 & & 1468 & 6917 & 8641 \\
\hline $\begin{array}{l}\text { Varying cage } \\
\text { occupancy }\end{array}$ & $\begin{array}{l}\text { Cage occupancy } \\
\text { (small cages) }\end{array}$ & & & & & \\
\hline Model1 & $100 \%$ & 512 & 30 & 2944 & 6917 & 10403 \\
\hline Model2 & $75 \%$ & 480 & 30 & 2944 & 6917 & 10371 \\
\hline Model3 & $50 \%$ & 448 & 30 & 2944 & 6917 & 10339 \\
\hline Model4 & $25 \%$ & 416 & 30 & 2944 & 6917 & 10307 \\
\hline Model5 & $0 \%$ & 384 & 30 & 2944 & 6917 & 10275 \\
\hline $\begin{array}{c}\text { Varying the } \\
\text { concentration of } \mathrm{CO}_{2} \\
\text { in liquid phase }\end{array}$ & $\begin{array}{l}\text { Percentage levels } \\
\text { of } \\
\text { undersaturation }\end{array}$ & & & & & \\
\hline \multicolumn{7}{|l|}{$\begin{array}{l}\text { At } 100 \% \text { cage } \\
\text { occupancy }\end{array}$} \\
\hline Model1 & 100 & 512 & 52 & 2944 & 6917 & 10425 \\
\hline Model2 & 75 & 512 & 39 & 2944 & 6917 & 10412 \\
\hline Model3 & 50 & 512 & 26 & 2944 & 6917 & 10399 \\
\hline Model4 & 0 & 512 & 0 & 2944 & 6917 & 10373 \\
\hline \multicolumn{7}{|l|}{$\begin{array}{l}\text { At } 0 \% \text { cage } \\
\text { occupancy }\end{array}$} \\
\hline Model1 & 100 & 384 & 52 & 2944 & 6917 & 10297 \\
\hline Model2 & 75 & 384 & 39 & 2944 & 6917 & 10284 \\
\hline Model3 & 50 & 384 & 26 & 2944 & 6917 & 10271 \\
\hline Model4 & 0 & 384 & 0 & 2944 & 6917 & 10245 \\
\hline
\end{tabular}


All the models have been simulated for similar timescales of 36 ns. A model with 32 unit cells $(4 \times 4 \times 2)$ of hydrate phase was constructed each for methane and $\mathrm{CO}_{2}$ hydrates with the same size of liquid water phase appended to it. These models were constructed and simulated to show the importance of choosing the size of the simulation cell. The details of all the different models constructed have been tabulated in a Table 3.4 and Table 3.5.

Table 3.5 Number of molecules in each phase in each of the simulations on methane hydrate

\begin{tabular}{|c|c|c|c|c|c|c|}
\hline \multicolumn{7}{|c|}{ Simulations on methane hydrate } \\
\hline & & \multicolumn{2}{|c|}{$\begin{array}{c}\text { Number of methane } \\
\text { molecules }\end{array}$} & \multicolumn{2}{|c|}{$\begin{array}{c}\text { Number of water } \\
\text { molecules }\end{array}$} & \multirow[t]{2}{*}{$\begin{array}{l}\text { Total number } \\
\text { of molecules }\end{array}$} \\
\hline & & $\begin{array}{c}\text { Hydrate } \\
\text { phase }\end{array}$ & $\begin{array}{c}\text { Liquid } \\
\text { phase }\end{array}$ & $\begin{array}{c}\text { Hydrate } \\
\text { phase }\end{array}$ & $\begin{array}{c}\text { Liquid } \\
\text { phase }\end{array}$ & \\
\hline $\begin{array}{c}\text { Varying the size of } \\
\text { hydrate phase }\end{array}$ & $\begin{array}{l}\text { Number of unit } \\
\text { cells of hydrate }\end{array}$ & & & & & \\
\hline Model1 & 64 & 512 & & 2944 & 6799 & 10255 \\
\hline Model2 & 32 & 256 & & 1468 & 6799 & 8523 \\
\hline $\begin{array}{l}\text { Varying cage } \\
\text { occupancy }\end{array}$ & $\begin{array}{l}\text { Cage occupancy } \\
\text { (small cages) }\end{array}$ & & & & & \\
\hline Model1 & $100 \%$ & 512 & 0 & 2944 & 6799 & 10255 \\
\hline Model2 & $75 \%$ & 480 & 0 & 2944 & 6799 & 10223 \\
\hline Model3 & $50 \%$ & 449 & 0 & 2944 & 6799 & 10192 \\
\hline Model4 & $25 \%$ & 416 & 0 & 2944 & 6917 & 10277 \\
\hline Model5 & $0 \%$ & 384 & 0 & 2944 & 6917 & 10245 \\
\hline $\begin{array}{c}\text { Varying the } \\
\text { concentration of } \mathrm{CH}_{4} \\
\text { in liquid phase }\end{array}$ & $\begin{array}{c}\text { Percentage } \\
\text { levels of } \\
\text { undersaturation } \\
\end{array}$ & & & & & \\
\hline \multicolumn{7}{|l|}{$\begin{array}{c}\text { At } 100 \% \text { cage } \\
\text { occupancy }\end{array}$} \\
\hline Model1 & 100 & 512 & 9 & 2944 & 6799 & 10264 \\
\hline Model2 & 75 & 512 & 7 & 2944 & 6799 & 10262 \\
\hline Model3 & 50 & 512 & 5 & 2944 & 6799 & 10260 \\
\hline Model4 & 0 & 512 & 0 & 2944 & 6799 & 10255 \\
\hline \multicolumn{7}{|l|}{$\begin{array}{l}\text { At } 0 \% \text { cage } \\
\text { occupancy }\end{array}$} \\
\hline Model1 & 100 & 384 & 9 & 2944 & 6799 & 10136 \\
\hline Model2 & 75 & 384 & 7 & 2944 & 6799 & 10134 \\
\hline Model3 & 50 & 384 & 5 & 2944 & 6799 & 10132 \\
\hline Model4 & 0 & 384 & 0 & 2944 & 6799 & 10127 \\
\hline
\end{tabular}




\subsection{Intermolecular potential used for Carbon dioxide}

Simulations on $\mathrm{CO}_{2}$ hydrate studying its dissolution in water were tested using 2 types of potentials Harris and Yung ${ }^{5}$ potential and Velaga et al. ${ }^{11}$ model. A large difference was observed between these potentials with respect to the amount of dissolution that occurred. Many $\mathrm{CO}_{2}$ molecules in the hydrate phase were found to dissolve in to the liquid phase in the case of Harris and Yung ${ }^{5}$ potential compared to a much smaller number in the case of Velaga et al. ${ }^{11}$ model. Solubility of $\mathrm{CO}_{2}$ in water calculated based on the simulations on gaseous $\mathrm{CO}_{2}$ in water were also compared for these two potentials. In this case, the number of $\mathrm{CO}_{2}$ molecules moving in to the water phase from the gaseous phase was again larger in the case of Harris and Yung potential than that in Velaga et al. model. But, the difference was much lesser than that observed in the

presence of hydrate. The solubility of $\mathrm{CO}_{2}$ calculated with Harris and Yung potential in mols of $\mathrm{CO}_{2} /$ mols of water was found to be 0.007518 while that with Velaga et al. model was found to be 0.005782 . The intermolecular potential given by Velaga et al. seemed to be very strong for the $\mathrm{CO}_{2}$ molecules in a hydrate. Moreover, Harris and Yung model is a widely used potential for $\mathrm{CO}_{2}$. Therefore, the Harris and Yung model was used for $\mathrm{CO}_{2}$ in all the simulations in this work. 


\subsection{References}

1. Jorgensen, W. L.; Madura, J. D. "Temperature and Size Dependence for Monte Carlo Simulations of TIP4P Water." Mol. Phys. 1985, 56, 1381.

2. Jorgensen, W. L.; Madura, J. D.; Swenson, C. J. "Optimized Intermolecular Potential Functions for Liquid Hydrocarbons" J. Am. Chem. Soc.1984, 106, 6638.

3. van Gunsteren, W. F.; Billeter, S. R.; Eising, A. A.; Hünenberger, P. H.; Krüger, P.; Mark, A. E.; Scott, W. R. P.; Tironi, I. G. "Biomolecular Simulation: GROMOS96 Manual and User Guide."BIOMOS b.v.: Zürich, Groningen, 1996.

4. Anderson, B. J.; Tester, J. W.; Trout, B. L. "Accurate Potentials for Argon-water and Methane-Water Interactions via Ab Initio Methods and Their Application to Clathrate Hydrates." J. Phys. Chem. B 2004, 108, 18705.

5. Harris, J. G.; Yung, K. H. "Carbon Dioxide's Liquid-Vapor Coexistence Curve And Critical Properties as Predicted by a Simple Molecular Model" J. Phys. Chem. 1995, 99, 12021.

6. Allen, M. P.; Tildesley, D. J. Computer Simulation of Liquids; Clarendon Press: Oxford, UK, 1987

7. Ewald, P. P. "Evaluation of Optical and Electrostatic Lattice Potentials."Ann. Phys. 1921, 64, 253.

8. Van der Spoel, D.; Lindahl, E.; Hess, B.; van Buuren, A.; Apol, E.; Tieleman, P.; Meulenhoff, P.; Sijbers, A.; Feenstra, A.; Drunen, R.;Berendsen, H. "Gromacs User Manual, version 3.3" www.gromacs.org, 2005.

9. Sloan, E. D.; Koh, C. A. Clathrate hydrates of natural gases, $3^{\text {rd }} \mathrm{Ed}, 2007$.

10. Ba'ez, L. A.; Clancy, P. "Computer Simulation of the Crystal Growth and Dissolution of Natural Gas Hydrates." Ann. N.Y. Acad. Sci. 1994, 715, 177.

11. Velaga, S. Phase Equilibrium and Cage Occupancy Calculations of Carbon Dioxide Hydrates using $\mathrm{Ab}$ Initio Intermolecular Potentials, M. S. Thesis, West Virginia University, 2009.

12. G.A. Jeffrey, J.L. Atwood, E.D. Davies and D.D. MacNichol (eds.), "Inclusion Compounds", Acad. Publ., 1984, 1, 135. 


\section{Dissolution of methane and $\mathrm{CO}_{2}$ hydrates in water and the effect of small driving forces using MD simulations}

\subsection{Introduction}

In the previous chapter, methane hydrate dissociation in water and the effect of temperature on dissociation has been studied using molecular dynamic simulations. Lattice constants of methane hydrate crystal were also calculated and compared for the different potentials used for methane. A further comparison of the three potentials of methane was done based on the hydrate dissociation behavior in water. This helped to validate the different potentials considered for methane and also get an introduction to hydrate dissociation in water. In this chapter, hydrate dissolution, which is a much slower process compared to hydrate dissociation has been studied. Therefore, simulations here were run for much longer timescales.

\subsection{Results}

Molecular dynamic simulations were performed to study and compare the dissolution of methane and $\mathrm{CO}_{2}$ hydrates in water. These simulations were chosen to be performed at temperature and pressure conditions of $275 \mathrm{~K}$ and $50 \mathrm{bar}$, which are within the hydrate stability zone for both methane and $\mathrm{CO}_{2}$ hydrates. All of the simulations that were run for $\mathrm{CO}_{2}$ and methane hydrates in water showed that $\mathrm{CO}_{2}$ hydrates dissolve much faster compared to methane hydrates.

\subsubsection{Choice of the size of the simulation box}

In simulations done varying the size of the hydrate phase, it was observed that a 32 unit cell hydrate phase dissolved faster compared to a 64 unit cell hydrate phase in same amount of water 
phase. The 32 unit cell $\mathrm{CO}_{2}$ hydrate was found to dissociate completely within 5 ns whereas the 64 unit cell hydrate was found to be stable even after 20 ns. Even in the case of methane hydrate, there was a significant difference in the dissolution behavior of hydrates of the 2 different sizes.

The 64-unit cell methane hydrate was found to be very stable compared to a 32-unit cell hydrate. It was found that the 32-unit cell hydrate is highly unstable. This can be again related to one of the previous works discussed before, where dissociation of hydrate is thought to have caused by the fact that the hydrate crystallite is subcritical in size. Critical size of nucleation estimated by classical theory of nucleation is $32 \AA^{1}$ while that given by Radhakrishnan and Trout $^{8}$ is $14.5 \AA$. The 32 unit cell hydrate that has been considered here has a size of $24 \AA$ in the $\mathrm{z}$-direction, which is less than the critical size of nucleation according to one of the estimates. So, the hydrate crystal could be subcritical in size, although it is not sure. But, it can be said that the choice of the size of hydrate crystal required to study a dissolution process is important and hydrate crystal should have a size more than the critical size of nucleation.

\subsubsection{Dissolution of methane and $\mathrm{CO}_{2}$ hydrates}

MD Simulations were run for methane and $\mathrm{CO}_{2}$ hydrates at $275 \mathrm{~K}$ and 50 bar for $36 \mathrm{~ns}$ with all the cavities completely occupied and the liquid phase having no gas molecules. It was observed that $\mathrm{CO}_{2}$ hydrate dissolved very rapidly compared to methane hydrate. A high amount of dissolution was found to occur within the first $10 \mathrm{~ns}$ in the case of $\mathrm{CO}_{2}$ hydrate and a slow decrease in the overall rate of dissolution was observed thereafter. The amount of dissolution was found to increase very slowly in the case of methane hydrate compared to that in $\mathrm{CO}_{2}$ hydrates from the beginning of the simulation, which can be seen from the plot in Figure 4.1. This particular simulation was continued and monitored till 75 ns. Neither methane nor $\mathrm{CO}_{2}$ 
hydrate was found to near a complete dissolution till $75 \mathrm{~ns}$, though there was a slow increase in the amount of gas dissolution in to water.

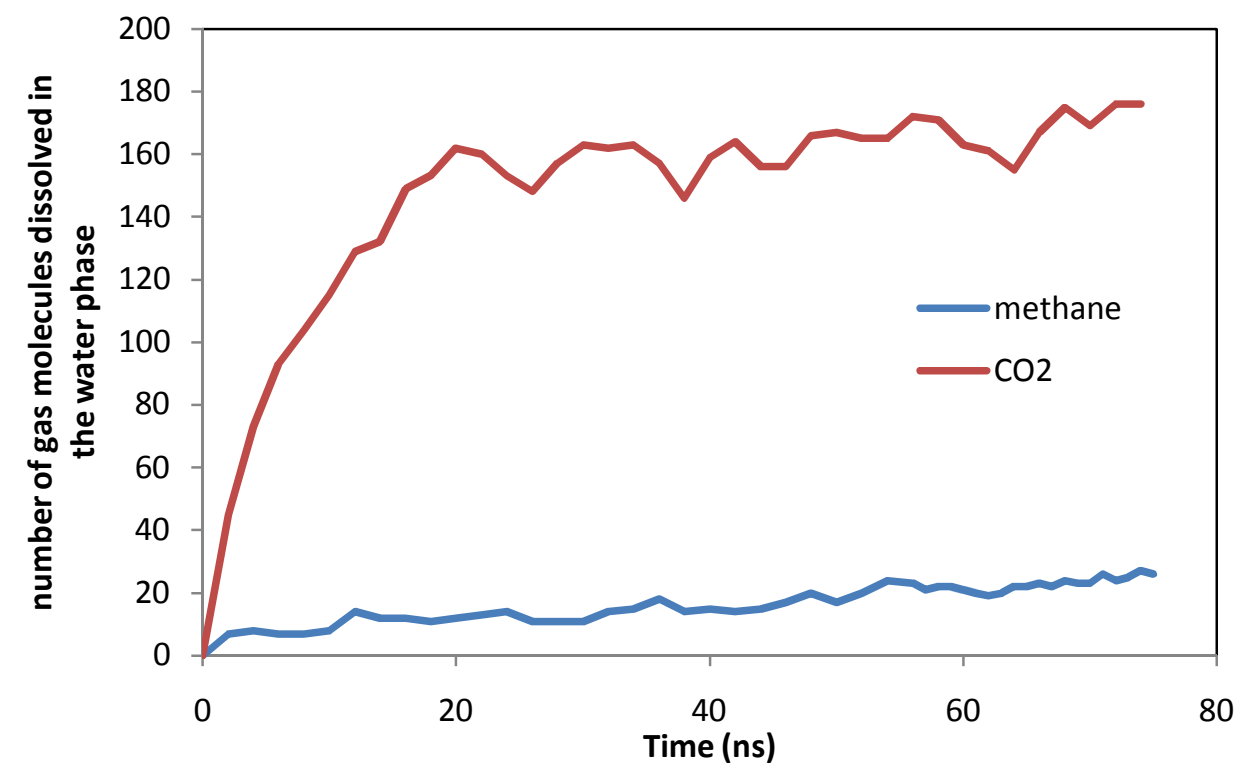

Figure 4.1 The amount of dissolution of methane and $\mathrm{CO}_{2}$ from hydrate in to water as a function of time with water phase completely unsaturated at the start of the simulation

Dissolution occurred at the hydrate-water interface on either sides of the hydrate phase. Figure 4.2 shows a density plot of the $\mathrm{CO}_{2}$ molecules across the simulation box and a corresponding snapshot of the box in VMD after the entire simulation. As mentioned in the earlier chapter, density plot of the $\mathrm{CO}_{2}$ molecules is obtained based on the number of molecules in each of the fixed number of slabs the simulation box is divided along the $z$-direction. The number density of the gas molecules in these slabs is plotted as a function $z$-parameter of the simulation box. The box was divided in to 100 slabs for all the density plots made in this work. The peaks on the left hand side of the plot correspond to $\mathrm{CO}_{2}$ molecules within the hydrate phase while the rest corresponds to its density in the water phase. A decrease in the height of the peaks at the hydrate- 
water interface on either sides of the hydrate phase is an indication of hydrate dissolution process which causes the interface to move in to the hydrate phase.

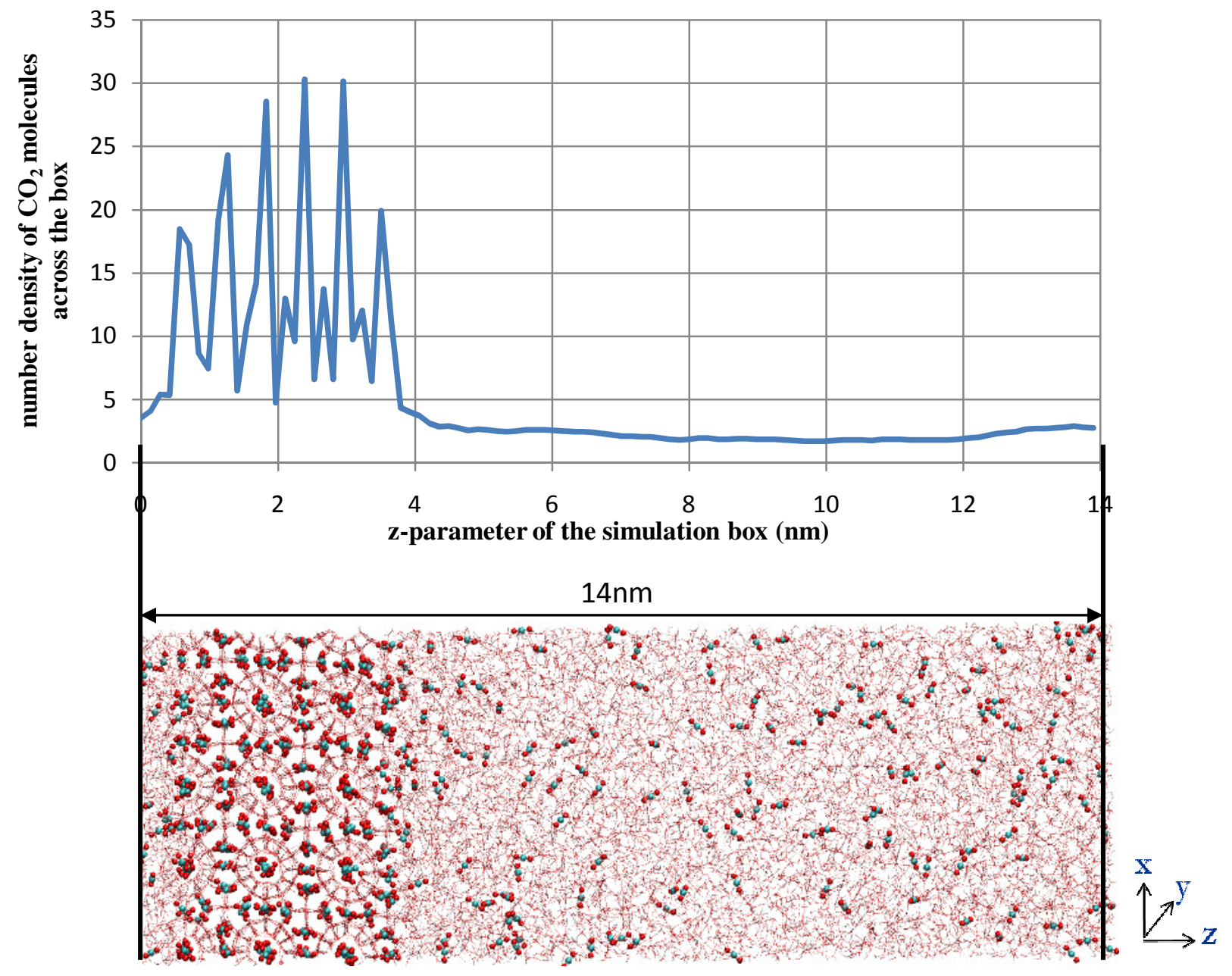

Figure 4. 2 Density plot of $\mathrm{CO}_{2}$ molecules in the box (divided in to 100 slabs) after $36 \mathrm{~ns}$ across the simulation box and a corresponding snapshot of $\mathrm{CO}_{2}$ hydrate simulation box showing the dissolution of the hydrate after $36 \mathrm{~ns}$.

This can further clearly be understood from another density plot within the hydrate phase shown in Figure 4.3 which shows a comparison of the density of the gas molecules before and after the entire simulation. This has been plotted for both methane and $\mathrm{CO}_{2}$ hydrates. It can be seen that the peaks at the hydrate-water interface on either side of the hydrate disappear in the case of $\mathrm{CO}_{2}$ 
hydrate while they are still intact in the case of methane hydrate after the entire simulation run for $36 \mathrm{~ns}$. This clearly shows the difference in the extent of their dissolution for a time of $36 \mathrm{~ns}$.

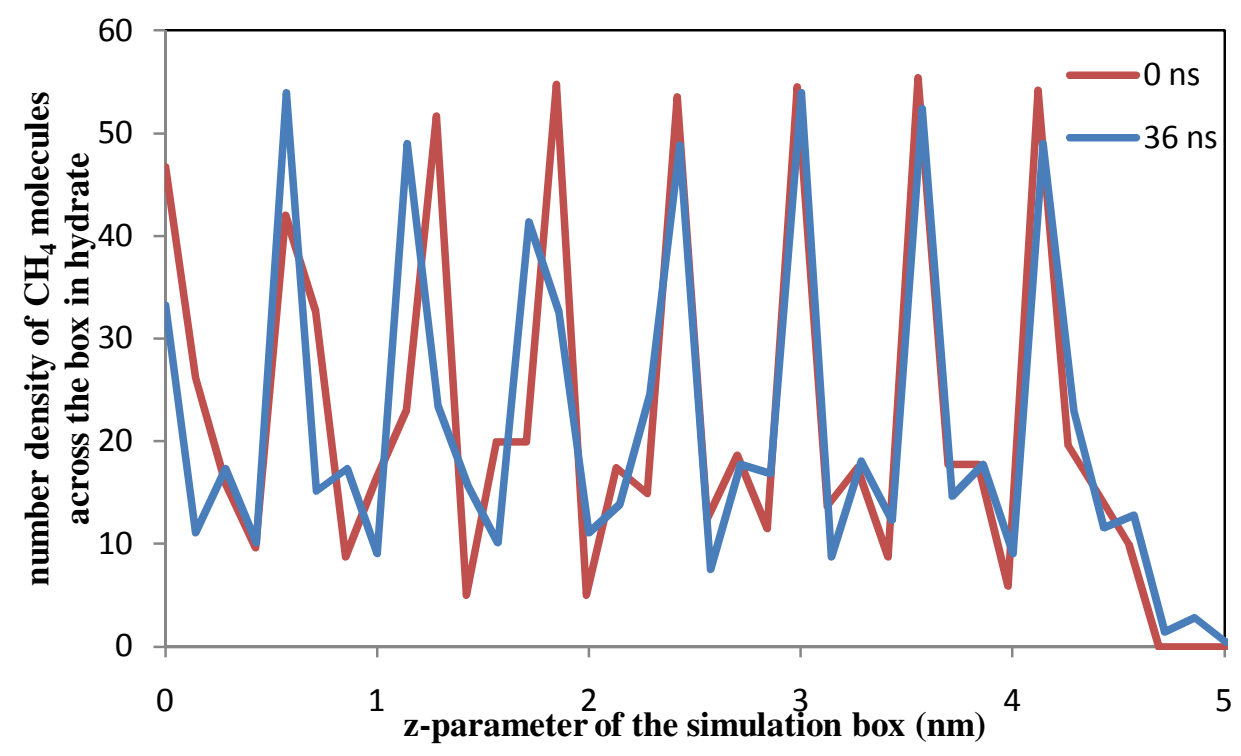

(a)

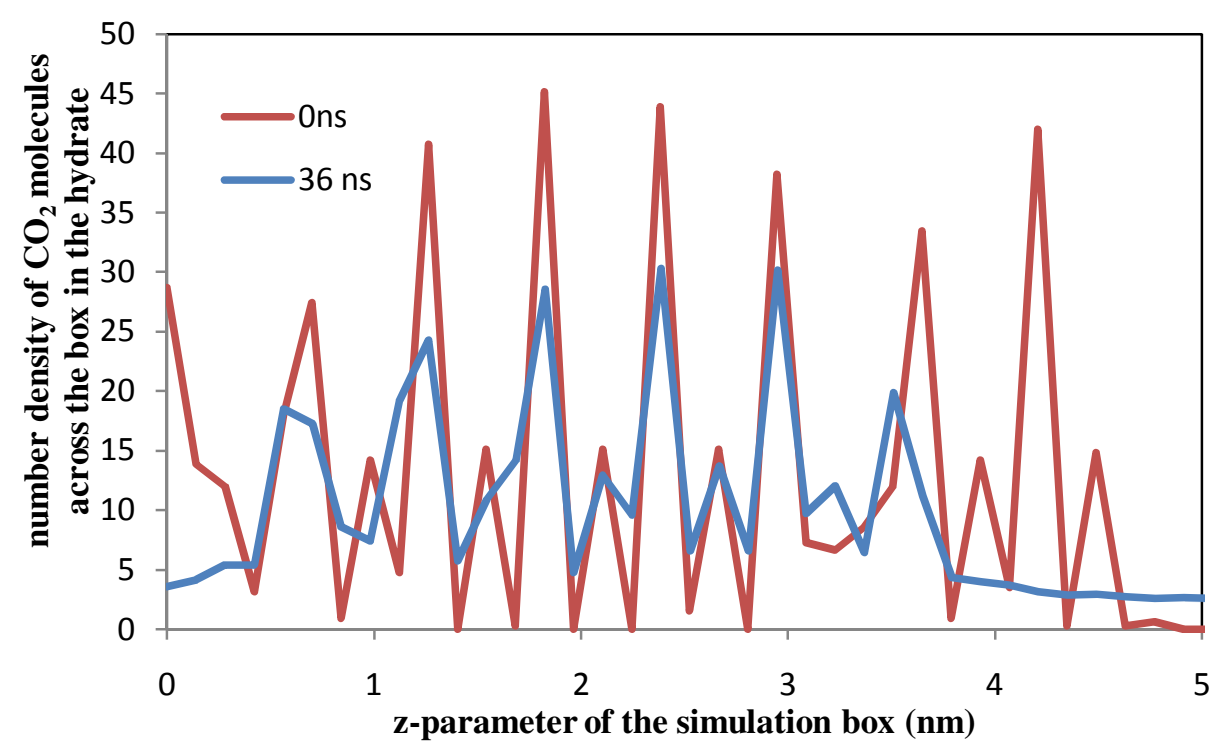

(b)

Figure 4.3 Density plot of gas molecules across the simulation box truncated at the interface on either sides to view the change in number density within the hydrate phase of the box before and after simulation till $36 \mathrm{~ns}$ for (a) methane (b) $\mathrm{CO}_{2}$ 


\subsubsection{Effect of cage occupancy}

The dissolution of the hydrate in water has been studied as a function of percentage of occupancy of the small cages of the hydrate at $100 \%, 75 \%, 50 \%, 25 \%$ and $0 \%$ for both methane and $\mathrm{CO}_{2}$ hydrates at $275 \mathrm{~K}$ and 50 bar. All the simulations for methane hydrate in this section were started at $0 \%$ gas saturation in the liquid phase, which implies that there were no methane molecules in the water phase initially. The dissolution of $\mathrm{CO}_{2}$ hydrate was found to be very fast at $0 \%$ gas saturation. To have a better comparison of simulations at different cage occupancies, simulations for $\mathrm{CO}_{2}$ hydrate were started with 30 molecules of $\mathrm{CO}_{2}$ within the water phase so that it reduces the concentration difference of $\mathrm{CO}_{2}$ between hydrate and water phases.

The number of gas molecules that moved from the hydrate in to the liquid phase as a result of dissolution has been plotted against time for the entire simulation run for $35 \mathrm{~ns}$ for both methane and $\mathrm{CO}_{2}$ hydrates at different cage occupancies as shown in the Figure 4.4 and Figure 4.5.

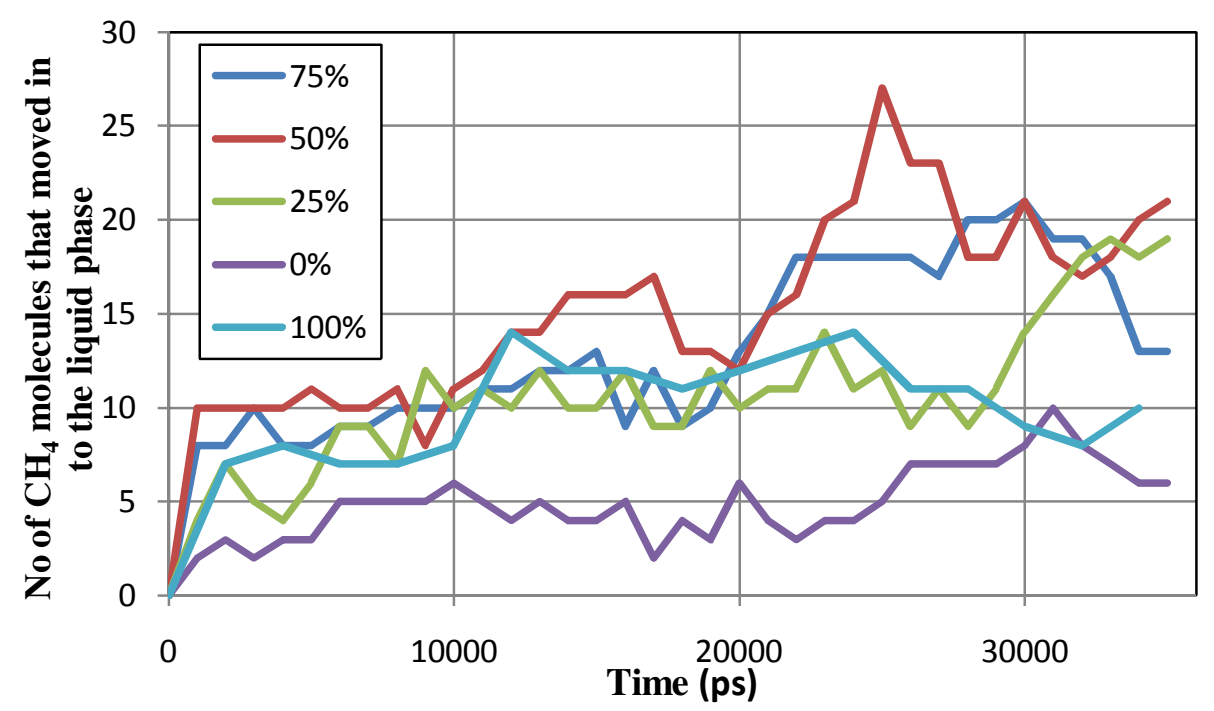

Figure 4.4 Number of methane molecules that moved in to the liquid phase from the hydrate phase as a function of time at different cage occupancies at $0 \%$ gas saturation in the water phase 
It can be seen from the plots that the rate of dissolution is neither constant nor a steady change throughout the simulation. A mean of these numbers over the last 2000 frames of each of these simulations was calculated and used to measure the average number of gas molecules moving out in to the water phase in a time of $35 \mathrm{~ns}$. These results were tabulated as shown in Table 4.1

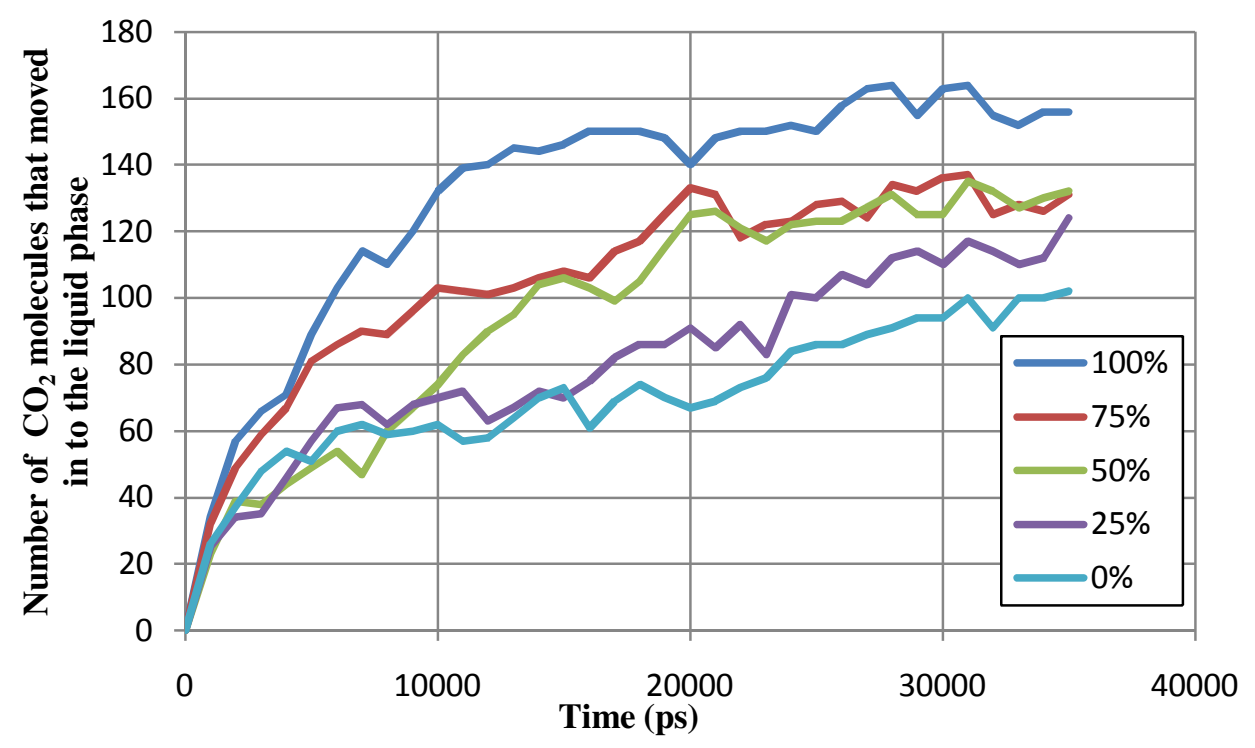

Figure 4.5 Number of $\mathrm{CO}_{2}$ molecules that moved in to the water phase from the hydrate phase as a function of time during the simulation at different cage occupancies at $57.6 \%$ gas saturation in water phase

It is evident from the Table 4.1 that the amount of dissolution in the case of methane hydrate is lower compared to that of $\mathrm{CO}_{2}$ hydrates, by a factor of 10 or greater. It was observed that the amount of dissolution of methane hydrate is lower at $100 \%$ cage occupancy and increased with decrease in occupancy till $25 \%$. But methane hydrate was found to be very stable at $0 \%$ occupancy. A relatively higher stability or lesser dissolution of hydrate at $100 \%$ or $0 \%$ cage occupancy over hydrate at other occupancies can be explained by their lack of defects in the periodic crystal structure. At these occupancies, the hydrate has a more symmetrical crystal 
structure compared to other occupancies that introduce crystal defects. This effect is observed more in the case of methane hydrate than $\mathrm{CO}_{2}$ hydrate as the amount of methane hydrate dissolution is also very low unlike the dissolution in the case of $\mathrm{CO}_{2}$ hydrates. The regular increase in the amount of methane hydrate dissolution with decrease in cage occupancy shows that methane hydrate is more stable at small cage occupancy close to $100 \%$.

On the other hand, $\mathrm{CO}_{2}$ hydrate was found to dissolve faster at $100 \%$ cage occupancy compared to hydrate at other occupancies. The dissolution rate was found to decrease with decrease in cage occupancy till $0 \%$. So, these results imply a higher stability of $\mathrm{CO}_{2}$ hydrate at lower cage occupancies. The symmetrical structure of the $\mathrm{CO}_{2}$ hydrate at $0 \%$ cage occupancy could be an added advantage for the hydrate to be much stable compared to that at other occupancies. This shows that $\mathrm{CO}_{2}$ hydrate is stable at lower cage occupancies close to $0 \%$. The effect of small cage occupancy on the dissolution rates of methane hydrates in comparison to $\mathrm{CO}_{2}$ hydrates has also been plotted in a histogram as shown in Figure 4.6.

Table 4. 1 Effect of cage occupancy on the average amount of dissolution of methane and $\mathrm{CO}_{2}$ hydrates in 35 ns of simulation

\begin{tabular}{|c|c|c|c|}
\hline $\begin{array}{c}\text { Percentage cage } \\
\text { occupancy }\end{array}$ & $\begin{array}{c}\text { Number of gas } \\
\text { molecules in } \\
\text { hydrate }\end{array}$ & \multicolumn{2}{|c|}{$\begin{array}{c}\text { Number of gas molecules that } \\
\text { dissolved in to the liquid phase } \\
\text { averaged over last 200 ps }\end{array}$} \\
\hline & 512 & Methane & $\mathrm{CO}_{2}$ \\
\hline 100 & 480 & 11 & 160 \\
\hline 75 & 448 & 19 & 132 \\
\hline 50 & 416 & 21 & 120 \\
\hline 25 & 384 & 8 & 100 \\
\hline 0 & & & \\
\hline
\end{tabular}


The dissolution rates of both methane and $\mathrm{CO}_{2}$ hydrates were found to be steady only for the first 2 ns of all the simulations and were found to display an oscillating behavior thereafter. This is similar to what Myshakin et al. ${ }^{2}$ observed in their simulations on methane hydrate. This range of oscillations was more irregular in the case of methane hydrate than that observed in the case of $\mathrm{CO}_{2}$ hydrates. Analysis of all the simulations on methane hydrate showed that the number of hydrate-like waters in the simulation box increased to a number higher than that present in the hydrate initially. This was not observed in the case of $\mathrm{CO}_{2}$ hydrate. Moreover, these additional hydrate-like waters were found at the hydrate-water interface. So, the water molecules in the liquid phase should be grouping together to form a tetrahedral structure. This could be an indication towards a growth of hydrate at the hydrate-water interface.

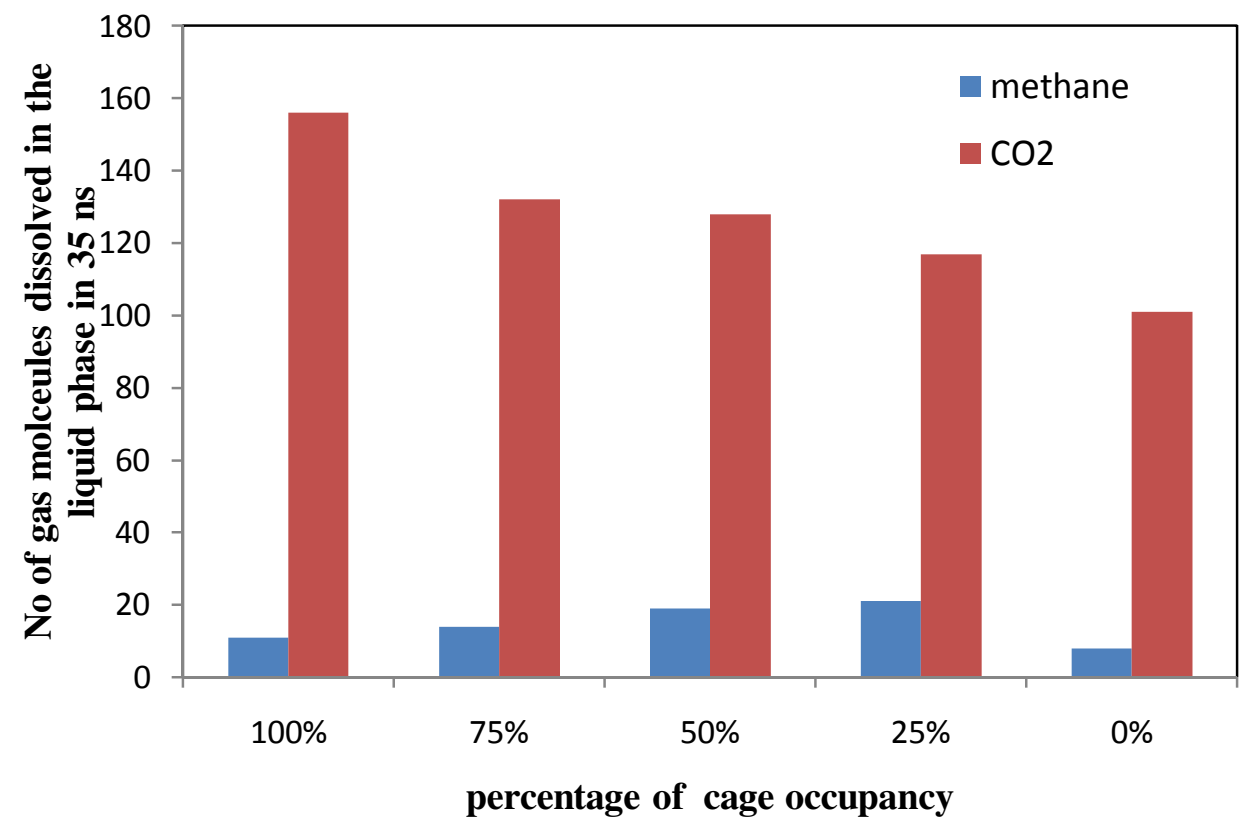

Figure 4.6 Comparing the effect of small cage occupancy on the dissolution of methane and $\mathrm{CO}_{2}$ hydrates in water. 


\subsubsection{Effect of water phase undersaturation}

The effect of undersaturating the water phase with respect to the gas forming hydrate on the dissolution rates of the hydrate in to water has been studied at different levels of undersaturation of the liquid phase $100 \%, 75 \%, 50 \%$ and $0 \%$.

The solubility of methane and $\mathrm{CO}_{2}$ in water has been estimated in this work using an MD simulation. The snapshots of the simulation boxes at the end of simulation are shown in Figure 4.8. This simulation was run at $275 \mathrm{~K}$ and 50 bar for $20 \mathrm{~ns}$. With the help of density plots, it was found that 9 molecules of methane completely dissolved in to a water phase of 6799 molecules while 52 molecules of $\mathrm{CO}_{2}$ dissolved in to 6917 water molecules. A density plot of $\mathrm{CO}_{2}$ molecules across the simulation box is shown in Figure 4.7. The number of gas molecules that moved in to water phase were calculated at every $2 \mathrm{~ns}$ of the entire simulation based on a moving average for a span of $2 \mathrm{~ns}$. The average number of gas molecules in the water phase as a function of time was plotted as shown in Figure 4.11. The plot shows that the number reached an equilibrium value after $20 \mathrm{~ns}$ in the case of methane hydrate. In the case of $\mathrm{CO}_{2}$ hydrate, though the number did not reach equilibrium, showed an asymptotic behavior over the last $5 \mathrm{~ns}$. It is further clear from the energy plots that there is a small drift in the average energy of the system in the case of $\mathrm{CO}_{2}$ hydrate. In the case of methane hydrate, a higher range of fluctuations in the total energy were observed predicted to have caused by a continuous exchange of methane molecules between the two phases. Figure 4.9 and Figure 4.10 show the energy plots corresponding to these simulations on $\mathrm{CO}_{2}$ and methane respectively. 


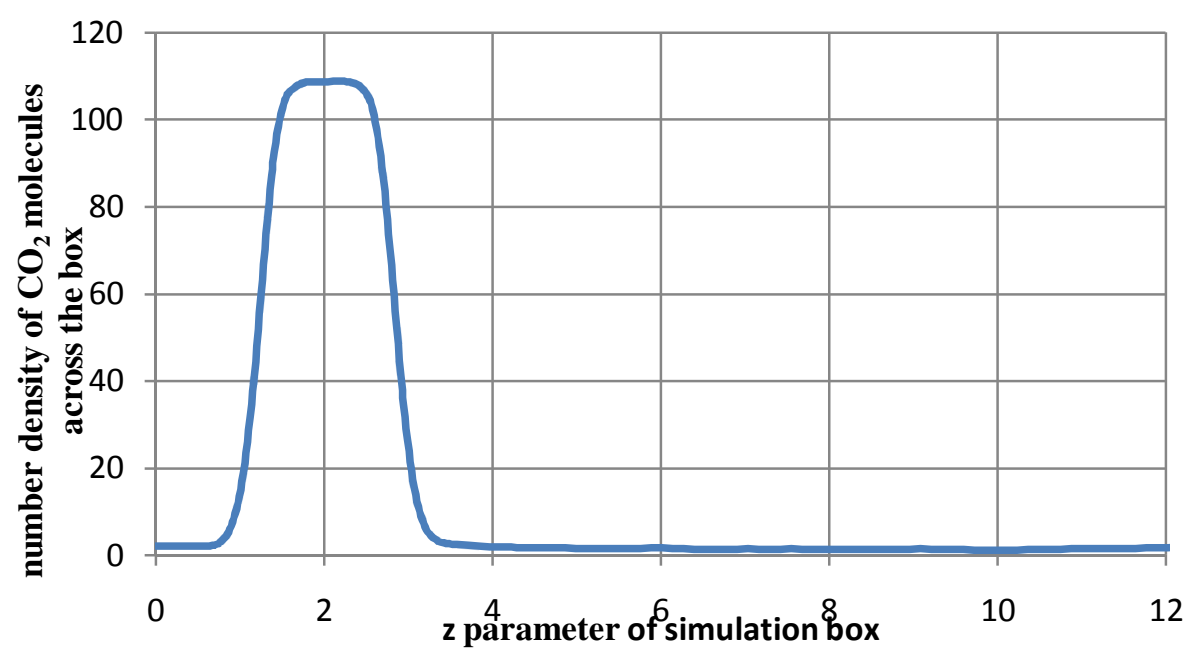

Figure 4.7 Density plot of $\mathrm{CO}_{2}$ molecules across the box in the simulation used to calculate the solubility of $\mathrm{CO}_{2}$ in water

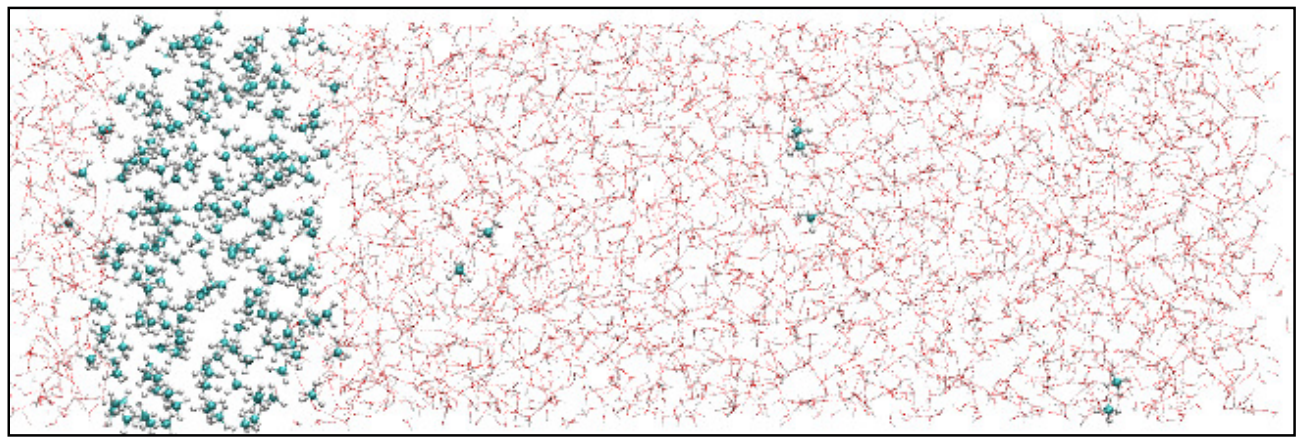

(a)

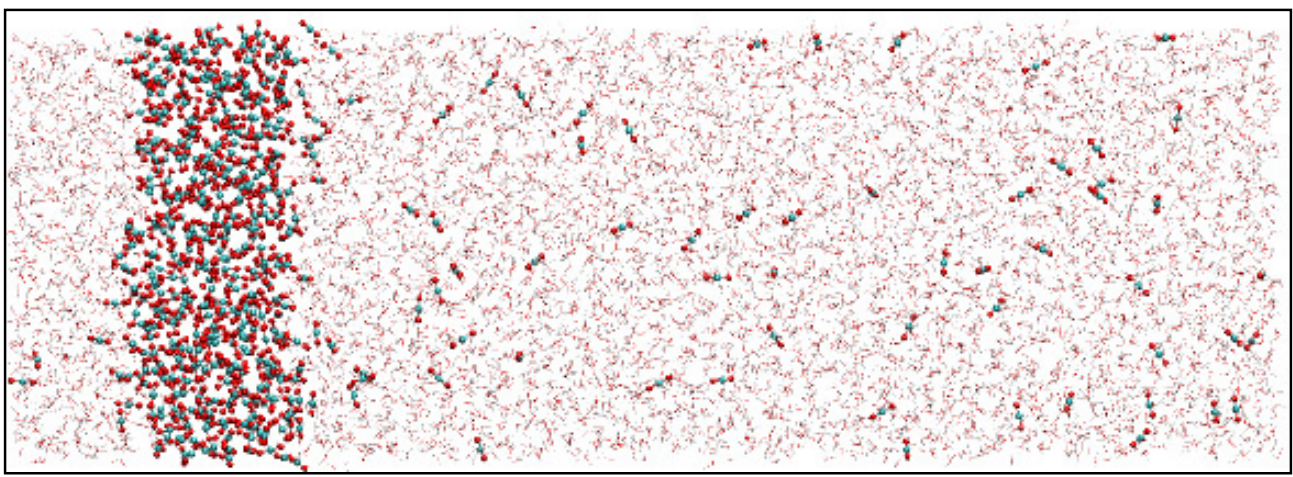

(b)

Figure 4.8 Snapshots of simulation box in the simulation done to calculate solubility in water for (a) methane (b) $\mathrm{CO}_{2}$ after $20 \mathrm{~ns}$ 


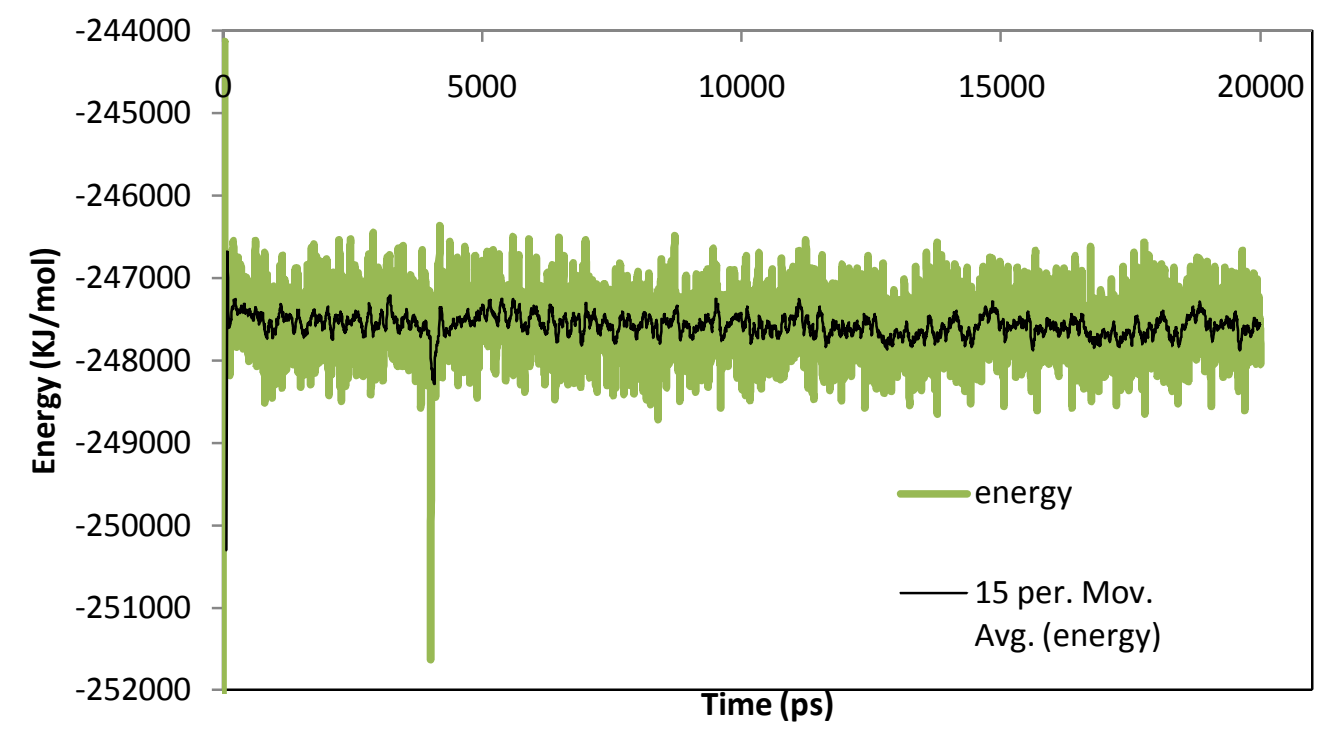

Figure 4.9 Total energy of the system as a function of time along with a moving average in the simulation for calculating solubility of $\mathrm{CO}_{2}$ in water

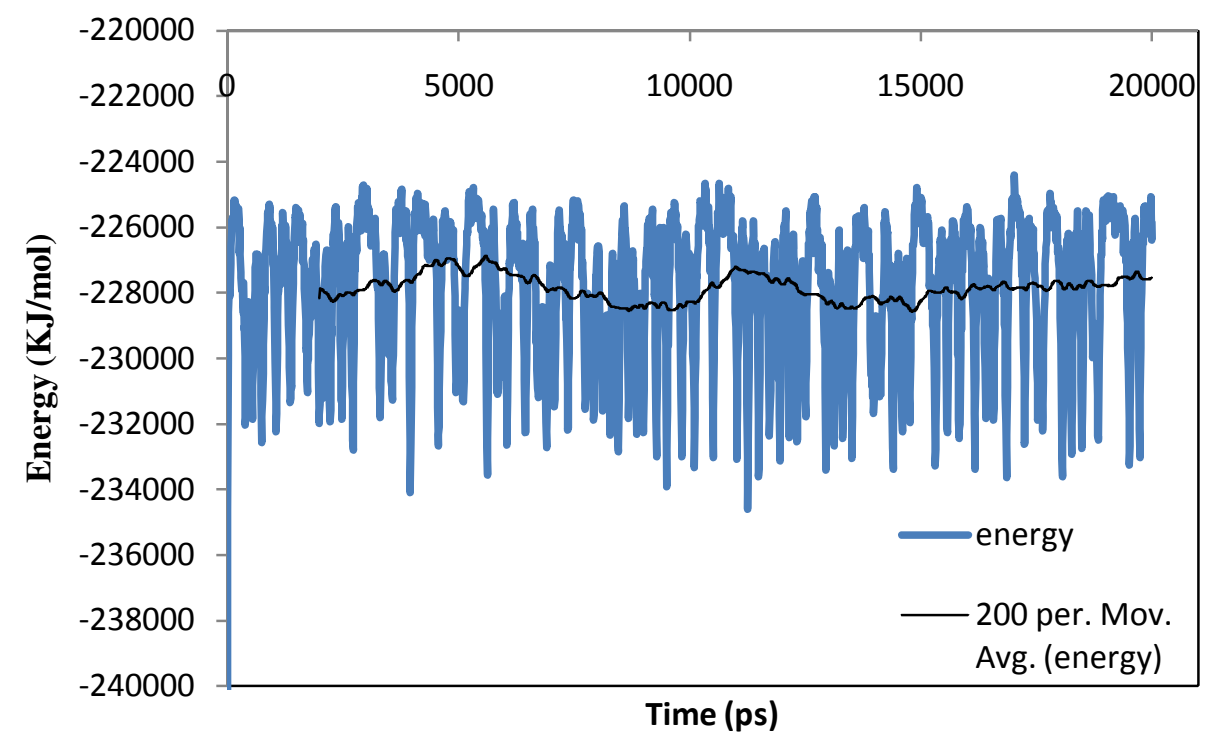

Figure 4. 10 Total energy of the system as a function of time along with a moving average in the simulation for calculating solubility of $\mathrm{CO}_{2}$ in water 


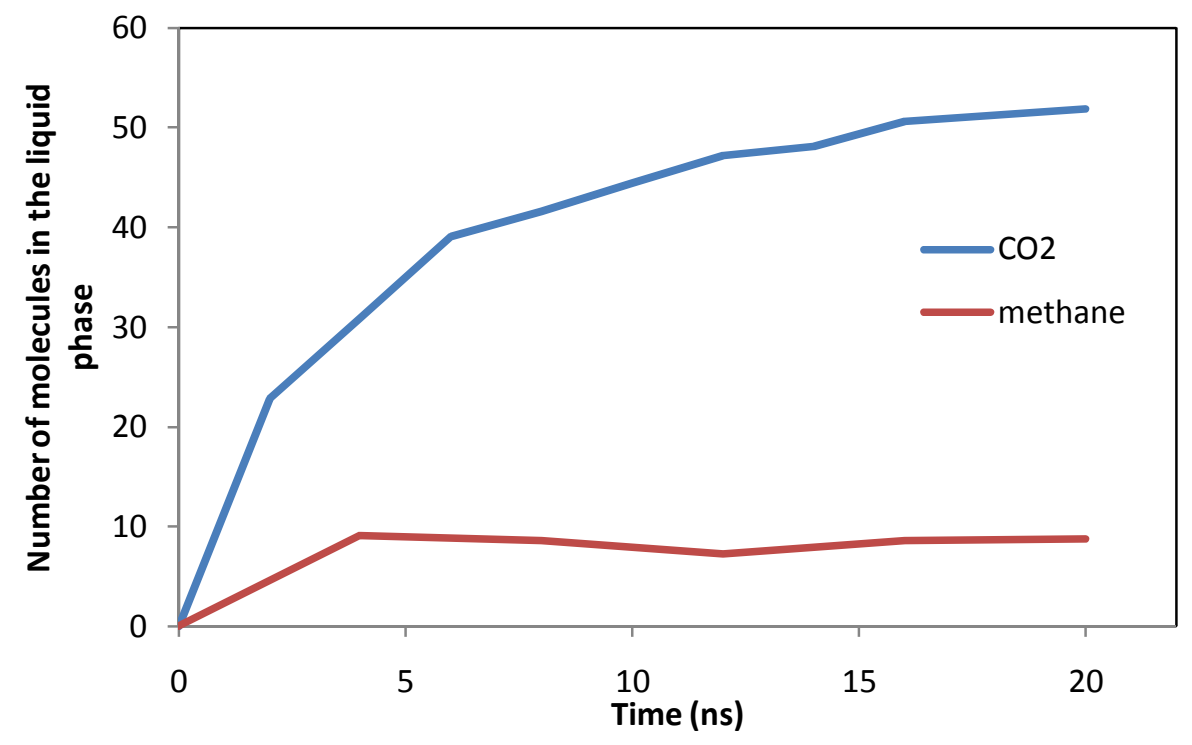

Figure 4.11 Average number of gas molecules in the water phase as a function of time for both methane and $\mathrm{CO}_{2}$

In order to get a more accurate value, reverse calculations were also tried, wherein the water phase was oversaturated with the gas molecules and simulated. But, this was not successfully as the gas molecules in the water were found to move in small packets. The solubilities of methane and $\mathrm{CO}_{2}$ in molefraction were calculated to be 0.001322 and 0.007461 compared to the experimental values of $0.002334^{3}$ and $0.01739^{4}$ respectively. Based on these values, the simulation boxes at different levels of undersaturation of the liquid phase have been constructed as mentioned before.

The simulations studying the effect of gas undersaturation in water phase for both methane and $\mathrm{CO}_{2}$ hydrates were done each at $100 \%$ and $0 \%$ cage occupancy separately. The number of molecules that moved in to the liquid phase as a result of dissolution has been plotted as a 
function of time for each of the simulations at different levels of undersaturation for both methane and $\mathrm{CO}_{2}$ hydrates as shown in the Figure 4.12. The plot again displayed an oscillating behavior as observed in the previous simulations.

Methane hydrate with $100 \%$ cage occupancy in hydrate and $100 \%$ gas saturation in liquid phase was found to be very stable. As, it has already been seen that the methane hydrate is very stable at $100 \%$ cage occupancy and $0 \%$ gas saturation, it is expected that it should be much more stable at $100 \%$ gas saturation. But, it was interesting to observe that the number of methane molecules in the hydrate phase was found to increase past the number that was present initially. In fact, this was observed even with the simulation at $75 \%$ gas saturation. This can be seen from the plot in Figure 4.12 (a) where there are times at which the curve goes above the black solid line in the case of $100 \%$ and $75 \%$ gas saturation. This might have occurred because there is a possibility of the methane molecules already present in the water phase moving in to the hydrate phase, which again is an indication that a hydrate growth is possible.

Similar analysis on the simulation done on methane hydrate with $0 \%$ cage occupancy and $100 \%$ gas saturation gave better results supporting the possibility of a hydrate growth. The number of hydrate-like waters in the simulation box for methane and $\mathrm{CO}_{2}$ hydrates has been calculated with the help of the phase recognition code at different times during the course of simulation. It is plotted as shown in Figure 4.13 (b). The number of waters in the hydrate phase at the beginning of the simulation is 2944 molecules. The plot shows that the number increases steadily for some time and then shows an oscillating behavior. 


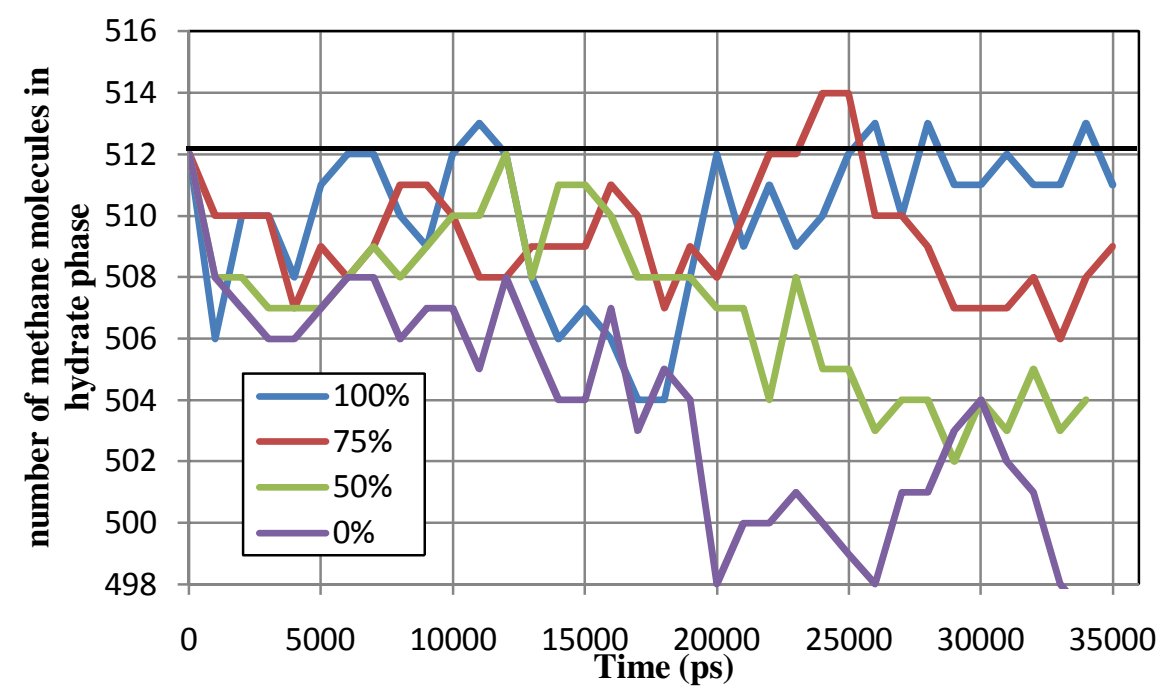

(a)

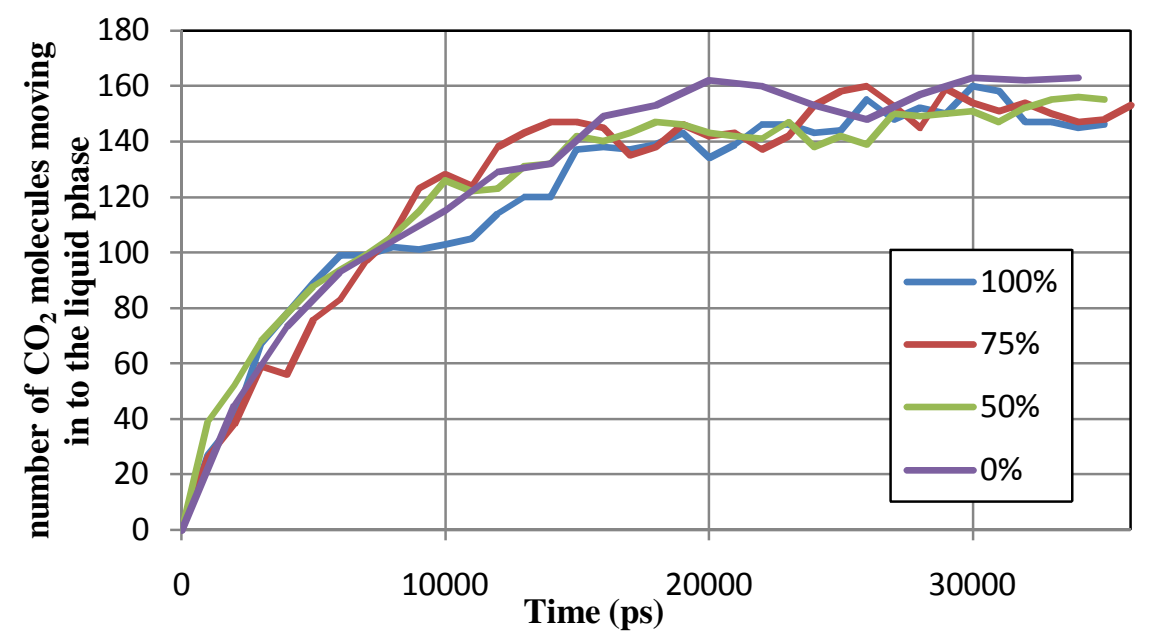

(b)

Figure 4.12 (a) Number of methane molecules in the hydrate phase at different times during the simulation corresponding to the initial number of methane molecules marked by a black solid line (b) Number of $\mathrm{CO}_{2}$ molecules moving in to the liquid phase as a function of time during the simulation at different levels of gas undersaturation in water phase at $100 \%$ cage occupancy

There is an increase in the number of hydrate-like waters in the methane hydrate at least by an amount of 100 water molecules. Most of these extra hydrate-like waters were found to be present near the hydrate-water interface which can be seen from the plot in Figure 4.14. It shows 


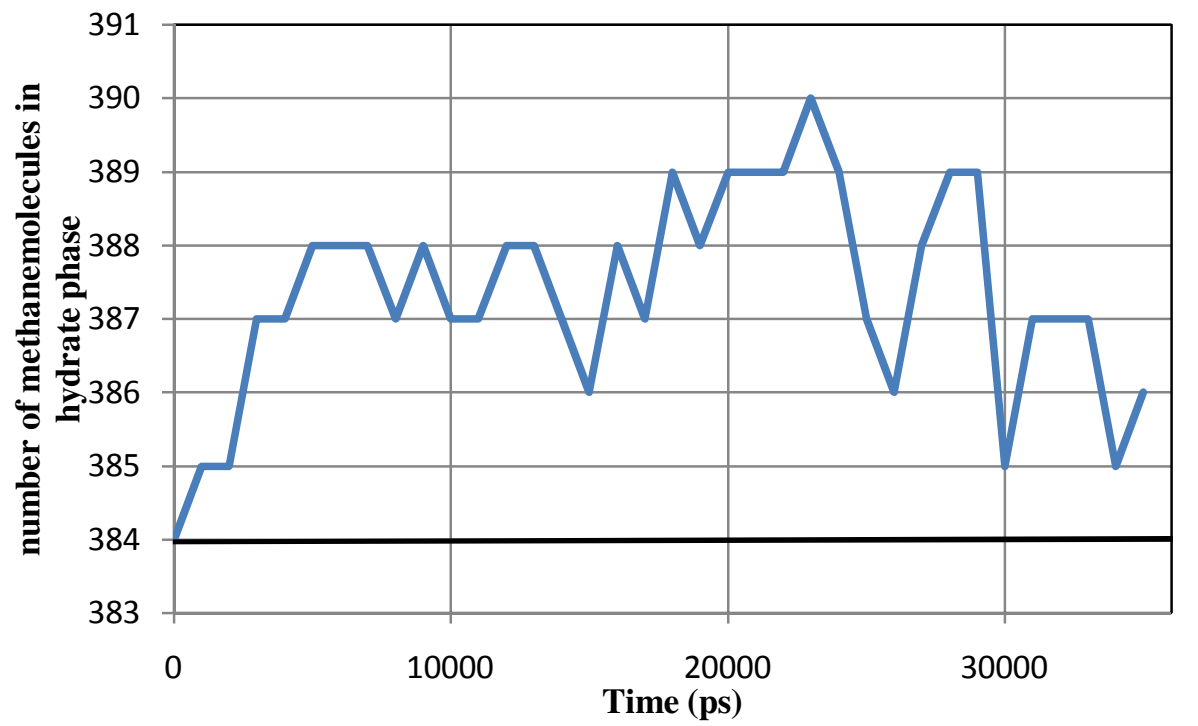

(a)

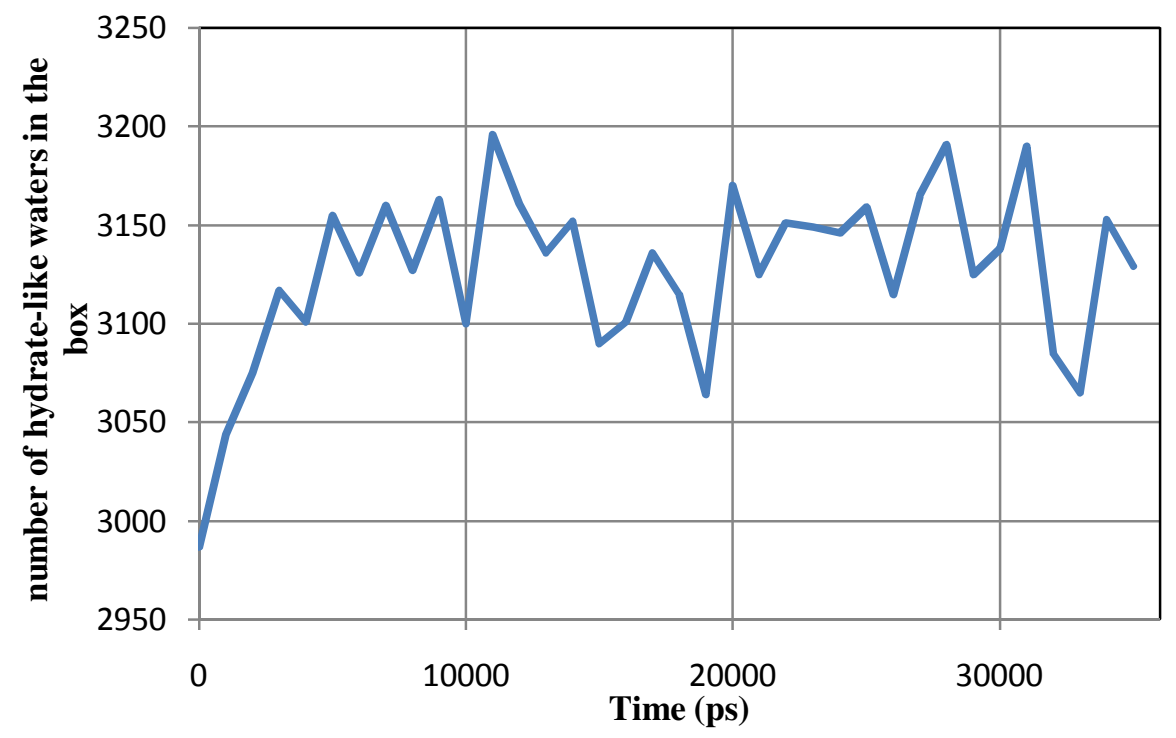

(b)

Figure 4.13 Simulation at $100 \%$ gas saturation in water phase and $0 \%$ cage occupancy (a) Number of methane molecules in the hydrate phase as a function of time corresponding to the initial number of methane marked by a solid black line (b) Number of hydrate-like waters in the simulation box as a function of time during the simulation

the number of hydrate-like waters at the beginning and the end of the simulation in each of the 10 parts the box that it has been divided. It also shows a corresponding snapshot of the 
simulation box at the end of simulation. There has been a significant increase in the number at the interface on either side while it is almost same within the hydrate phase.

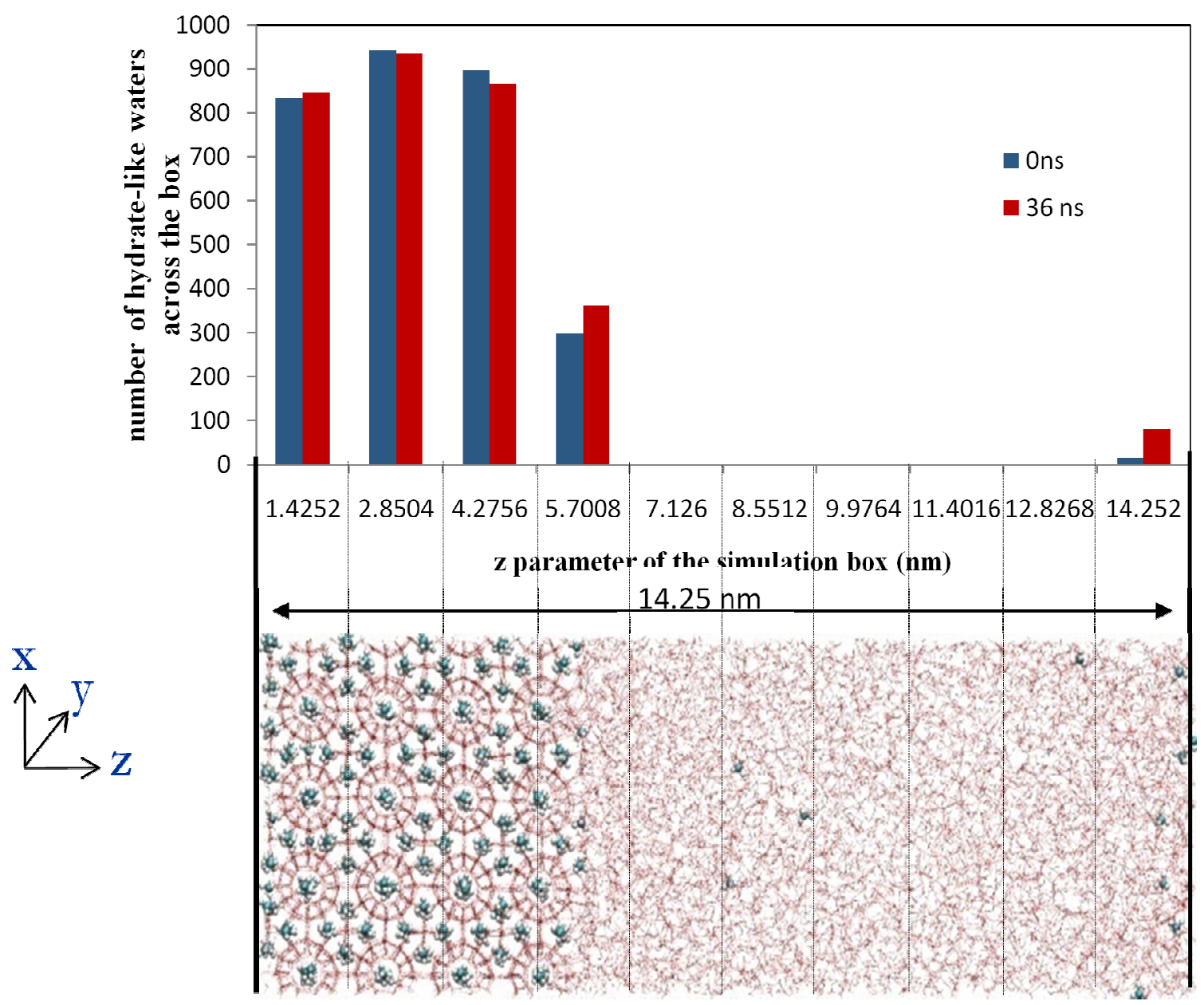

Figure 4. 14 Comparing the number of hydrate-like waters in each of 10 slices before and after simulation at $100 \%$ water phase saturation and $0 \%$ cage occupancy in methane hydrate. (The simulation box is divided in the z-direction in to 10 slices) A corresponding snapshot of methane hydrate simulation box.

The increase in the number of methane molecules in the hydrate phase from the initial value of 384 is also shown in a plot in the Figure 4.13 (a). This increase in the number of methane molecules in the hydrate phase and the hydrate-like waters has been observed at $100 \%$ gas 
saturation in the water phase and at both the cage occupancies of $100 \%$ and $0 \%$. Methane hydrate has been found to be very stable at these conditions. The presence of methane molecules within the water phase and a stable hydrate is thought to have triggered the water molecules to group in to a tetrahedral structure at the hydrate-water interface. Therefore, these observations indicate towards a possibility of a hydrate growth at the hydrate-water interface.

As the percentage gas saturation in the water phase decreased from $100 \%$ to $0 \%$, the tendency of methane molecules to move in to the liquid phase increased slowly. The number of methane molecules that moved in to the liquid phase increased with decrease in level of undersaturation in water, but the total number of methane molecules in the liquid phase at the end of the simulation was almost same in all the cases as it can be seen from Table 4.2. In the case of simulation done at $100 \%$ cage occupancy, the total number of molecules in the water phase was found to be around the number required to saturate the water phase.

Table 4. 2 Effect of gas undersaturation in the water phase on methane and $\mathrm{CO}_{2}$ hydrate dissolution at $100 \%$ cage occupancy

\begin{tabular}{|c|c|c|c|c|c|c|}
\hline $\begin{array}{c}\text { Percentage } \\
\text { level of gas } \\
\text { satuaration }\end{array}$ & $\begin{array}{c}\text { Number of gas molecules } \\
\text { that moved in to the } \\
\text { liquid phase averaged } \\
\text { over last } 4 \mathrm{~ns}\end{array}$ & \multicolumn{2}{|c|}{$\begin{array}{c}\text { Number of gas } \\
\text { molecules initially } \\
\text { present in the liquid } \\
\text { phase }\end{array}$} & \multicolumn{2}{|c|}{$\begin{array}{c}\text { Total number of gas } \\
\text { molecules in the water } \\
\text { phase averaged over last } \\
4 \text { ns of simulation }\end{array}$} \\
\hline & methane & $\mathrm{CO}_{2}$ & methane & $\mathrm{CO}_{2}$ & methane & $\mathrm{CO}_{2}$ \\
\hline 100 & 1 & 145 & 9 & 52 & 10 & 197 \\
\hline 75 & 4 & 149 & 7 & 39 & 11 & 188 \\
\hline 50 & 11 & 154 & 5 & 26 & 15 & 180 \\
\hline 0 & 10 & 162 & 0 & 0 & 11 & 162 \\
\hline
\end{tabular}


At $0 \%$ cage occupancy, the amount of dissolution was found to show a similar trend with respect to percentage gas undersaturation. But, the amount of dissolution of methane molecules lowered by a small amount when compared to that at $100 \%$ cage occupancy. So, it seems that the dissolution is driven by a difference between methane concentration and its solubility in water phase. The concentration of the guest species definitely plays an important role in providing the necessary concentration gradient as noted by Nihous and Masutani ${ }^{5}$ based on their model. This can be seen from the Table 4.2 and Table 4.3. But behavior of $\mathrm{CO}_{2}$ hydrate is not clearly understood.

In the case of $\mathrm{CO}_{2}$ hydrate, a high amount of dissolution was found to occur within the first $10 \mathrm{~ns}$ followed by a slow increase in the number of $\mathrm{CO}_{2}$ molecules moving in to the water phase and a steady decrease in the dissolution rate. As the level of gas saturation decreased from $100 \%$ to $0 \%$, the number of $\mathrm{CO}_{2}$ molecules moving in to the liquid phase increased, but the increase was not proportional to the decrease in the level of undersaturation. At $100 \%$ cage occupancy, the number of $\mathrm{CO}_{2}$ molecules in the water phase was found to be more than 3 times the number of molecules required to saturate the water phase as per the value of its solubility that has been obtained.

It has already been seen that $\mathrm{CO}_{2}$ hydrate is stable at $0 \%$ cage occupancy. So, the effect of water phase undersaturation has also been studied at $0 \%$ cage occupancy and the results are tabulated as shown in Table 4.3. At $0 \%$ cage occupancy, the number of $\mathrm{CO}_{2}$ molecules moving in to the liquid phase was found to display a similar trend with the change in percentage gas saturation in 
the water phase. But, the amount of dissolution was found to be much lesser at $0 \%$ cage occupancy than at $100 \%$ occupancy in all different cases of water phase undersaturation.

Table 4. 3 Effect of gas undersaturation in the water phase on methane and $\mathrm{CO}_{2}$ hydrate dissolution at $0 \%$ cage occupancy

\begin{tabular}{|c|c|c|c|c|c|c|}
\hline $\begin{array}{c}\text { Percentage } \\
\text { level of gas } \\
\text { satuaration }\end{array}$ & \multicolumn{2}{|c|}{$\begin{array}{c}\text { Number of gas molecules } \\
\text { that moved in to the liquid } \\
\text { phase averaged over last } \\
4 \text { ns of simulation }\end{array}$} & \multicolumn{2}{|c|}{$\begin{array}{c}\text { Number of gas } \\
\text { molecules initially } \\
\text { present in the liquid } \\
\text { phase }\end{array}$} & \multicolumn{2}{|c|}{$\begin{array}{c}\text { Total number of gas } \\
\text { molecules in the water } \\
\text { phase averaged over last } \\
4 \text { ns of simulation }\end{array}$} \\
\hline & methane & $\mathrm{CO}_{2}$ & methane & $\mathrm{CO}_{2}$ & methane & $\mathrm{CO}_{2}$ \\
\hline 100 & $-2^{*}$ & 88 & 9 & 52 & 7 & 140 \\
\hline 75 & 4 & 96 & 7 & 39 & 11 & 135 \\
\hline 50 & 7 & 101 & 5 & 26 & 12 & 127 \\
\hline 0 & 8 & 111 & 0 & 0 & 8 & 111 \\
\hline
\end{tabular}

*negative sign in the table indicates the opposite direction of movement

Even in the case of $0 \%$ cage occupancy, the total number of $\mathrm{CO}_{2}$ molecules in the water phase at the end of each simulation was found to be much higher than that required to saturate the water phase. However, the reason for the increase in solubility of $\mathrm{CO}_{2}$ in water in the presence of a hydrate is not clearly understood. It is predicted that the presence of hydrate causes a change in the structure of the water phase but no evidence was found supporting this. The question whether it is a structural change of water in the presence of hydrate that causes the increase in solubility of $\mathrm{CO}_{2}$ in water and the reason is unanswered. 
$\mathrm{CO}_{2}$ hydrate was observed to be stable at $0 \%$ small cage occupancy within the considered range. But, a removal of $\mathrm{CO}_{2}$ molecules from large cages may further increase its stability, which has not been considered in this work. Dissolution of $\mathrm{CO}_{2}$ hydrate was found not to be proportional to the These exceptions observed in the case of $\mathrm{CO}_{2}$ hydrate is also thought to have caused by a weak intermolecular potential given by Harris and $\mathrm{Yung}^{6}$ for $\mathrm{CO}_{2}$ molecules in hydrate. Velaga et al. ${ }^{7}$ also mentioned a weak intermolecular potential of $\mathrm{CO}_{2}$ in a hydrate in their work using abinitio calculations. 


\subsection{References}

1. Larson M. A. ; Garside J., Chem. Eng. Sci. , 1986, 41,1285.

2. Lekvam, K.; Bishnoi, P. R., "Dissolution of methane in water at low temperatures and intermediate pressures", Fluid phase Equilibria, 1997, 131, 297

3. Servio P. ; Englezos P. "Effect of temperature and pressure on the solubility of carbon dioxide in water in the presence of gas hydrate", Fluid phase Equilibria, 2001, 190,127.

4. Myshakin, E., Jiang, H., Warzinski, R., Jordan, K., in review, "Molecular Dynamics Simulations of Methane Hydrate Decomposition”, J. Phys. Chem., 2009, 113, 1913.

5. Nihous, G.C.; Masutani, S.M. "Notes on the dissolution rate of gas hydrates in undersaturated water", Chemical Engineering Science, 2006, 61, 7827.

6. Harris, J. G.; Yung, K. H. "Carbon Dioxide's Liquid-Vapor Coexistence Curve And Critical Properties as Predicted by a Simple Molecular Model” J. Phys. Chem. 1995, 99, 12021.

7. Velaga, S. Phase Equilibrium and Cage Occupancy Calculations of Carbon Dioxide Hydrates using $\mathrm{Ab}$ Initio Intermolecular Potentials, M. S. Thesis, West Virginia University, 2009.

8. Radhakrishnan, R.; Trout, B. L. "A new approach for studying nucleation phenomena using molecular simulations: Application to $\mathrm{CO}_{2}$ hydrate clathrates", J. Chem. Phys., 2002, 117, 1786 


\section{Conclusions and Recommendations}

\subsection{Conclusions}

Molecular dynamic simulations were performed on methane and $\mathrm{CO}_{2}$ hydrates with an objective of understanding the role of gas concentration in both hydrate and water phases in guiding the dissolution phenomenon. The effect of small cage occupancy in the hydrate and the level of gas undersaturation within the water phase on hydrate dissolution in water were studied.

As a part of the preliminary work, the average lattice constants of the structure I and structure II methane hydrate at different potentials of methane OPLS ${ }^{1}$, GROMACS $^{2}$ were calculated and compared to the experimental value to validate these potentials. This was done based on short time simulations on a 8 unit cell methane hydrate crystal at different temperatures and it was found that the lattice constant increased with temperature till the point of dissociation was reached. Lattice constant of structure I methane hydrate at $273 \mathrm{~K}$ and 1 bar was noted to be 1.187 $\mathrm{nm}$ for OPLS and $1.189 \mathrm{~nm}$ for GROMACS potential from this plot and was found to be comparable to the experimental value $\mathrm{e}^{3}$ of $1.2 \mathrm{~nm}$. Lattice constant of structure II methane hydrate at the same conditions were noted to be $1.705 \mathrm{~nm}$ for OPLS and $1.722 \mathrm{~nm}$ for GROMACS potential, which were also comparable to the experimental value ${ }^{3}$ of $1.73 \mathrm{~nm}$. These potentials along with Anderson et al. $^{4}$ model were further compared based on a study of hydrate dissociation of methane hydrate in the presence of water at 1 bar. The rate of dissociation was found to increase with the increase in temperature from $250 \mathrm{~K}$ to $300 \mathrm{~K}$. Complete dissociation of the hydrate was found to occur at $260 \mathrm{~K}$ for OPLS and Anderson et al. model while it was 
found to occur at $285 \mathrm{~K}$ for GROMACS potential. The GROMACS intermolecular potential for methane seemed to be strong for molecules in a hydrate compared to other two potentials.

Dissolution of methane and $\mathrm{CO}_{2}$ hydrates was studied at $275 \mathrm{~K}$ and 50 bar for a timescale of 36 ns and it was observed that $\mathrm{CO}_{2}$ hydrate dissolves at a much higher rate in water compared to methane hydrate. A high amount of dissolution was found to take place within the first $10 \mathrm{~ns}$ of the simulation in the case of $\mathrm{CO}_{2}$ hydrate followed by a steady decrease in the dissolution rate. Simulations were also done on two different sizes of hydrate crystals in the presence of water. A 64 unit cell hydrate was found to be very stable while a 32 unit cell hydrate was found to dissociate very quickly in the same amount of water phase. So, it was observed that it is important that the size of hydrate crystal chosen should have a size greater than the critical size of nucleation.

Methane hydrate was found to be stable at small cage occupancies close to $100 \%$ while $\mathrm{CO}_{2}$ hydrate was found to be most stable at small cage occupancies close to $0 \%$ using the Harris and Yung ${ }^{5}$ potential. For the chosen time of $36 \mathrm{~ns}$, the amount of dissolution was found to be lower at $100 \%$ cage occupancy and increase with decrease in the cage occupancy. The trend was in the opposite direction in the case of $\mathrm{CO}_{2}$ hydrate where higher degree of dissolution were found to occur at $100 \%$ cage occupancy and the amount of dissolution decreased with a decrease in the cage occupancy. As an exception, methane hydrate was also found to be very stable at $0 \%$ small cage occupancy compared to other occupancies. A more symmetrical structure of the hydrate at $0 \%$ and $100 \%$ occupancy compared to other occupancies is predicted to give the hydrate an advantage in the form of higher stability due to lack of crystal defects. This was observed to be 
significant in the case of methane hydrates because of a very low amount of dissolution occurring.

MD Simulations were performed to calculate the solubility of methane and $\mathrm{CO}_{2}$ in water to be 0.001322 and 0.007461 in molefraction. Different levels of water phase undersaturation with respect to these gases were fixed based on these values. The effect of undersaturation on hydrate dissolution of methane and $\mathrm{CO}_{2}$ hydrates was studied at both $100 \%$ and $0 \%$ cage occupancy of the hydrate. These simulations showed that hydrate dissolution is driven by a difference between gas solubility and the gas concentration in the water phase, although the dissolution of $\mathrm{CO}_{2}$ hydrate was not found to be proportional to the amount of undersaturation in the water. The amount of dissolution was found to increase with a decrease in the percentage of saturation from $100 \%$ to $0 \%$ both in the case of methane and $\mathrm{CO}_{2}$ hydrates. The amount of dissolution was found to be proportional to the level of undersaturation in the water phase in the case of methane hydrates. In the case of $\mathrm{CO}_{2}$ hydrate, the amount of dissolution of $\mathrm{CO}_{2}$ molecules in to the water phase was found to be higher than the number of molecules required to saturate the water phase, the reason for which is not understood. But, it is thought to have caused by a change in the local structuring of the water molecules in the liquid phase in the presence of a hydrate. An exceptional behavior of $\mathrm{CO}_{2}$ hydrate dissolution is also predicted to be because of a weak intermolecular potential given by Harris and Yung for $\mathrm{CO}_{2}$ in hydrate.

Another interesting observation pertaining to all the simulations on methane hydrate was that the number of hydrate-like water molecules was found to be higher than the initial number of water molecules in the hydrate phase. This demonstrates a possibility of a hydrate growth at the 
hydrate-water interface. The increase in the number of methane molecules in the hydrate phase in some cases also supports the possibility of a hydrate growth.

It is clear from this work that methane hydrate is very stable compared to $\mathrm{CO}_{2}$ hydrate. Even at very low levels of gas saturation in the water phase as may be the case of methane concentration in oceans, it can be said that the amount of dissolution that has been observed is very low. The possibility of hydrate growth that has been observed in most of the simulations further support in saying that methane hydrate can stay stable provided there is enough amount of methane concentration in the water surrounding the hydrate. $\mathrm{CO}_{2}$ hydrate on the other hand is not as stable as methane hydrate and it dissolves at a higher rate. A high solubility of $\mathrm{CO}_{2}$ in water is responsible for a greater degree of dissolution.

\subsection{Recommendations}

1. The increase in the solubility of $\mathrm{CO}_{2}$ in water in the presence of a hydrate that has been observed could not be reasoned in this work. It is thought that a local structuring of the water molecules surrounding the hydrate is responsible for this. Classification of water molecules in the liquid phase based on their structuring using specific order parameters should help us understand the reason for the increase in solubility.

2. Molecular dynamic simulations should be done to understand how diffusion of $\mathrm{CO}_{2}$ takes place within the hydrate phase. This can be done by creating a simulation box which has $\mathrm{CO}_{2}$ hydrate with gaseous $\mathrm{CO}_{2}$ on one side and a water phase on the other side. This can supplement the dissolution model given by Gabitto et al. ${ }^{6}$

3. An intermolecular potential for $\mathrm{CO}_{2}$ should be developed which can explain the behavior of $\mathrm{CO}_{2}$ hydrate more accurately. 


\subsection{References}

1. Jorgensen, W. L.; Madura, J. D.; Swenson, C. J. "Optimized Intermolecular Potential Functions for Liquid Hydrocarbons" J. Am. Chem. Soc.1984, 106, 6638.

2. van Gunsteren, W. F.; Billeter, S. R.; Eising, A. A.; Hünenberger, P. H.; Krüger, P.; Mark, A. E.; Scott, W. R. P.; Tironi, I. G. "Biomolecular Simulation: GROMOS96 Manual and User Guide."BIOMOS b.v.: Zürich, Groningen, 1996.

3. G.A. Jeffrey, J.L. Atwood, E.D. Davies and D.D. MacNichol (eds.), "Inclusion Compounds", Acad. Publ., 1984, 1, 135.

4. Anderson, B. J.; Tester, J. W.; Trout, B. L. "Accurate Potentials for Argon-water and Methane-Water Interactions via Ab Initio Methods and Their Application to Clathrate Hydrates." J. Phys. Chem. B ,2004, 108, 18705.

5. Harris, J. G.; Yung, K. H. "Carbon Dioxide's Liquid-Vapor Coexistence Curve And Critical Properties as Predicted by a Simple Molecular Model" J. Phys. Chem. 1995, 99, 12021.

6. Gabitto, J.; Tsouris, C. "Dissolution mechanisms of $\mathrm{CO}_{2}$ hydrate droplets in deep seawaters", Energy conversion and management, 2006, 47, 494. 